\title{
Assembling Non-Place Collage: \\ Architecture of the Terminal
}

\author{
Nicholas De Socio
}

A thesis submitted to the Faculty of Graduate Studies and Research in partial fulfillment of the requirements for the degree of

Master of Architecture (M.ARCH) Professional

Carleton University, Ottawa, Canada.

Nicholas L. De Socio (C) 2006 


\begin{abstract}
The non-places of transit are a concept based on temporary transitory moments of everyday life. Non-places are the daily spaces of contemporary life that are distinguishable from places by their lack of history, culture and identity. As the occurrence and necessity of travel rises in contemporary times, the necessity for architecture which process human movement increases and the role for architecture within destinations of transitional experience must become prevalent. Successful architecture requires a balance between both the function and program of a building and a positive result of the occupant's memories and experience. This thesis explores how the technique of collage has the potential to inform the concept of the architecture of transit non-places. For this thesis, collage thinking and making performs as the catalyst for the creation of architectural space. Programmatically, the design for a new inter-city bus terminal in Ottawa is undertaken in order to create meaningful, exciting, unique places of transit architecture.
\end{abstract}




\section{Table of Contents}

Abstract

Table of Contents

List of Figures

Introduction

Part One: Architecture of Non-Place

Chapter One: Inhabiting Non-Places

1.1 Distinguishing Between Place and Non-Place 2

1.2 Spaces of Obedience 6

1.3 Liminal Space 9

1.4 The Threshold Experience: Architecture of Arrival and Departure 11

1.5 The Non-Place Paradox: When Non-Places Become Place 14

$\begin{array}{ll}1.6 \text { The Invisible Terminal } & 17\end{array}$

1.7 Terminal Precedents 18

Part Two: The Collage Experiments

Chapter Two

2.1 Collage Objectives $\quad 24$

2.2 Defining Collage $\quad 26$

2.3 The Emergence of Collage 28

2.4 Montage vs. Collage $\quad 29$

Chapter Three: Collage Thinking in Architecture

3.1 Collage Precedents $\quad 30$

Chapter Four: The Collage Experiments (Methodology)

$\begin{array}{ll}4.1 \text { Explanation } & 37\end{array}$

4.2 Site Collages 39

4.3 Rules of Operation $\quad 44$

4.4 Extruding Architecture $\quad 45$

Part Three: The Design Proposal

Chapter Five: Program and Site 48

5.1 Program: Ottawa Greyhound Bus Terminal 53

$\begin{array}{ll}5.2 \text { Spatial Requirements } & 54\end{array}$

5.3 Current Greyhound Bus Terminal Site $\quad 56$

$\begin{array}{lr}\text { Chapter Six: Building Design } & 59\end{array}$

$\begin{array}{ll}\text { Conclusion } & 69\end{array}$

$\begin{array}{ll}\text { Bibliography } & 71\end{array}$ 


\section{List of Figures}

All images by author unless otherwise stated.

Figure 1. Non-Places

Figure 2. Mental Space

Figure 3. Port Authority Bus Terminal

Figure 4. Nils Ericson Terminal

Figure 5. Oriente Station

Figure 6. Pennsylvania Station

Figure 7. Still Life with Chair Canning

Figure 8. Dada Collages

Figure 9. West Cell Wall

Figure 10. Saggital Name Collage

Figure 11. Kleptoman Cell

Figure 12. Meier Collages

Figure 13. Le Corbusier's collage thinking 36

Figure 14. Initial Collages

Figure 15. Site Collage One 39

Figure 16. Site Collage Two 40

Figure 17. Site Collage Three 41

Figure 18. Site Collage Four 42

Figure 19. Site Collage Five 42

Figure 20. Site Collage Six 43

Figure 21. Site Collage Seven 44

Figure 22. Bus Terminal Collage 46

Figure 23. Office Collage 46

Figure 24. Plaza Collage 47

Figure 25. Consumerism Collage 47

Figure 26. Location Plan 48

Figure 27. Site Plan 49

Figure 28. Site Montage 50 
Figure 29. Site Montage 51

Figure 30. Autogrill 51

$\begin{array}{ll}\text { Figure 31. Existing terminal montage } & 57\end{array}$

Figure 32. Interior of existing terminal 59

$\begin{array}{ll}\text { Figure 33. Site Model } & 60\end{array}$

$\begin{array}{ll}\text { Figure 34. Site Plan } & 61\end{array}$

Figure 35. Site Plan and first level plan 62

Figure 36. Terminal surroundings 63

Figure 37. Rochester Street entrance 63

$\begin{array}{ll}\text { Figure 38. Preston Street entrance } & 64\end{array}$

Figure 39. Preston Street interaction $\quad 65$

Figure 40. Rooftop space $\quad 66$

$\begin{array}{ll}\text { Figure 41. Level one plan } & 67\end{array}$

$\begin{array}{ll}\text { Figure 42. Level two plan } & 67\end{array}$

$\begin{array}{ll}\text { Figure 43. Highway view } & 68\end{array}$

Figure 44. Longitudinal Section $\quad 69$

$\begin{array}{lr}\text { Figure 45. Lateral Section } & 69\end{array}$ 


\section{Introduction}

The non-places of transit are a concept based on temporary transitory moments of everyday life. While the frequency of travel in today's culture continues to rise, the social importance of the architecture of the non-place is evermore relevant. Non-places are the daily spaces of contemporary life that are distinguishable from places by their lack of history, culture and identity. As the occurrence and necessity of travel rises in contemporary times, the necessity for architecture which process human movement increases and the role for architecture within destinations of transitional experience must become prevalent. Non-places encompass the idea that freedom and identity in contemporary life rely on the networks, structures and phenomena that readily mediate our movements. Often times they are regarded as purely functional architecture in which slight thought is devoted to successful design. Successful architecture requires a balance between both the function and program of a building and a positive result of the occupant's memories and experience.

As a reversal to the negative trend of sole emphasis on function in architecture, typically found in non-places of transit, this thesis examines the potential for a solution to solve this continuing problem. New methods and techniques must be incorporated in order to assure the execution of good building design. Since architecture is both formal and functional, the technique of collage enables architecture to sustain both in harmony. The nature of collage is to link diverse elements into a new entity and create new relationships between those different elements. Sometimes by chance, sometimes by intuition and sometimes by deliberation, the method and process of collage is capable of extracting and advising innovative, memorable, unique design allowing non-places to be 
regarded as places possessing identity, history and culture. It is apparent that successful architecture has the ability to transform non-places into places.

This thesis explores how the technique of collage has the potential to inform the concept of the architecture of transit non-places. For this thesis, collage thinking and making performs as the catalyst for the creation of architectural space. Programmatically, the design for a new inter-city bus terminal in Ottawa is undertaken in order to create meaningful, exciting, unique places of transit architecture.

In the first section of the thesis, issues of the temporary inhabitation of non-places of transit are addressed and their relevance within our daily lives. The liminal spaces of transit architecture and the terminal as signifier of the threshold of arrival and departure and the inherent mystery of the invisible terminals are examined. The thesis analyzes precedents which support collage's role within architecture as well as the architecture of transportation terminals. And lastly, a series of collage experiments is then undertaken in order to prove whether this process is feasible in order to create a successful architecture.

\section{Part One: Non-Place Architecture}

\section{Chapter One: Inhabiting Non-Places}

\subsection{Distinguishing Between Place and Non-Place}

The desire to defeat the tyranny of place is as old as humanity: technology has simply provided us with far more effective means- just consider the automobile and the possibility of separating home and workplace that is has brought. ${ }^{1}$

A considerable portion of one's life is now spent immersed in netherworlds of terminals, highways, hotels, supermarkets and shopping malls. This can be a result of the

\footnotetext{
${ }^{1}$ Karsten Harries, The Ethical Function of Architecture. (Cambridge: MIT Press, 1998) 168.
} 
desire to escape and it stems from the aspiration of departure; a departure from daily life; a departure from uniformity; a departure from reality. As a result of this existing trend, one may ask, are these just unimportant intervals between other events that have more meaning to us, or are these transient locations equally meaningful? Do these spaces present its inhabitants with a significant experience and more than simply performing as a building whose purpose is to perform a singular function?

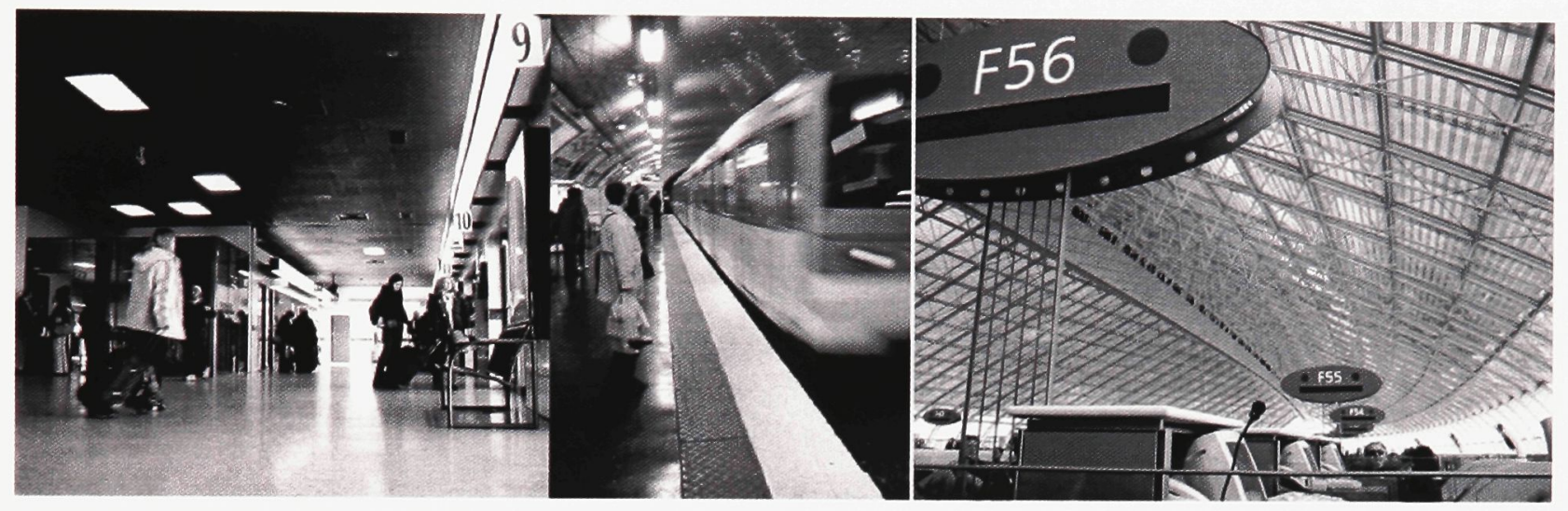

Figure 1. Non-Places.

These are three examples of non-places of transit. From the left is the Ottawa Voyageur Bus Terminal, the Barcelona Metro Station and Charles de Gaulle Airport in Paris.

The French social anthropologist and historian Michel de Certeau coined the termed non-place in his writings The Practice of Everyday Life, originally written in

1974. De Certeau differentiates between a place and a non-place and suggests:

A place is the order (of whatever kind) in accord with which elements are distributed in relationships of coexistence. It thus excludes the possibility of two things being in the same location. The law of the "proper" rules in the place: the elements taken into consideration are beside one another, each situated in its own "proper" and distinct location, a location it defines. A place is thus an instantaneous configuration of positions. It implies an indication of stability ${ }^{2}$.

According to de Certeau, the sense of place can be portrayed by these substantial elements. A place may have a name that is known and can be defined such as

\footnotetext{
${ }^{2}$ Michel de Certeau, The Practice of Everyday Life, trans. Steven Rendall, University of California Press: Berkely, 1984, 117.
} 
The French theorist Marc Augé develops de Certeau's ideas of non-place in his writings in, Non Places: Introduction to an Anthropology of Supermodernity written in

1995. Augé defines the fundamental concept of the non-place:

If a place can be defined as relational, historical and concerned with identity, then a space which cannot be defined as relational, or historical, or concerned with identity will be a non-place. The hypothesis advanced here is that supermodernity produces non-places, meaning spaces which are not themselves anthropological places and which do not integrate the earlier places. ${ }^{3}$

It is evident here that Augé sets out clear guidelines which enable him to decipher which places are in fact non-places. According to Augé, in order to interpret a non-place, one must ask three basic questions: Does this place hold historical meaning, cultural value or a sense of individuality? Augé transforms place into a kind of abstracted form, or a point on the map. He points out that it is the quantity and physical location of these points on the map that makes each of them a non-place. They are labeled and thereby transformed from places into non-places; all created by the traveler, the world of tourism and temporary existence. It is the place presented on a postcard.

However, non-place must not be misinterpreted or misread as "nowhere."

Often times, non-places are found amid the bustling city, in close proximity to a place. Yet what makes these spaces non-places is the lack of connection the building and its occupants have to their surrounding environment and to history, culture and identity. Existing in a physical place does not connote that one inhabits in psychological reality and sometimes it is expressed as the inability to "connect" with the surroundings. The effect of disorientation that travel produces is the experience of the non-place. As Marc

\footnotetext{
${ }^{3}$ Marc Augé, Non-Places: Introduction to an Anthropology of Supermodernity. (New York: Verso Publishers, 1995) 78.
} 
Augé states, "The traveller's space is the archetype of non-place ${ }^{4 "}$. The traveller moves through notions and understandings of a location as place, but they do not necessarily interact or understand the site specificity of the locations traversed.

However, non-places which are physically located far outside the city like airports have the potential to be regarded as places. If the architecture contains history, culture and identity and it evokes memory, its physical location is of lesser importance than the three characteristics which make up non-place.

Non-places are regarded as the widespread everyday spaces of capitalist cities. These spaces are not tied to any geographic location and the characteristics of urban life are extended outwards from the city where traditional rules of morphological organization of urban spaces cease to exist. These are spaces where consumerism and economics are more apparent than those spaces that maintain a connection to history, culture and identity. Non-places also present themselves as processing machines for efficient human movement and displacement. They possess a highly functional program (i.e., a terminal's function is to process human movement quickly and efficiently). Nonplaces often embody the characteristics of functionalist architecture, where functionality of program supersedes the buildings' social contribution.

However it is important to decipher between Functionalism in architecture and functional architecture since they are not identical terms. In the early 20 th century, the American Architect Louis Sullivan adopted the term "form ever follows function"." This was the mentality behind Functionalist architecture. It is the principle that the design of a

\footnotetext{
${ }^{4}$ Marc Augé, Non-Places: Introduction to an Anthropology of Supermodernity. (New York: Verso Publishers, 1995) 87.

5 , Louis Sullivan. The Autobiography of an Idea, (Press of the American institute of Architects, Inc.: New York City, 1924)12.
} 
building should be entirely based on the purpose of that particular building. The insinuation is that if the functional aspects of the design are satisfied, the buildings architectural beauty would logically and automatically follow. Conversely, functional architecture describes whether a buildings purpose or task performs properly and successfully. A building that is functional insinuates that the programmatic elements are carried out efficiently.

Transportation terminals were initially created as functionalist architecture, devoted to performing a particular purpose since there were no classical precedents. Presently, these have advanced far beyond their typological origins into a new species of building incorporating several programs and functions and in some cases reinstating it as the new civic space, functioning comparably to the traditional piazza as public gathering point.

Although the basis for all terminals is to transport its occupants quickly and efficiently, this does not render all transportation terminals as non-places. The elements of a place exist in relation to each other and in their own space and so form a sense of location, a sense of the unique experience. This indicates that transit terminals have the capacity to convey characteristics of place.

\subsection{Spaces of Obedience}

Transit terminals of any nature, be it bus station, train station or airport, are all suitable examples of Henri Lefebvre's term "lived obedience." These spaces of obedience exist in locations where passengers and visitors are to move only in the directions allocated to them and visit only the spaces that they have designated access to. 
Generally, within all buildings there exists some kind of imposed order. Program and function will inevitably dictate how the occupant may use the space. This dictated use of space is evermore apparent in non-places since efficiency of performance is dependant upon order, systems and structures of organization. Boundaries and restrictions, transmission of information and signage are all contributors to spaces of obedience. In his book, The Production of Space written in 1991, Henri Lefebvre acknowledges that space can determine and prescribe to its inhabitants the manner in which to use the particular space.

Space lays down the law because it implies a certain order- and hence also a certain disorder... space commands bodies, prescribing or proscribing gestures, routes and distances to be covered... The reading of a space is thus merely a secondary and practically irrelevant upshot, a rather superfluous reward to the individual for blind, spontaneous and lived obedience ${ }^{6}$.

No other spaces are more obviously and literally spaces of obedience as those spaces of non-place. These spaces dictate to its users what to do/what not to do, where to go/ where not to go, all by means of literal signage, and the configuration of circulation routes, gates, controls, and counters. They are all characteristics of terminals, malls, supermarkets, motorways, hotels, and banks. As a result, non-places essentially dictate to its inhabitants how to experience architectural space. In doing so, non-places essentially create non-experiences. Non-experiences are pre-planned occurrences set out for the inhabitants in order to create functional efficiency within architecture.

Typical non-places are arranged by building planners to be experienced temporarily by transitory and mobile dwellers which include tourists, commuters, corporate nomads, shoppers, migrants, and virtual workers on the move. Marc Augé

\footnotetext{
${ }^{6}$ Henri Lefebvre, The Production of Space. (Malden: Blackwell Publishing Ltd., 1991) 82-83.
} 
suggests that once an occupant crosses the threshold of a non-place and engages with it, they enter into a contractual relationship with it. They agree to obey its rules, regulations and policies in hopes of a "pleasant" experience. The inhabitants' visual field is littered with directions and instructions, while aurally they are soothed with music, white noise and chatter. Therefore, the occupant of the non-place is heaved within a world of predestined choices allowing little room for the exploration of space and the anticipation of discovery.

Spaces of obedience inevitably affect the program of architecture. They do so by connoting particular functions to a space. A sign which demarks "line-up here" or a bench placed against a wall will inevitably have an effect upon the function and the use of space. These indicators dictate how to experience the space placing more emphasis on the importance of efficiency. Adequate spatial requisites are then adjusted by planners according to the program and function they perform. However, these spaces of obedience are a necessity when dealing with transportation terminals of any kind. Without signage and demarcation within spaces of transit, chaos and disorder would exist and terminals simply would not function properly. The importance of creating a balance between experiences and non-experiences within transportation terminals creates a more successful architecture. In some instances the space must be permitted to dictate and the user must obey the policies and rules whereas in other instances, the inhabitant must maintain the freedom to discover and experience architecture for themselves. 


\subsection{Liminal Space}

The concept of the "liminal" was first introduced to the field of anthropology by Arnold Van Gennep in his book, Les Rites de Passage written in 1909. He described a three-part structure in which all rites of passage possessed: 1. separation, 2. liminal period, 3. reassimilation. The person undergoing the passage is first separated from their social status that they previously possessed, then installed into the liminal period of transition, and finally given a new status once re-introduce into society. "His term rite of liminality refers to the precarious threshold between a person's previous role in society and his new, evolved existence. Liminality is always associated with ephemerality and transitional passage between alternative states. ${ }^{7}$ " These alternative states may exist in time, space and in movement and travel.

However it was the writings of Victor Turner in the second half of the 20th century that expanded Van Gennep's terms "liminal" and "liminality." Turner elaborated and investigated on the three-part structure expressed by Van Gennep in $1909 . \mathrm{He}$ formulated his theory of liminality in his writing, The Forest of Symbols: Aspects of Ndembu Ritual, written in 1960. In this book, Turner focused heavily on Van Gennep's second stage; That which centers on the transitional or liminal stage. He notes,

The subject of passage ritual is, in the liminal period, structurally, if not physically, 'invisible'... Liminality may perhaps be regarded as the nay to all positive structural assertions, but as in some sense the source of them all, and, more than that, as a realm of pure possibility whence novel configurations of ideas and relations may arise ${ }^{8}$.

\footnotetext{
${ }^{7}$ Catherine Smith. "Looking for Liminality in Architectural Space." Limen: Journal for Theory and Practice of Liminal Phenomenon no.1 (2001): 06 June $2006<\mathrm{http}$ ://www.cartage.org.lb/en/themes/Arts/Architec/ ArchitecturalStructure/LookingforLiminality/LookingforLiminality.htm>

${ }^{8}$ Victor Turner. The Forest of Symbols: Aspects of Ndembu Ritual. (New York: Cornell University Press, 1967) 96-97.
} 
In this writing, Turner fundamentally describes how liminality affects the sociological structures of class. He delegates liminals, meaning those who are in a state of liminality, to the edges of the social structure. In general, Turner denotes liminality as a midpoint between a starting point and an ending point, and is a temporary state that ends when one is reincorporated into the social structure. Today, transportation terminals can be seen as devices which impose a social structure upon its occupants.

In terms of architecture, "Liminal" space or the "In-Between" space refers to those spaces that are transitional passages or thresholds between other states. In classical Roman architecture, liminal architecture refers to the arches, portals, gateways and fortifications which border the periphery of a city. These are representative of the spaces which lay in-between two places. Today, liminal space is the space which juxtaposes and strengthens the interaction between the two differing states. The transportation terminal is an example of liminal space within architecture, by functioning as the in-between spaces connecting two differing conditions. They represent the crossing over from one state into the next. The two opposing conditions may vary between destination and origin, the visited city and the permanent city and moreover, people and place. The state of liminality within the terminal space can be seen as "in-betweeness" or the "not here, nor there" states of existence. Terminals function as gateways and arrival points to any given city where some terminals maintain a connectedness to the city whereas others lie segregated from the city and are pushed towards the periphery. Those terminals that are pushed outwards, for example, the airport often lack the "place-ness" of the city. These are characterized as the non-places of transit. Whereas train stations and bus stations are capable of being located within the city center can demonstrate a sense of place. 


\subsection{The Threshold Experience: Architecture of Arrival and Departure}

Given that the transportation terminal, a significant non-place, is often the initial link to which a passer-through or resident orients one self to any particular city, it is necessary to recognize this architectural experience as potentially one of great importance and significance. It is evident that non-places thus become the new spaces of experience often associated with territorialism and temporality. These connections one has to a city are made through its architecture and non-places act as the initial link to the destination one desires to reach. These spaces are what greet and say farewell to its occupiers. Threshold spaces are spaces of transition; they are the buffer zone between the road, sky, or rail and the city. However these points of transition have become increasingly more than simply points of arrival and departure and yet they continue to remain nondestinations; they become moments of celebration and demarcation.

Because the transportation terminal acts as an individual's first and subsequently their final physical interaction with the city, architecture factors strongly into the experience of this threshold. The threshold is the point of arrival and departure of its occupants within the city. These buildings typologies are often regarded as mere processing machines for its temporary inhabitants where its function supersedes beauty and the poetics of space. This is the case because sensitivity to architecture is often disregarded is such spaces. As seen in examples such as the greyhound bus terminal in Ottawa, functionalist building types frequently dismiss the effect they generate upon society. Therefore, it is imperative to understand and value the role of architecture in the non-places of transit, which is to create the connection between the means of travel and 
the point of arrival and departure; to create an effective meaningful architecture out of the over-looked aspects of daily transitory commuter life.

Often times, non-places have the ability to mentally generate experiences that are far removed from the physicality of the real world. They remain fixated within the minds of passengers and consumers. These experiences occur in all types of non-places but the most pertinent include, the two very different, highways and terminals since these are the instances which greeting and bidding farewell to its occupants occur. The anticipatory sensation while approaching the destination is often a catalyst to create these mental spaces. As the traveler veers towards anticipated destinations mental spaces are construed along the way.

Henri Lefebrve provides a persuasive warning against the collapse of various spaces around us into the mental spaces figured in metaphors of reading:

When codes worked up from literary spaces are applied to spaces--to urban spaces, say--we remain, as may easily be shown, on the purely descriptive level. Any attempt to use such codes as a means of deciphering social space must surely reduce that space itself to the status of a message, and the inhabiting of it to the status of a reading. ${ }^{9}$

\footnotetext{
${ }^{9}$ Henri Lefebvre, The Production of Space. (Malden: Blackwell Publishing Ltd., 1991) 7.
} 


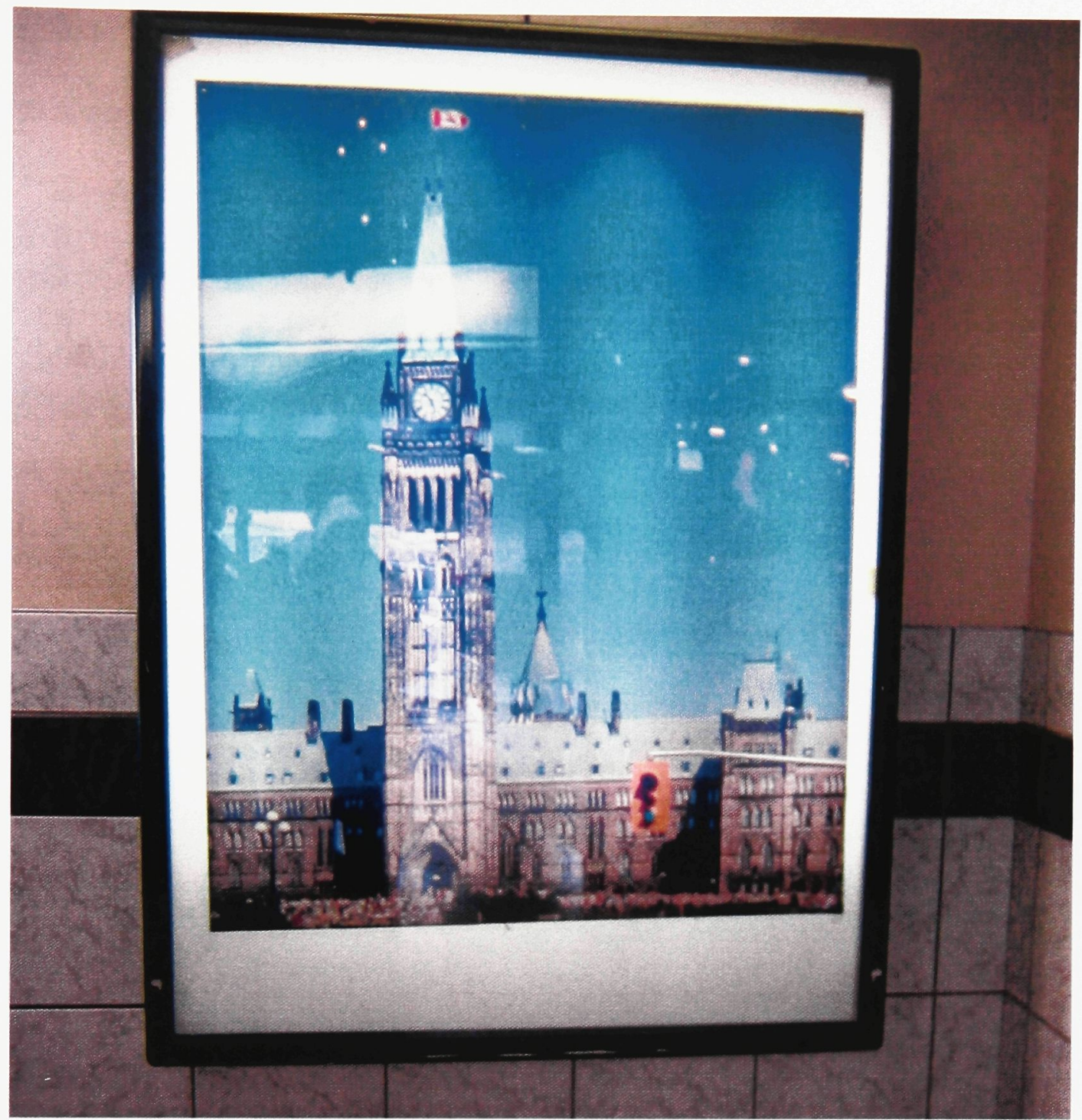

Figure 2. Mental Space

This figure is a poster of Parliament Hill found in the Ottawa Voyageur terminal. Billboards and posters like this are found within most transportation terminals and are located in spaces of arrival. Images like Parliament Hill in Ottawa remind travelers of the city's attractions. However, typical non-places of transit are found far outside the city limits and are nowhere near what is depicted in the posters.

Non-places encourage us to do just this: reduce a world of embedded histories and relationships to a sign on the highway or photo postcard. Often times, a "welcome to..." roadway sign or random roadway image triggers mental spaces. These displaced signs specify that the traveler has now entered into a new place yet there is no physical indication that one has reached the desired spaces. The traveler mentally draws up connections to a particular space and place when reading or looking at particular images. 
The significant traits of the non-places of transit are their important links to the individuals' memory.

...perhaps the most important trait of the non-place is its impact upon memory. The most important function of memory is to shape identity. Without memory, one is "nobody"; without shared memory nothing collective can exist ${ }^{10}$.

In terms of architectural space, these memories may create architecturally mental collages of spaces and experiences which are linked to non-places and places of transit architecture.

\subsection{The Non-Place Paradox: When Non-Place become Place}

When one travels, they displace themselves from their familiar surroundings, the setting of sameness. In doing so, they merely experience a different sameness of another's for a brief moment in time.

A paradox of non-place: a foreigner lost in a country he does not know (a 'passing stranger') can feel at home there only in the anonymity of motorways, service stations, big stores or hotel chains ${ }^{11}$.

There exists a consistent phenomenon occurring within all non-places, especially the terminal. For many travelers, when one enters a new city they arrive inside the unknown and the terminal acts as the starting point for many. That is, the sense that one can feel 'right at home' in an unknown and unexperienced location. As a trait of all nonplaces, many travelers desire a sense of familiarity and sense of desired cognition,

\footnotetext{
${ }^{10}$ Catharina Gabrielsson. "Out of Nowhere.” 26 January 2006

$<$ http://www.mikaellevin.com/catharina_gabrielsson.html $>$

${ }^{11}$ Marc Augé, Non-Places: Introduction to an Anthropology of Supermodernity. (New York: Verso Publishers, 1995) 106.
} 
meaning those things that make one feel comfortable in an uncomfortable environment.

Typically, familiar links to brands or consumption are the activity

It is evident here that an individual may sense comfort in these places for

consumption. As Sharon Zukin states, in her essay entitled Politics and Aesthetics of

Public Space: The American Model (1998):

In North America, this model of re-aestheticizing public space has gone to an extreme by considering retail space- shops, restaurants, coffee bars- as public space. Similarly, streets and parks are designed as if they were spaces of consumption... the ideal city no longer influences the real city. Instead, the stores, entertainment complexes, and art museums that are important interventions in public space are shaping an ideal city based on consumption. The common symbols of public space are increasingly derived from the nexus of aesthetic display and commercial culture ${ }^{12}$.

Within the unknown spaces of the world, there are often certain triggers which allow one to feel comfortable while temporarily in the unfamiliar location. As unfamiliar and unexperienced as non-places may be to the traveler, there will always be present elements of recognition in any and every non-place. It is in this grey area of the nonplace where the definite definition of non-place becomes obscured. In order to design the familiar locations of non-places,

The recent movie entitled The Terminal depicts an unusual occurrence which takes place within a non-place. The character Viktor Navorski challenges the definition of non-place and discovers that it is not so black and white. Upon arrival into the United States, Viktor is held at Kennedy International Airport due to legal restrictions preventing him from entering the country. He remains stuck at KIA for nine months, and discovers what many travelers are increasingly detecting: that airports have become their own

\footnotetext{
${ }^{12}$ Sharon Zukin, "Politics and Aesthetics of Public Space: The American Model" Real City, Ideal City: Meaning and Function in Modern Urban Space. (Barcelona: CCCB Press, 1998) 38.
} 
worlds, laboratories for the latest forms of nourishment, commerce, entertainment, information, romance and fear. It is clear that non-places, especially those non-places of transit have the ability to become self sustaining microcosms of ever amenity desired and required by society. And it as this point when one feels at 'home' in these cultural abysses that non-places in fact become places to many.

As terminal amenities and food courts have expanded due to the growing number of commuters and travellers, and security concerns have increased the time people spend in them, terminals have become more than places for departures and arrivals, yet they still remain less than destinations. Without local history, tradition, religion or dialect, nonplaces borrow bits of each of these from the people passing through them. This is the inevitable consequence of the non-place. No matter what the architecture is around the inhabitants, transitory buildings will always maintain these traits. It is therefore the role of the architect to therefore make them liveable, expressive, and evocative to ameliorate the experience of the non-place.

The station, a vast organism which houses the big trains, the urban trains, the subway, a department store, and a whole underground commerce - the station gives the district its landmark which, according to certain urbanists, permits the city to signify, to be read. Dedicated to commerce, to transition, to departure, and yet kept in a unique structure, the station is stripped of the sacred character which ordinarily qualifies the major landmarks of our cities: cathedrals, town halls, historical monuments. ${ }^{13}$

It is evident here that the implications of non-place reveal the non-sacredness of such spaces. Typically sacred spaces are those which are most civic. As implied above, the places that uphold history, culture and identity are often deemed as superior to the significance of non-places. However, since the societal impact of non-places is becoming

\footnotetext{
${ }^{13}$ Manuel Castells and Hall, Peter, Technopoles of the World: The Making of 21st Century Industrial Complexes (London: Routledge Press, 1993) 38-42.
} 
so prominent in contemporary life, a shift of ideals and standards may be inevitable. The shift towards non-places becoming places may become evident in certain cases. The architecture of transportation terminals which impact its occupants and leave instances of memory will unavoidably shift the principles of non-place towards place and these spaces will gain the characteristics of place. The paradox is creating places out of nonplaces.

\subsection{The Invisible Terminal}

With the emergence of convenient and affordable air and railway travel, as well as the growing number of individuals with access to the automobile, the number of travelers who make use of the bus transportation has significantly decreased over time. According to the Dallas Times, the Dallas-based Greyhound Lines Inc. has seen a noteworthy drop in the number of passengers using the bus as a form of transportation over the past decade. The company has recently announced plans to upgrade the quality of all terminals and buses in response to the decline. "Our customers will notice dramatic improvements in the Greyhound travel experience," company CEO Steve Gorman said. This is an indication that bus travel is experiencing a withdrawal of users and that intercity bus transportation may be at risk of becoming extinct or even more invisible than now.

Often times, the bus terminal is seen by many as an undesirable space to experience. There are various reasons why the bus terminal is often seen as unappealing including the social class of the travelers or the terminal's physical location within the city. Typically bus travel is regarded as the most affordable means of transportation. Consequently, it is often understood that society's lower class frequents travel by bus. 
However, after examining the bus terminal in Ottawa, it is not often the case. Students and young adults hold a large percentage of those who ride the bus. And trips to nearby cities such as Toronto and Montreal are normally heavily populated with passengers. The bus terminal is often associated with the grimy, unpleasant aspects of the city but is not the case at the terminal in Ottawa.

With the ease of accessibility to other means of transportation, the bus terminal has stood in the shadows of the two other larger transportation edifices; those being the airport and the train station. And although highway travel continues to dominate the mode of transportation chosen by most, the number of travelers by bus travel pales in comparison. Consequently, theories and writings are quite limited in respect to the bus terminal. It is often over-looked that bus travel has played a major role in inter-city transportation. The bus terminal has become theoretically invisible in the sector of architectural writing. However, after researching the bus terminal, various examples of successful bus terminal design were uncovered and investigated.

\subsection{Terminal Precedents}

One example of successful bus terminal design is the Port Authority Bus Terminal in New York City developed by the Port Authority of New York/New Jersey and constructed in 1950. 


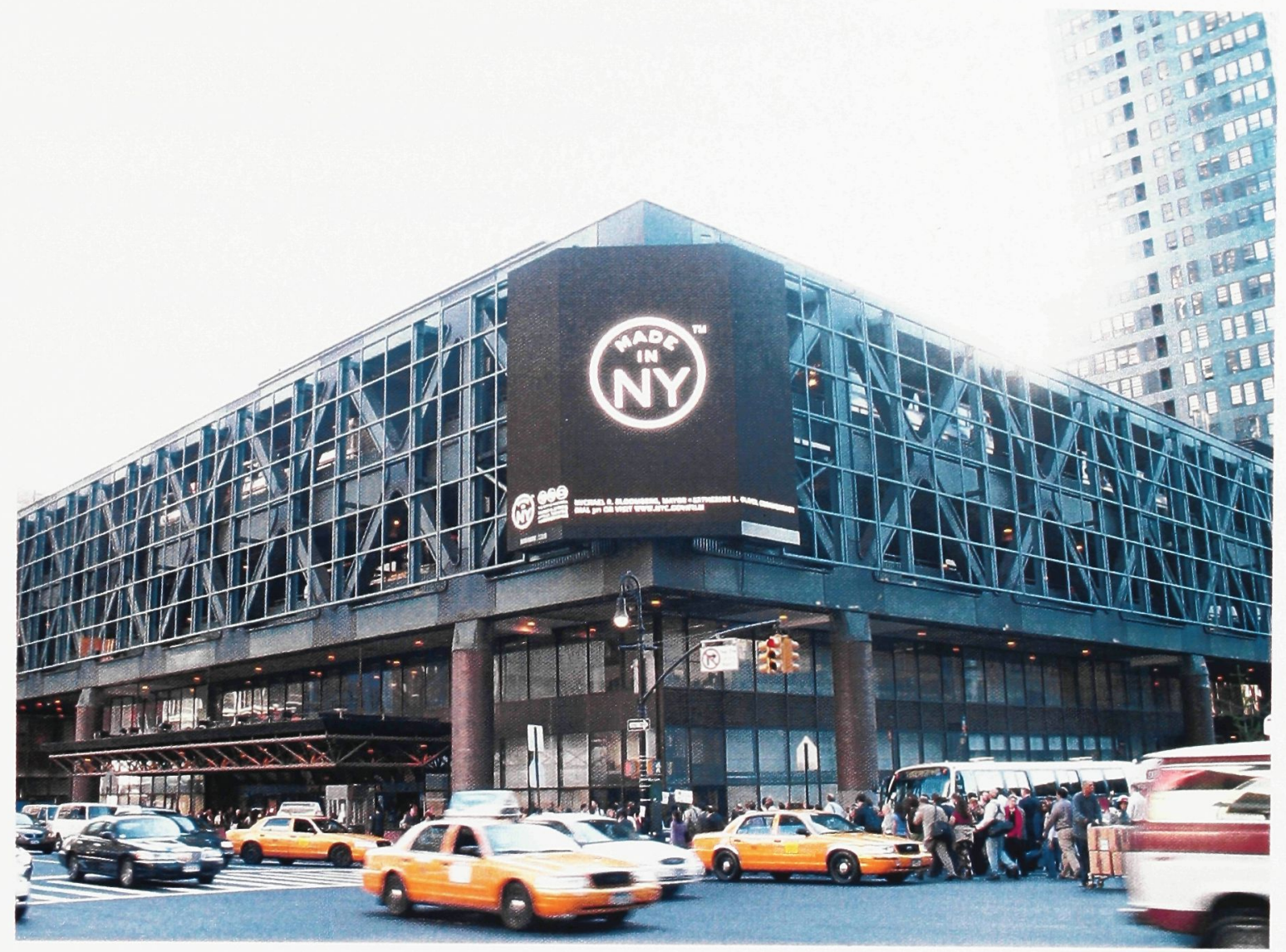

Figure 3. Port Authority Bus Terminal

This figure shows the Port Authority Bus Terminal located in New York City. It was originally built in 1950.

The terminal has become an essential part of the revitalized Times Square and theatre district areas, and acts as a crucial connection for the area's workers, travelers and visitors, serving more than 200,000 passengers daily. The Port Authority became the world's largest and most utilized transportation edifice. The terminal was to be built as a solution for a hectic array of various terminals spread throughout Manhattan. The goal was to centralize the flow of buses and create an efficiently functioning building. The district around the terminal was once commonly known as Hell's Kitchen but was revitalized during New York City's renaissance of the 1990's. Today the terminal is considered to be part of the Times Square theatre district. Located within the core of Midtown Manhattan at the site bordered by Eighth Avenue, 40th Street, Ninth Avenue 
and 41 st Street, the terminal is very much engulfed within its surroundings. Unlike examples of terminals which are pushed towards the periphery or buried underground, the Port Authority Bus Terminal sits within a rich historical environment complete with culture and identity. When the traveler or commuter enters the threshold, a desired sense of arrival into a "place" is experienced rather than a lifeless non-place far removed from the destination it corresponds to. This sense of place enables the occupant to feel as though they have crossed a threshold and entered into a aspired locale. The Port Authority Bus Terminal shows that not all transportation terminals are destined to be non-places and that even transitional liminal space can maintain a sense of place.

A second example of successful bus terminal design is the Nils Ericson Terminal at Gothenburg, Sweden built in 1999 by the architect Niels Torp.

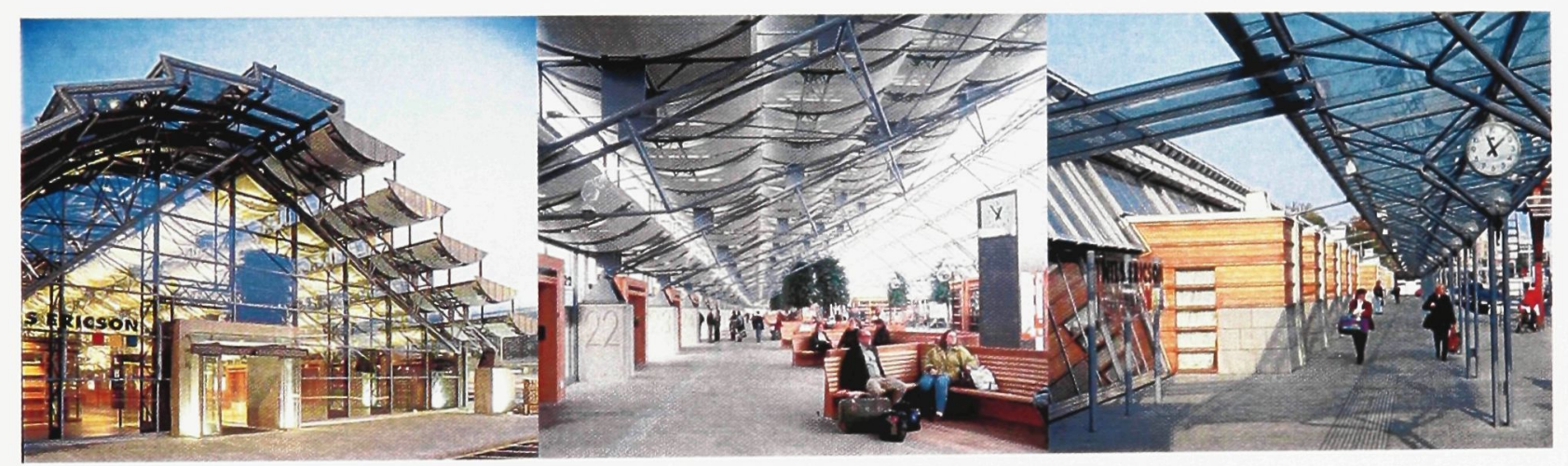

Figure 4. Nils Ericson Terminal

This figure shows the Nils Ericson Terminal located in Gothenburg, Sweden built in 1999. (http://www.ntorp.no/?module=Articles; $\mathrm{ID}=623$ )

The building exemplifies how the large scales of bus terminals can become humanized in order to create a more hospitable experience. The building itself is a relatively simple but bold intervention upon the existing site. Torp stretched a long glazed gallery along the axis of an already existing railway station. Both the railway and bus stations were unified in one move linked by the solitary straightforward form. The 
terminals' landscaping is an extension of the city's complex of green urban spaces and the exterior space which wraps around the terminal acts as a well defined urban space within the city. The language of the terminal is reminiscent of its surroundings, echoing the forms of traditional train sheds found throughout Europe. The most important aspect addressed was to achieve a human scale and a sense of place. The clarity of the Nils Ericson bus station avoids confusion and formlessness, yet it also escapes the monotony and institutionalism of large public buildings of simple program.

A third well executed transportation terminal is Oriente Station in Lisbon, Portugal built in 1998 by the architect/engineer Santiago Calatrava.

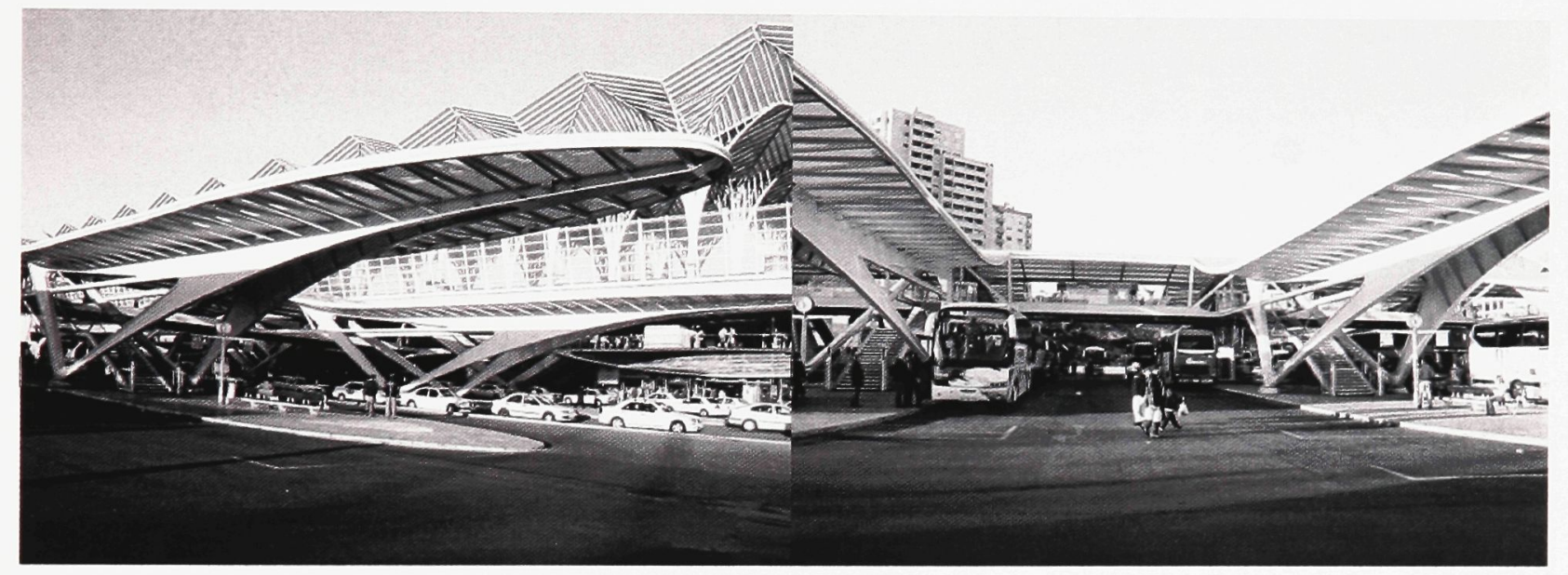

Figure 5. Oriente Station

This figure shows the Orient Station located in Lisbon, Portugal built in 1998. (http://www.bluffton.edu/ sullivanm/portugal/Lisbon/calatravastation/station.html)

Here, Calatrava solves the complex problem of two major transportation infrastructures joining together to share one hub. The building houses both the train station and the bus terminal in unison. Like several effective works by Calatrava, the overwhelming awe of this project is its strongpoint. This transit architecture has the ability to spatially positively affect its inhabitants and occupants. This project reveals that even projects devised out of no historical context have the ability to be understood as 
a "place." The memorable expressive architecture created by Calatrava remains engraved in the travelers minds creating a new sense of place.

As a counterpoint to successful terminals which demonstrate a sense of place, Penn Station in New York City is an example of a non-place of transit.

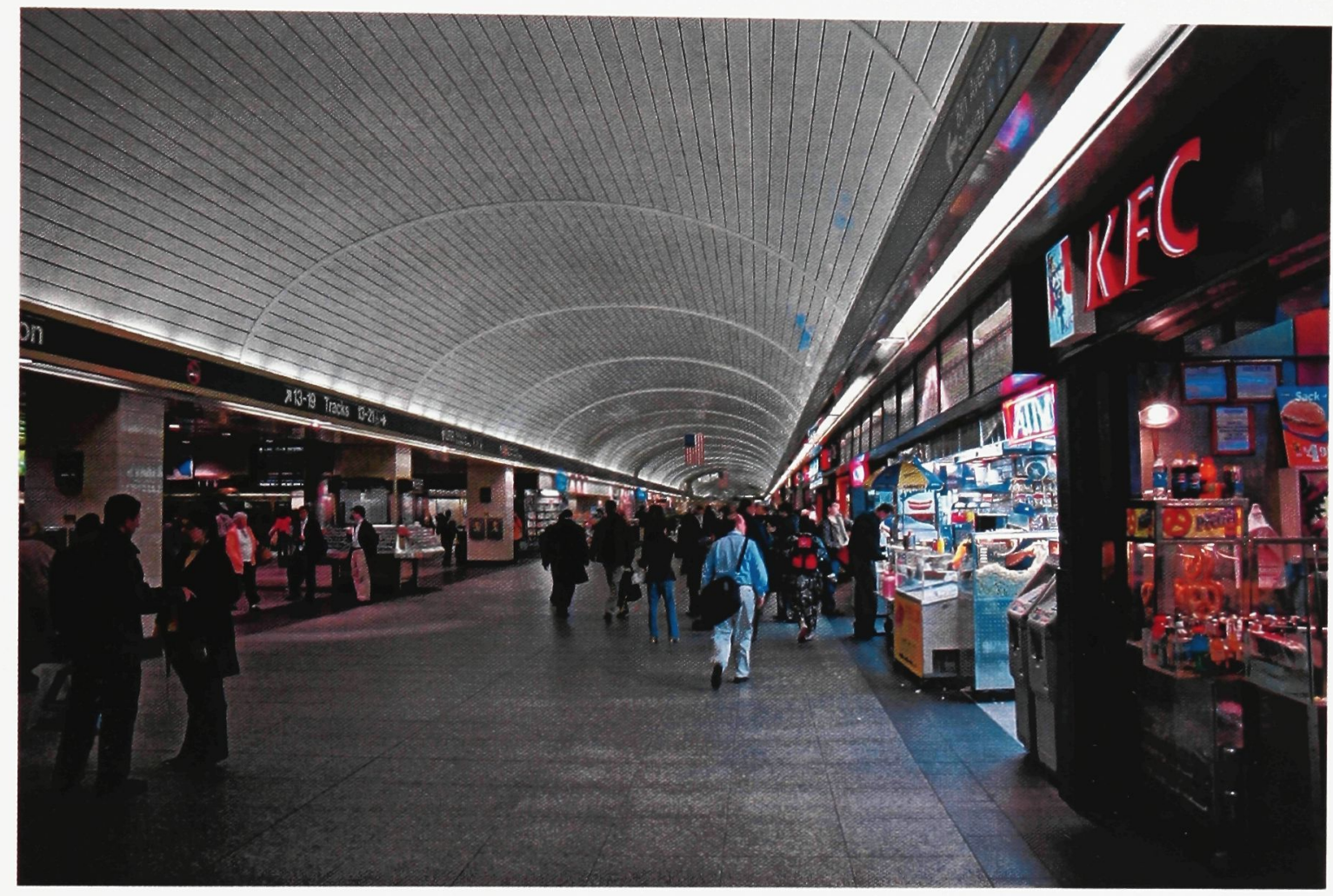

Figure 6. Pennsylvania Station

This figure shows Pennsylvania Station located in New York City.

(http://en.wikipedia.org/wiki/Pennsylvania_Station)

Built in 1910, Pennsylvania Station was seen as a great monument to travel as it upheld qualities of place. Its dramatic spaces echoed the Roman model of Baths of Caracalla and the terminal was seen as a significant demonstration of early 20 th century terminal design. However, with the advent of the automobile and air travel, transportation by train diminished significantly until the point where significant sections of Penn Station were demolished. Today the terminal lays buried deep underground. The occupant is submerged into a dark maze of passageways and tunnels with no concept of 
their surroundings. Connections are lost to the outside world, reinforcing a sense of being nowhere arises. The absence of humanness is apparent in this labyrinth and this as well as the lack of the historical significance of the place altered Penn Station from a place to a non-place. The effects of disorientation that travel produces a non-intimate experience creating instances of the non-place. Unlike the previous examples which all lead to terminals which are regarded as places, Penn Station in New York lacks the important characteristics needed to be deemed a place.

The various precedents explored here have influenced the proposed thesis design. The design will reflect the essential aspects depicted in the precedents examined. Transportation terminals have the ability to become important cultural and historical spaces allowing them to be considered places. 


\section{Part Two: The Collage Experiments}

\section{Chapter Two}

\subsection{Collage Objectives}

The accompanying component of the thesis entails a specific process driven design method whereby the examination of non-place architecture was explored, interpreted and extracted by the technique and methods of collage. The underlying intention of the design process was to extract and connote and reify architectural space from collage. Collage in architecture has the ability to instigate and forecast the creation of space.

Collage was not investigated as technique alone. The underlying principles of collage also share a valid importance and not only the aesthetic final product. The principles of collage refer to the extraction of an image or object out of its original context, reduced to a fragment, juxtaposed with other fragments and eventually simulated and portrayed these dissimilar objects into a new image, object or whole. The collage as image is not an imitation or mimic of architecture, but rather, acts as a tool of abstracted representation. Collages have the ability to be created by means of intuition over structure and order.

The criterion to successfully extract architecture from collage making is based on the ability to think intuitively, formally, as a way to consider program, function and social concerns while doing so. To create a collage is essentially creating form, space and texture in two- dimensions. The architect's role is to then translate this form, these shapes, extract the concealed space and expel it into architectural space in three 
dimensions. In this case, the architecture of destination of a journey- a movement from the liminal states of travel.

Designing and thinking by means of collage has the capability to generate architectural dynamism and the traits of place that functionalism alone does not. Collage is a type of place-making, or in this case a type of non-place-making. Often times, functionalism leads to stale, over-engineered buildings which show little regard to site or its impact on social repercussion. Remko Scha, a professor at the University of Amsterdam remarks:

Functionalism was an attempt to develop such an objective style. An attempt that failed: The architect, who focuses completely on functions that can be articulated explicitly, turns a building into a commodity which has a lot in common with a cupboard or a file cabinet ${ }^{14}$.

Here, Scha illustrates that if architecture was thought of in terms of functionalism alone, that the built world would be in imminent danger of becoming uninteresting and meaningless. The solution is to formulate a balance in architecture by making aesthetic and spatial choices as well as functionalist choices in order to ensure successful buildings are built. Where collage and function meet is the objective of the thesis. To create architecture using collage while always considering program and function will ensure a successful building. There must be equilibrium between the two disparate entities of architecture- generating form and programming the function of buildings.

\footnotetext{
${ }^{14}$ Remko Scha. "Towards an Architecture of Chance." Art, Chance and Algorithm. (Amsterdam: University of Amsterdam, 1992) 19.
} 


\subsection{Defining Collage}

The term collage comes from the French verb coller, the act of gluing or sticking together. Closely associated with the idea of collage - in both French and English - is the idea of assemblage, the fitting together of parts and pieces ${ }^{15}$. Another French term, bricolage, is defined as the putting together of seemingly dissimilar objects or pieces. Both coller and bricolage originated from the Greek term kólla, meaning glue.

In its simplest idiom, collages are the result of bringing together dissimilar things in order to create something with a new meaning or expression. These dissimilar things are countless ranging from the trompe l'oeil wood wallpaper used by Pablo Picasso seen in his Still Life with Chair Canning from 1912 (figure 5), to the seemingly random word poems created by the Futurists (figure 6 ) and also to the political propaganda devised by the Dadaists (figure 7). The cohesion that all three of these instances share is the binding of disparate objects or images or words together to form a new meaning or expression. However, these meanings which arise from the interpretation of collage is where the simplicity becomes complex. Like language, collage is defined as a multifaceted term comprised of innumerable personal interpretations and meanings. However, the intentionality of the artist also plays a role in the 'reading' of a collage. However, since the meaning of a collage is a product of each individuals own interpretations, understanding and analysis, collages tend to be understood subjectively as opposed to objectively. Meanings within a collage arise from individual readings where the observer derives his or her own conclusions based on one's own personal subjective perception.

\footnotetext{
${ }^{15}$ Christine Poggi. In Defiance of Painting: Cubism, Futurism and the Invention of Collage. (New Haven: Yale University Press, 1992) 37.
} 


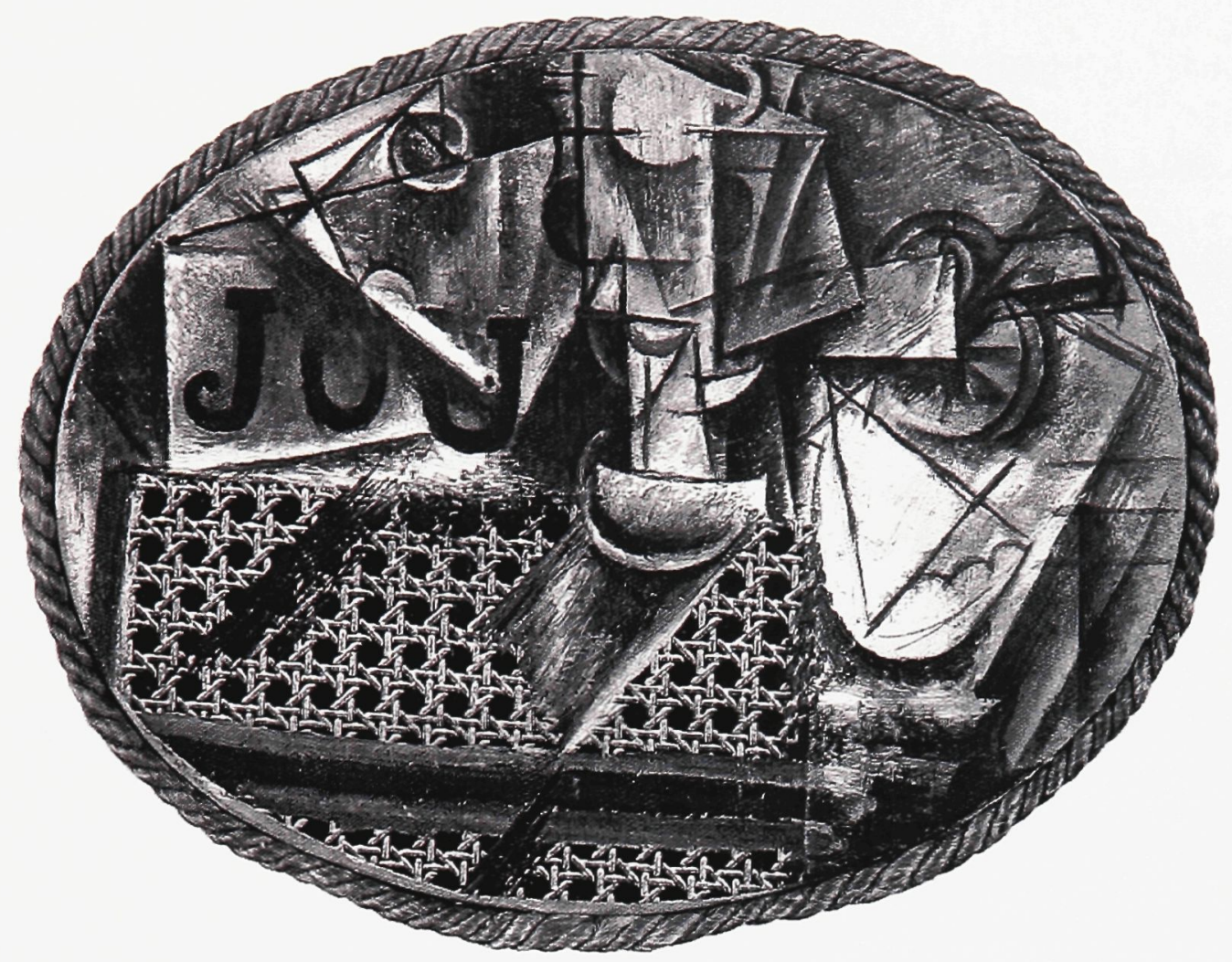

Figure 7. Still Life with Chair-Canning

Pablo Picasso,1912. Oil and oil cloth on canvas, with rope frame.

(In Defiance of Painting: Cubism, Futurism and the Invention of Collage. 1992) ix.
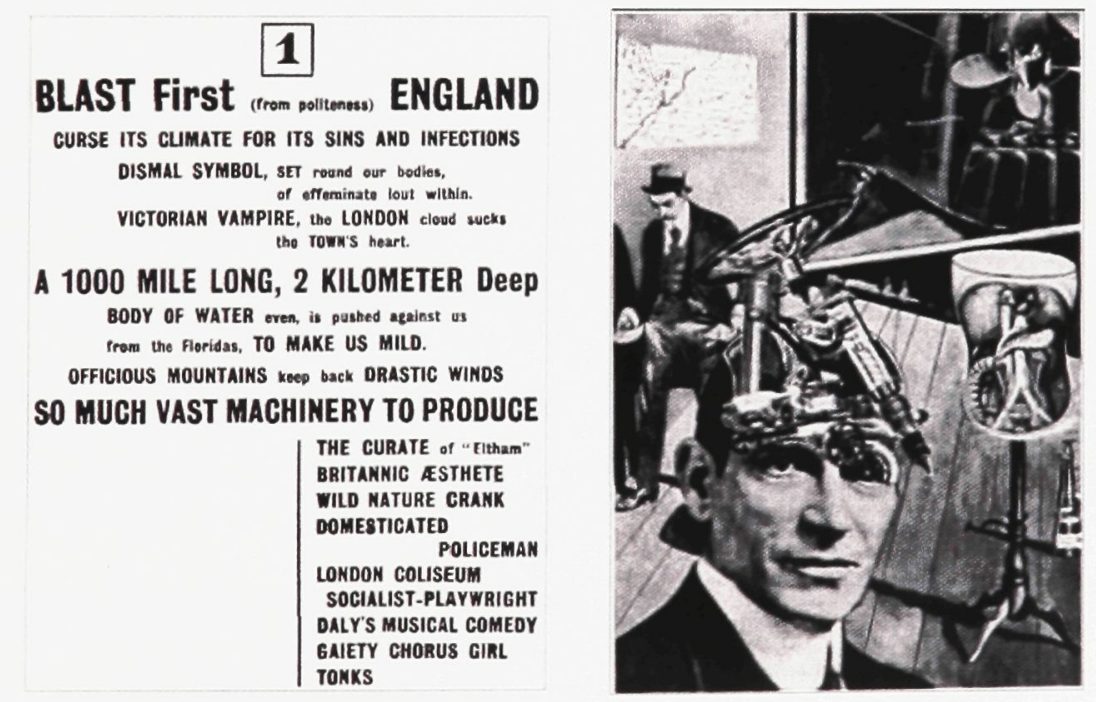

Figure 8. Dada Collages

(above left) Page from the Blast: Review of the Great English Vortex No. 1, 1914. (Futurism, 1999) 53. (above right) Raoul Hausman, Tatlin at Home, 1920. (Dada: Zurich, Berlin, Hanover, Cologne, New York, Paris, 2004) 37. 


\subsection{The Emergence of Collage}

In 1912, Pablo Picasso glued a piece of oil-cloth with a trompe l'oeil chaircanning pattern to a small oval shaped canvas representational of a café still life. For art historians, this tiny piece has been considered the first deliberately executed collage. For the first time in fine art, materials appropriated from everyday life were introduced to painting. This manipulation and inclusion of 'inappropriate' materials intruded upon the world of art and transformed it for good. In this first collage, the reading can be that Picasso has created architectural space and form upon the canvas.

The concepts of collage used by Picasso and Georges Braques in 1912 have the ability to synthesize a new world of recognizable forms from everyday things. That is to make something meaningful by heightening perception of the inherent synthetic properties of the banal and disregarded much like modern painting and sculpture have the ability to perform. By simply gluing a ticket stub to a piece of chair caning or by adding some paint on canvas to a playing card and a drawing of a clarinet involves the act of bringing disparate objects together forming a new cohesive product.

It is here, where the elements of collage have the most significance and impact. By 'de-naturing' or removing fragments from their existing environments it enhances their meaning. When juxtaposed with another disparate image or object the new meaning arises from the collage. In 1948, the painter and collagist Max Ernst eloquently defines the act of collage as bringing two dissimilar things together and the result of collage as the energy that exists afterward.

When two dissimilar aspects of reality are juxtaposed on a plane which would not appear to suit them ... the very fact of their being put next to one another leads to a mutual exchange of energy. ('Collage' is the word for this, in plain speech.) 
This exchange may proceed calmly and steadily, or it may take the form of an explosion accompanied by lightning and thunder ${ }^{16}$.

\subsection{Montage vs. Collage}

A collage is a fixed representation or composition that often indicates no evident passage of time. Collages remain static and do not typically correspond to the progression of time unlike montage. Whereas the collages created for this thesis are informative of space and form, montage is the depiction of the lapse of time, progress and continuation. Those collages that display a passage of time in space are regarded as montage. Montages are collages by means of imposed time. Montage is the act of depicting time through the assembly of images and is a term commonly used from cinematography. The Russian Soviet filmmaker Sergei Eisenstein theorized that the technique of montage could generate ideas and have a more significant impact than individual images alone. Eisenstein regarded montage as a dialectical means of creating meaning. By contrasting unrelated shots he tried to provoke associations in the viewer which were often produced by surprise and unpredictability. Eisenstein saw montage as capable of revealing by means of consciously engaging the viewer to construct their own meanings, within a certain set of parameters defined by the filmmaker. These montages are referred to the temporal juxtaposition of a succession of shots that may or may not be related to each other in terms of subject matter however they still share a common thematic element.

Highway travel and montage are linked by time. When one travels along the highway from destination to destination, point to point, they are able to form mental

\footnotetext{
${ }^{16}$ Max Ernst. Beyond Painting, and Other Writings by the Artist and his Friends. (New York, Schultz, 1948) 23.
} 
images as reference points along the journey. Fastened together, these images become montages; collages of time.

\section{Chapter Three: Collage Thinking in Architecture}

\subsection{Collage Precedents}

Architects who demonstrate the use and methods of collage within architecture, include Ben Nicholson, Richard Meier and Le Corbusier, all who support and influence the explorations of this thesis through their approaches to the methods, analysis and theories of collage. Although all the individuals present a varied interpretation and elaboration of collage, all exhibit important constituents of collage within architecture. These projects unify both concept and theory of collage within architecture.

\section{$\underline{\text { Ben Nicholson }}$}

The projects of Ben Nicholson commonly use the method of collage as an apparatus to create or delve out imbedded meanings within objects through their deconstruction and eventual reassembly. Nicholson obtains his diverse images from Sears's catalogs, catalogs for building contractors, catalogs for consumers, and from Michelangelo. He surgically cuts and pastes his images in strategically placed positions creating objects that may resemble an elevation, plan or section. As a result, these objects inform and influence the architectural language of the design.

Within each image used in Nicholson's collages, there already exists a preinstilled meaning. Unlike drawing, collages carry the 'instant history factor.' For example, in Nicholson's Saggital Name Collage, the images of the disheveled boots have 
the implanted historical reading. "The boots in this collage bring with them the entire history of shodding feet. ${ }^{17}$ " Nicholson writes:

Collage is an interstitial state: neither flat nor round, neither identifiable nor chaotic. When objects snipped from magazines are reformed into an ephemera of collage they transcend their former pictorial candor. The identity of a frying pan might be lost but its associated smells still linger. The task of collage is to regurgitate the frying pan enough times so that the metal is worn away but its patina is left intact. ${ }^{18}$

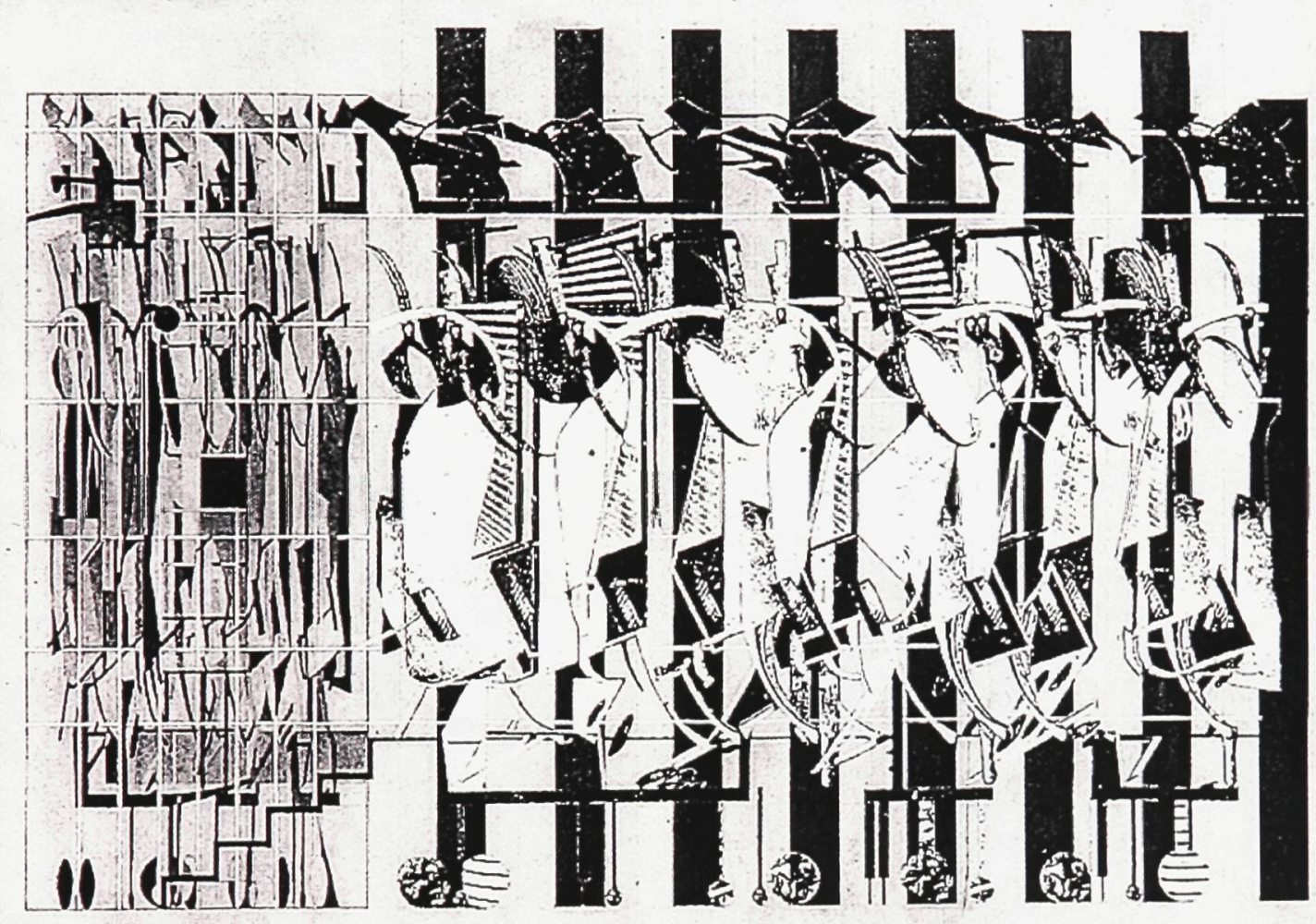

Figure 9.

Exterior elevation of West Cell Wall (The Idea of the City, 1996) 134.

\footnotetext{
${ }^{17}$ Ben Nicholson. "The Appliance House," The Idea of the City. (MIT Press, 1996) 123.

${ }^{18}$ Ben Nicholson The Appliance House. (Cambridge: MIT Press, 1990) 22.
} 


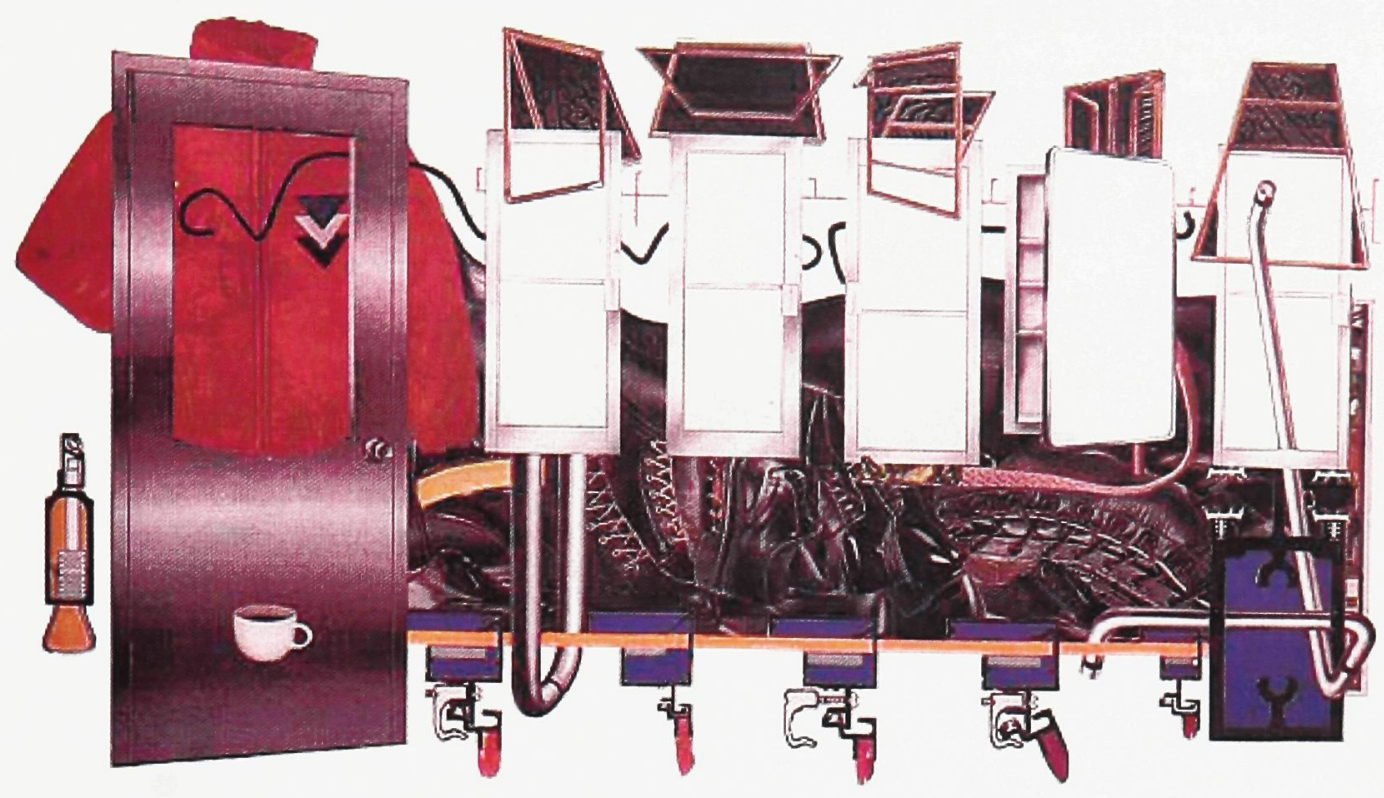

Figure 10.

Saggital Name Collage

(The Idea of the City, 1996) 124.
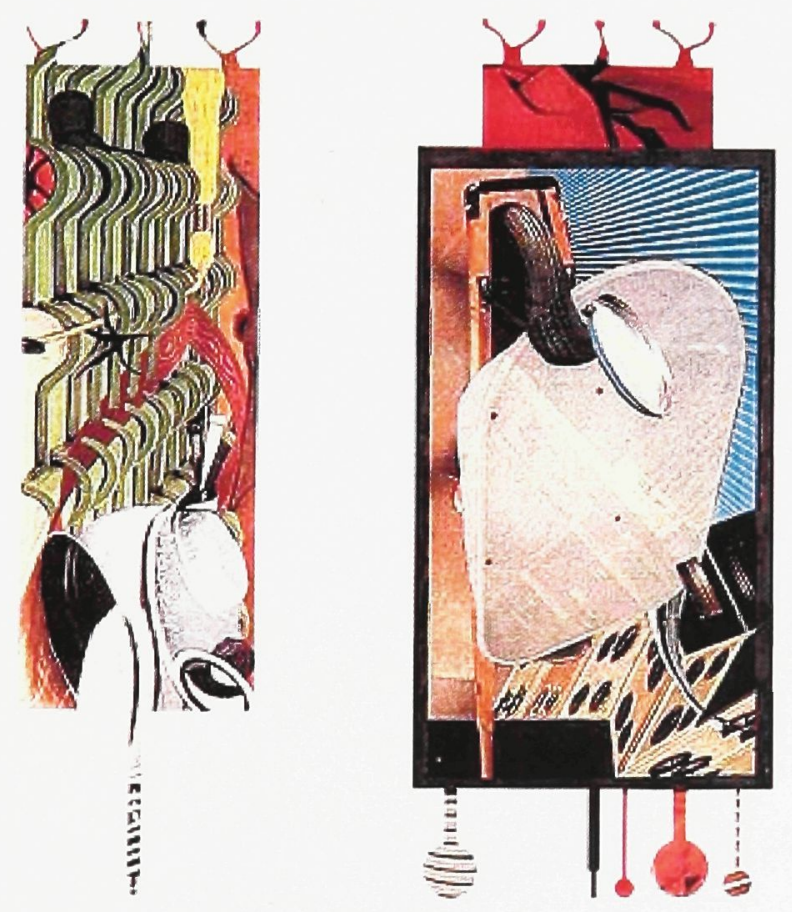

Figure 11.

Kleptoman Cell

(The Appliance House, 1990) 23. 
Nicholson's collages, drawings and architecture strive to make something new appear. They attempt to bring us into contact with a completely new sensation through the mediation of a picture or illustration. The moment does not come directly from any specific element in the drawing itself, but rather between the fragments of the collage and their mutual energy together. Nicholson's techniques are highly precise and his admiration for the act of physically creating the collage is obvious. His collages initially transform into objects in space, and then become representations of space or of actual spaces themselves.

Because the collages of Nicholson observed are constructed of an array of pieces of paper that combine an unlimited number of perspectival angles and scales produced by the lens of the camera or by the hand of the draftsman, the resultant collage object itself becomes a source of puzzlement and wonder. It is in this puzzlement and wonder where the architects mind may wander.

Because of the thinness of paper, collage relief also permits translucence. Light is reflected off a surface that is apparently hidden beneath a covering surface. Thus, a collage is the first hint at a condition of fullness than can exist after the substance of artistic intent has removed itself from the flattened surface of the canvas. The relief created by superimposition can be read as a talisman, as an indication of its three-dimensional qualities. Were the collage to become an object in space, its structure would inform the way it is to be built. ${ }^{19}$

\section{$\underline{\text { Richard Meier }}$}

The collages of Richard Meier engage a much different role in architecture than the collages of Nicholson. Meier's collages pay compliment to, rather than represent his architecture. Unlike his architecture or drawings, his collages are different. They record process and development rather than literally correspond to a building. His process is an

\footnotetext{
${ }^{19}$ Ibid, 23.
} 
unlimited one, in which his collages are never really 'finished' but rather remain in the state of constant progress and reconstruction and transformation.
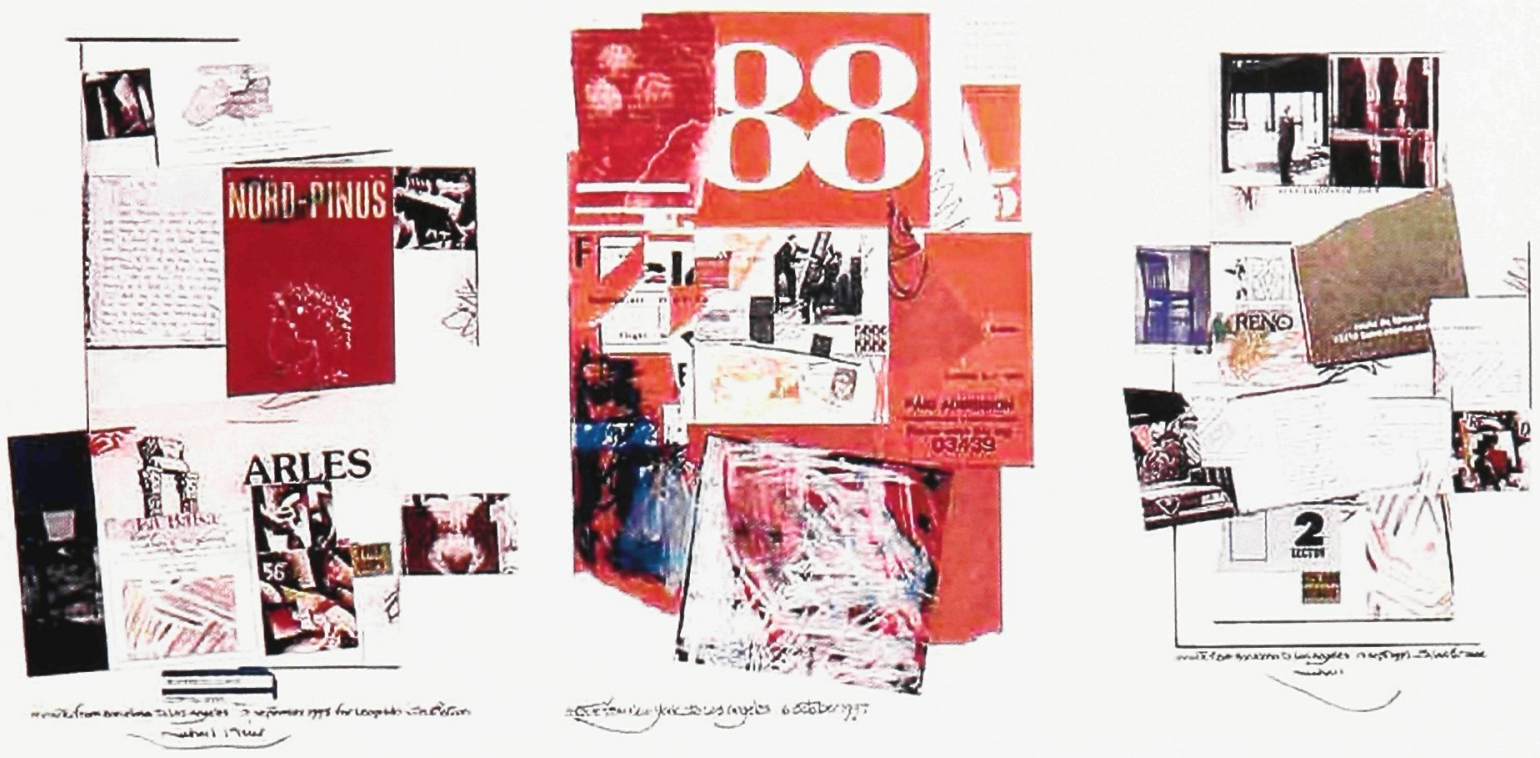

Figure 12.

Richard Meier Collages

(Richard Meier: The Architect as Designer and Artist, 2003) 49.

A single collage is not begun and finished by itself. On the contrary, works in various stages of evolution are left in notebooks and on the shelves of my studio, left sometimes for months or even years to await their own period of development. A collage is often the result of many revisions. Each must be seen as an element in my total work; they are, for me, an adjunct and a passion related to my life as an architect. ${ }^{20}$

It is evident here that collage does play a significant role in the architecture of Richard Meier. Although the collages are not visual representations of his buildings they act as important reminders and preservatives of one's personal history. Seen here, the materials used in Meier's collages are often fragments of his travels; reminders of the little experiences which make each person's own travel unique. They incorporate scraps

20 "Richard Meier Collages." Arcspace. 
of discarded and unwanted items from restaurants, airports, bars and other random places visited. These collages, although seemingly visually unarchitectural, depict the life of the traveling modern vagabond. They truly are the exemplification of non-place collages.

\section{$\underline{\text { Le Corbusier }}$}

In the influential book, Collage City (1978), Coin Rowe and Fred Koetter describe how the architect Le Corbusier affirms collage thinking within his architecture. In several of his projects including Unite d'Habitation and Ozenfant Studio, Le Corbusier accurately creates architectural collage. Unlike Nicholson and Meier, his collages are in three dimensions, joining spaces and forms in collage harmony.

Indeed among architects only that great straddler Le Corbusier, sometimes hedgehog, sometimes fox, has displayed any sympathy towards this kind of thing. His buildings, though not his city plans, are loaded with the results of a process which might be considered more or less to that of a collage. Objects and episodes are obtrusively imported and, while they retain the overtones of their source and origin, they gain also a wholly new impact from their changed context. In, for instance, the Ozenfant studio one is confronted with a mass of allusions and references which it would seem are all basically brought together by collage means ${ }^{21}$.

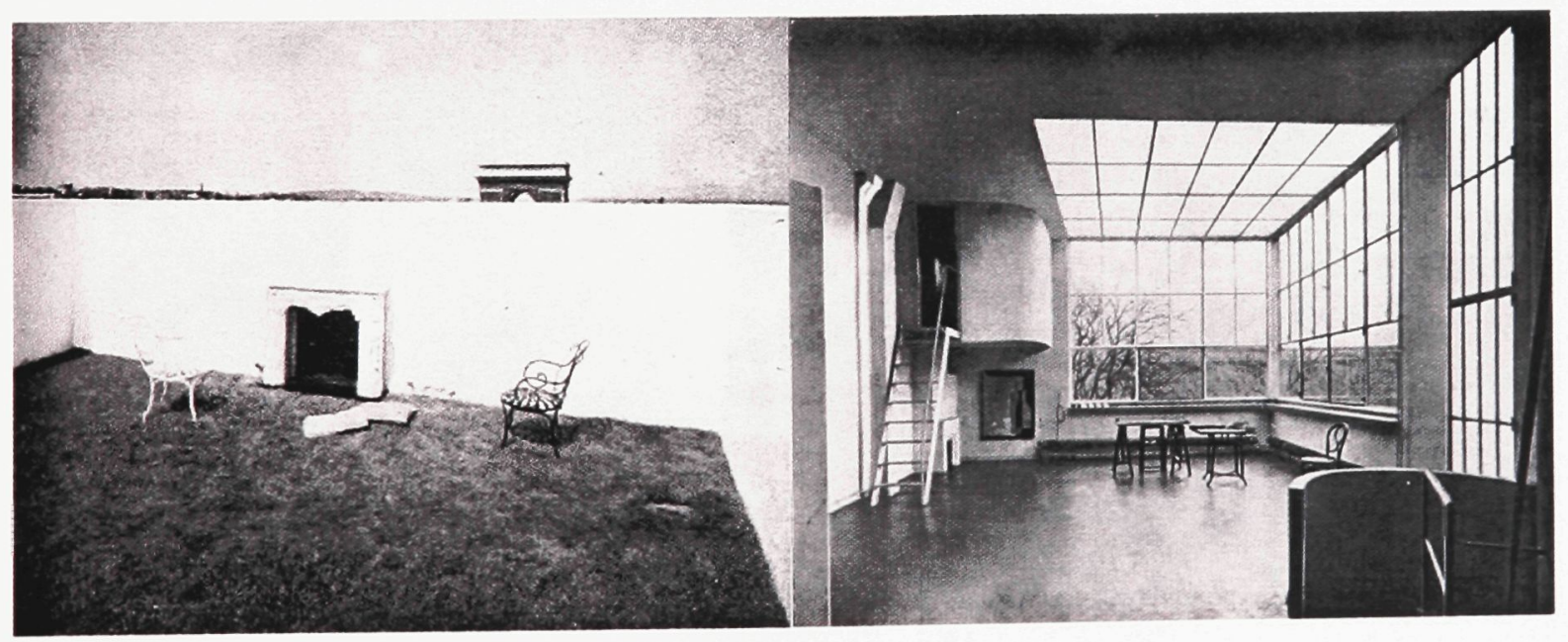

Figure 13. Le Corbusier's collage thinking (left) Marseilles, Unite d'Habitation roofscape, 1946. (right) Paris, Ozenfant Studio, 1922. (Collage City, 1978) 140-141.

\footnotetext{
${ }^{21}$ Colin Rowe and Fred Koetter. Collage City. (Cambridge: MIT Press, 1978) 140.
} 
Essential to Le Corbusier's thought process was an inherent intuitive method for conceiving and composing collages. The technique of Cubist collage combined diverse materials into a single composition. The choice of materials was determined fundamentally by formal rather than iconographic concerns. This technique generated colour, texture, rhythmic pattern and diverse scale effects. However, while Le Corbusier's collages did derive in some manner from Cubist compositions, his intentions were functional and metaphoric and were not devices which arose out of purely formal or visual considerations. Therefore the project, the preparatory drawings and his diagrams reveal different aspects of the same comprehensive search for a complex object.

Le Corbusier created collages by removing objects from the context of their ordinary use and bringing them together in new forms of association. By forcing the objects to coexist in unprecedented contiguities, Le Corbusier generated objects called 'thing-signs.' These objects carry new meanings or complex statements which have a strong impact on the thought and emotions of the viewer. It is evident here how collage thinking and collage making has shaped to work of Le Corbusier. It is evidence that collage can inform architecture in an effective manner. 


\section{Chapter Three: The Collage Experiments (Methodology)}

\subsection{Explanation}

As one gazes at a collage one 'lifts' it out of its 'flatness.' The collage becomes a 'relief.' What a relief! For relief is the first glimpse of roundness, not an acanthi erection but a filling-out in pregnancy, and in it the plane surface of drawing becomes the shadowy solid of three dimensional object $\mathrm{t}^{22}$.

As David Farrell Krell affirms here, collage has the ability to extract hidden and often a subconscious spaces and forms. Often accidental and often deliberately discovered form and shaped exist in collage. This aspect of the thesis deals with collage experiments undertaken as a tool to extract architectural form and space. Over the course of the thesis a numerous number of collages were created in order to reveal the potential of collage to the design of architectural space. Two fundamental questions where asked at this point: Can the collage process lead to a well constructed architectural space? And does collage thinking in architecture produce 'good' architecture?

After analyzing the collage method and technique, three steps were invented and followed when creating these architectural collages. The first stage deals with the extraction of the collage. That is to say, the initial choices the collage maker makes during the process. The desired palette of materials used, size and scale of the collage are assessed at this stage of collage making. Sometimes intuitive choices are made and other times particular images and objects are chosen for specific reasons. The second stage deals with the Expansion of the collage into its actual form. Pieces are cut, ripped and glued onto the canvas or card. The acts and techniques vary from the precision of the

\footnotetext{
${ }^{22}$ Krell, David Farrell. "Thinking Ben Nicholson's Collage Thinking: From the Laurentian Library to the Appliance House, Loaf House, and B-52 Pickup." 16.
} 
scalpel to the inaccuracy of ripping and tearing. Once the collages are completed the next step of transmission is to be undertaken. Drawings are created by laying vellum or trace paper upon the collages and they are interpreted into simple line drawing as well as more spatial architectural drawings are also extracted from the collages. This is the initial step taken of reinterpreting collage and forming it into architecture. From the drawings, models and other three dimensional objects are constructed. Simultaneously, from these objects, the implementation of both program and function then lead to architecture.
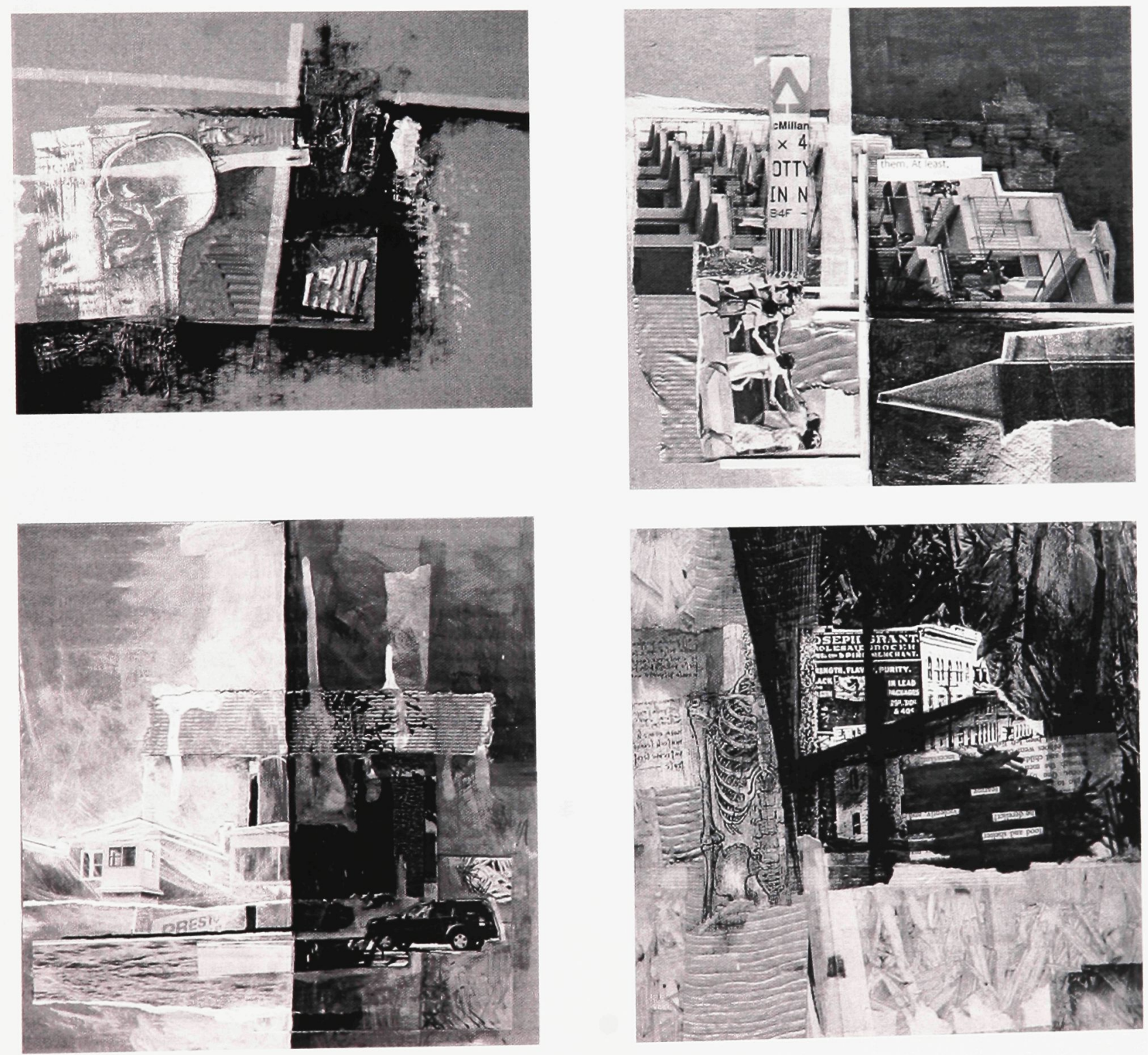

Figure 14. Initial Collages 


\subsection{Site Collages}

Upon gathering information and analyzing the site in the initial stages of the design process, a series of collages were created in order to generate the initial ideas behind collage in architecture. These collages are informative since they act as the catalyst to the design of space. They are fragments of space assembled into new images, evocative of the space they represent.

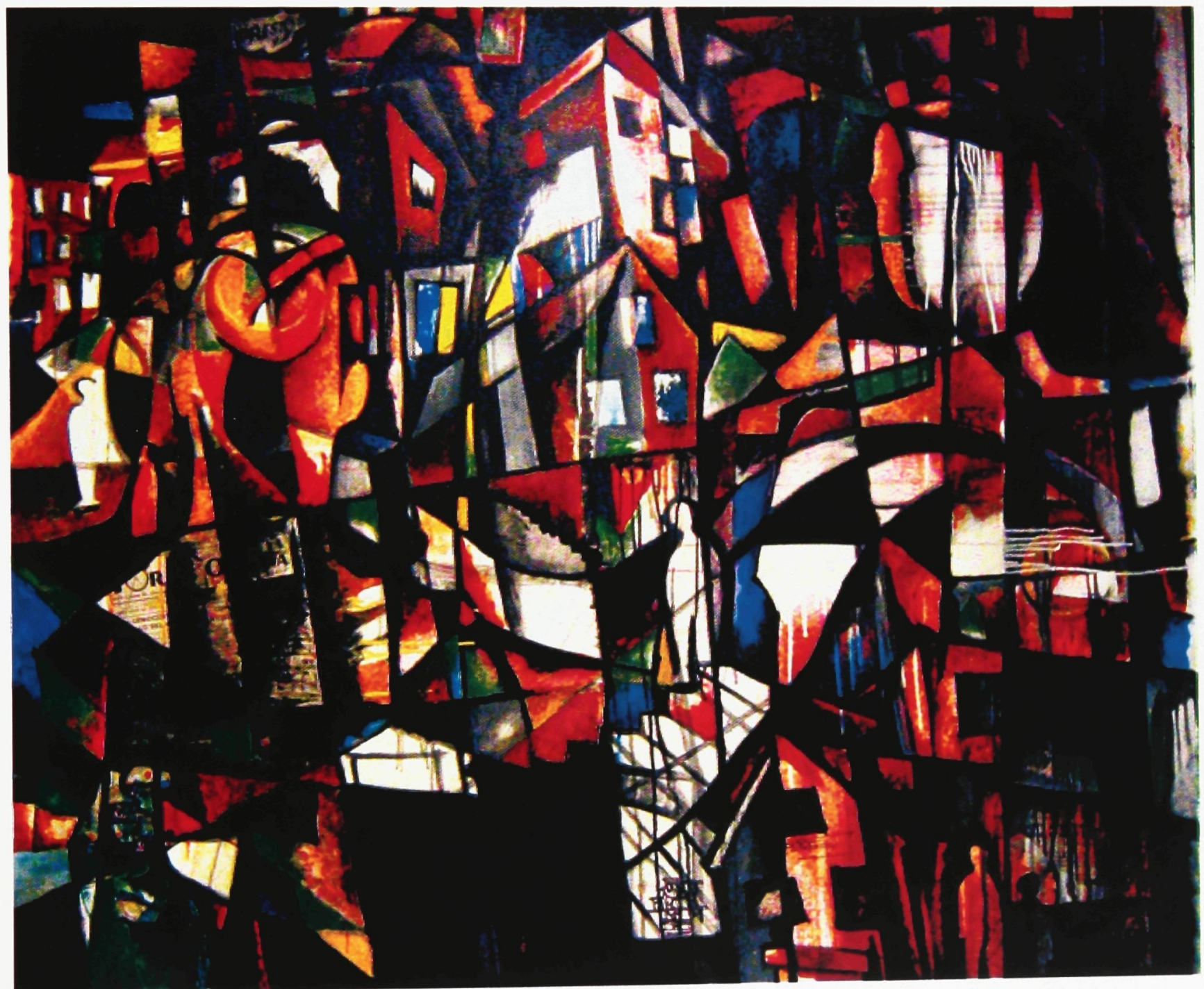

Figure 15. Site Collage One 


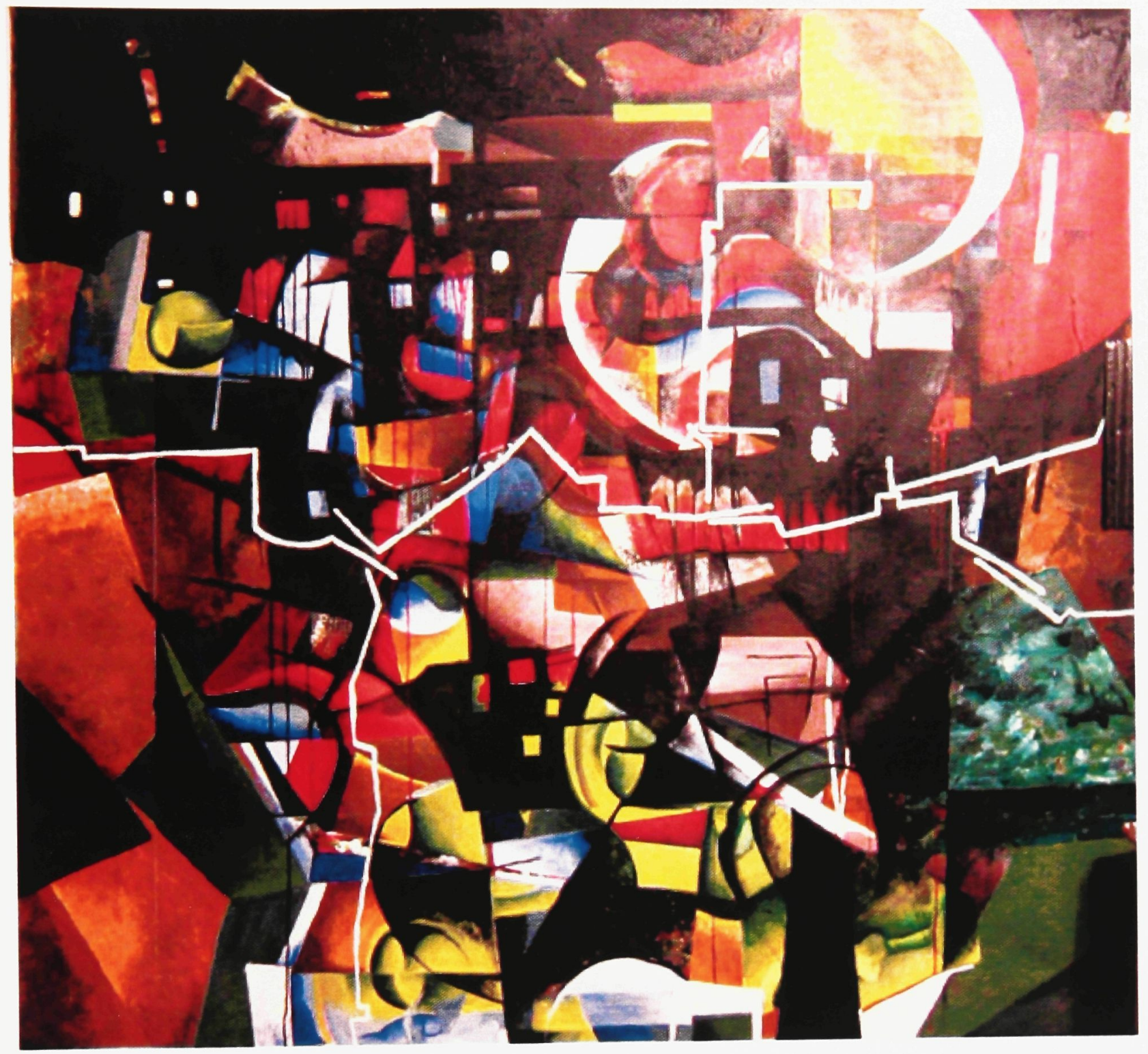

Figure 16. Site Collage Two 


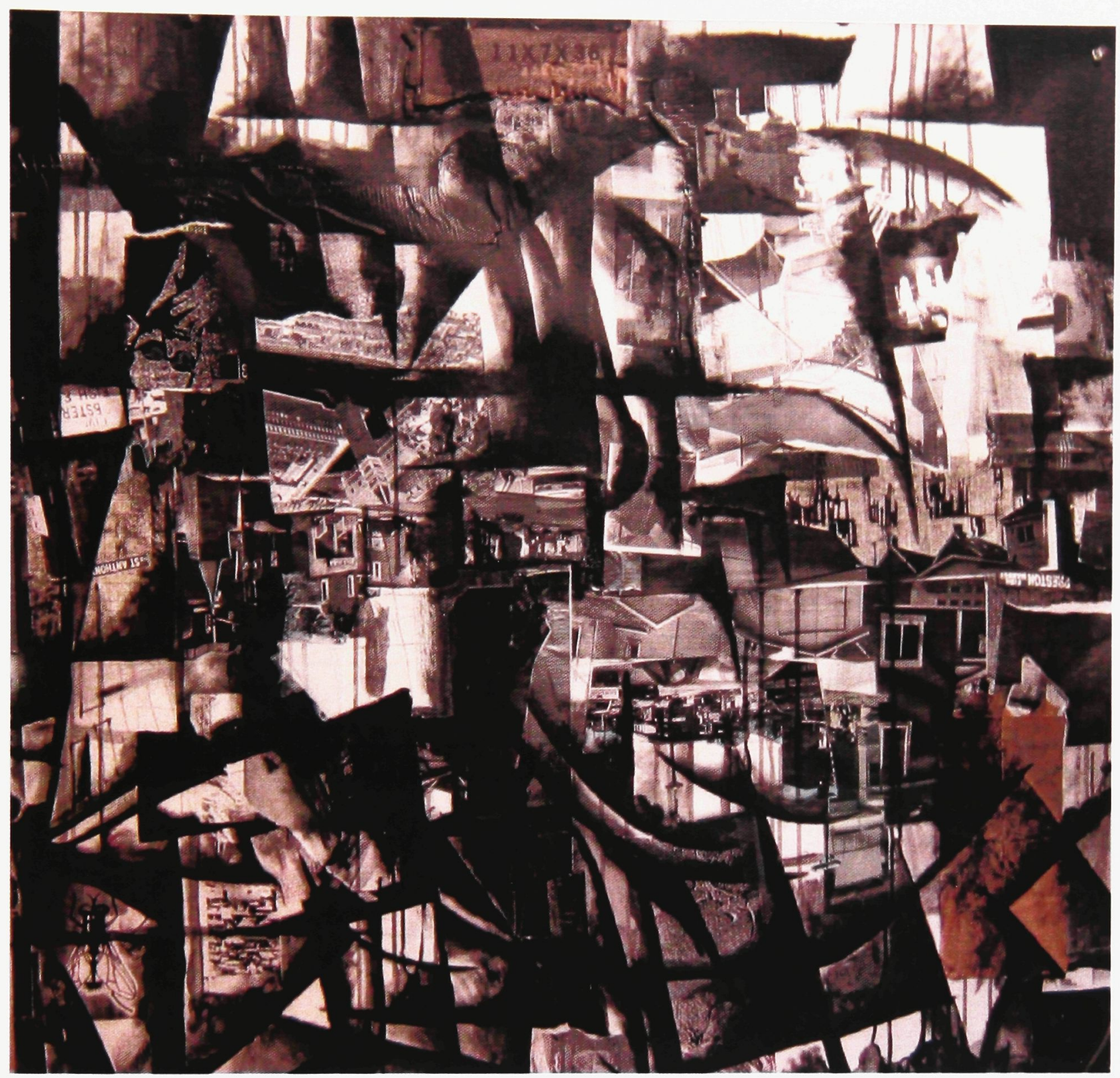

Figure 17. Site Collage Three 


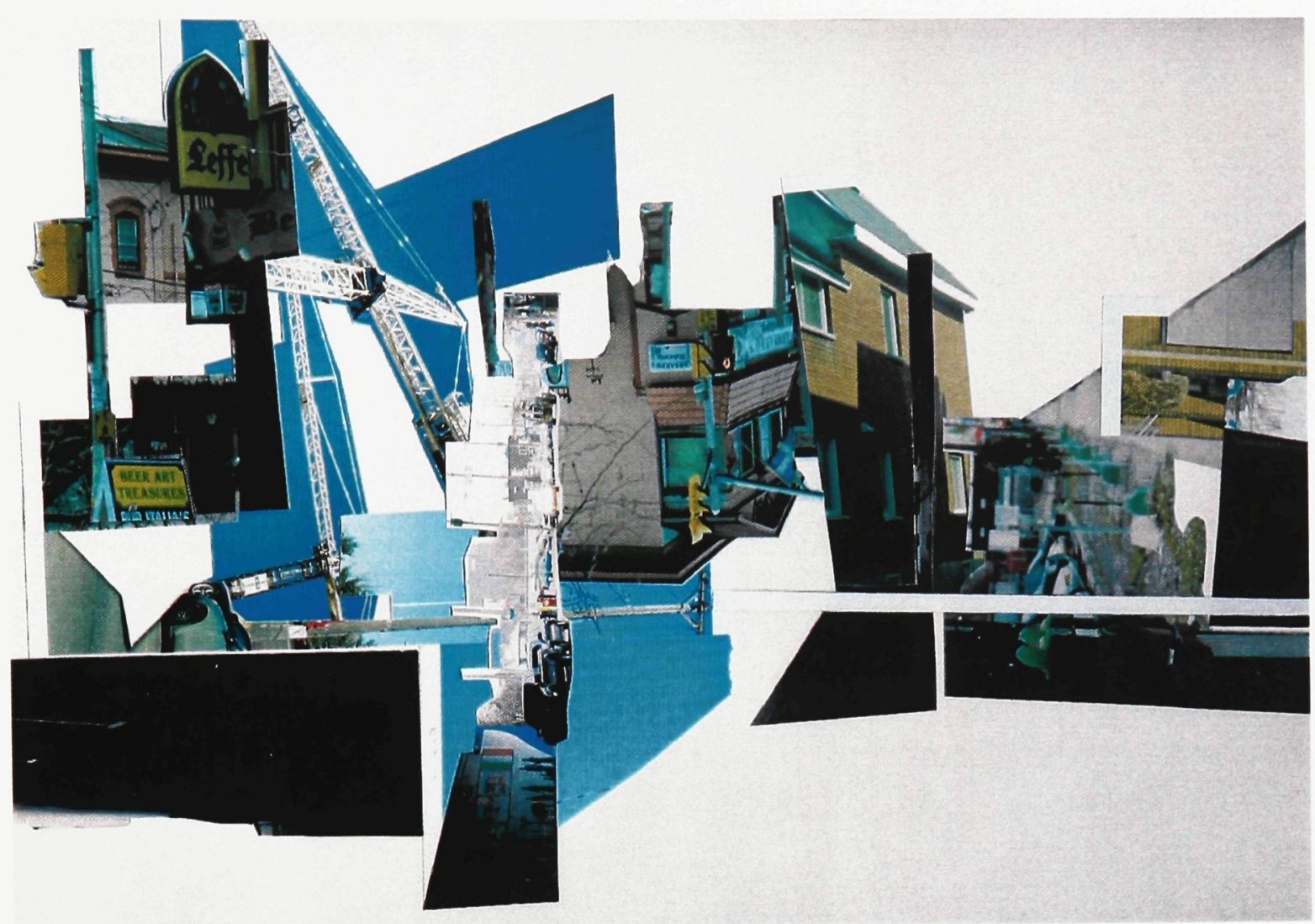

Figure 18. Site Collage Four

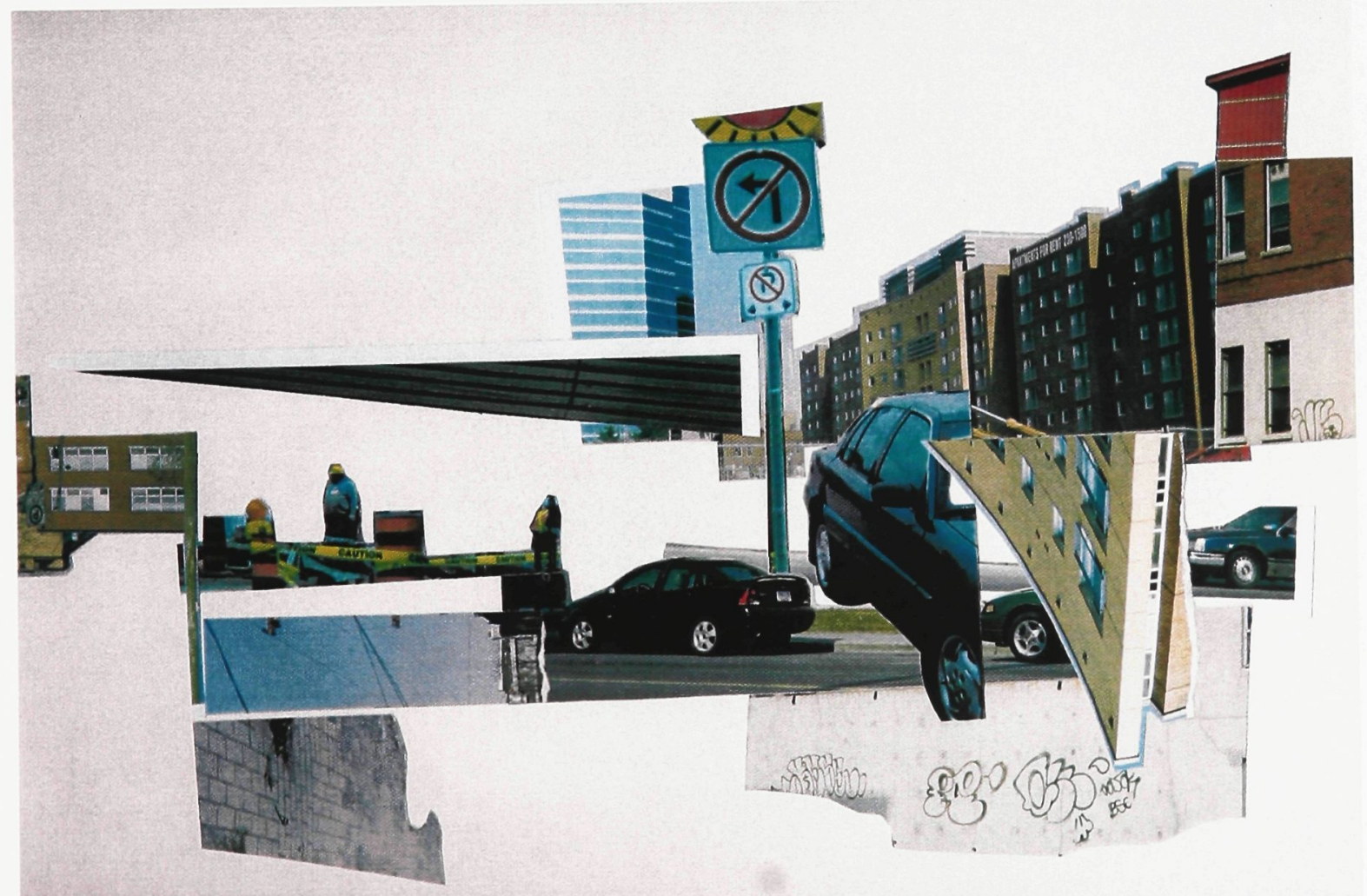

Figure 19. Site Collage Five 


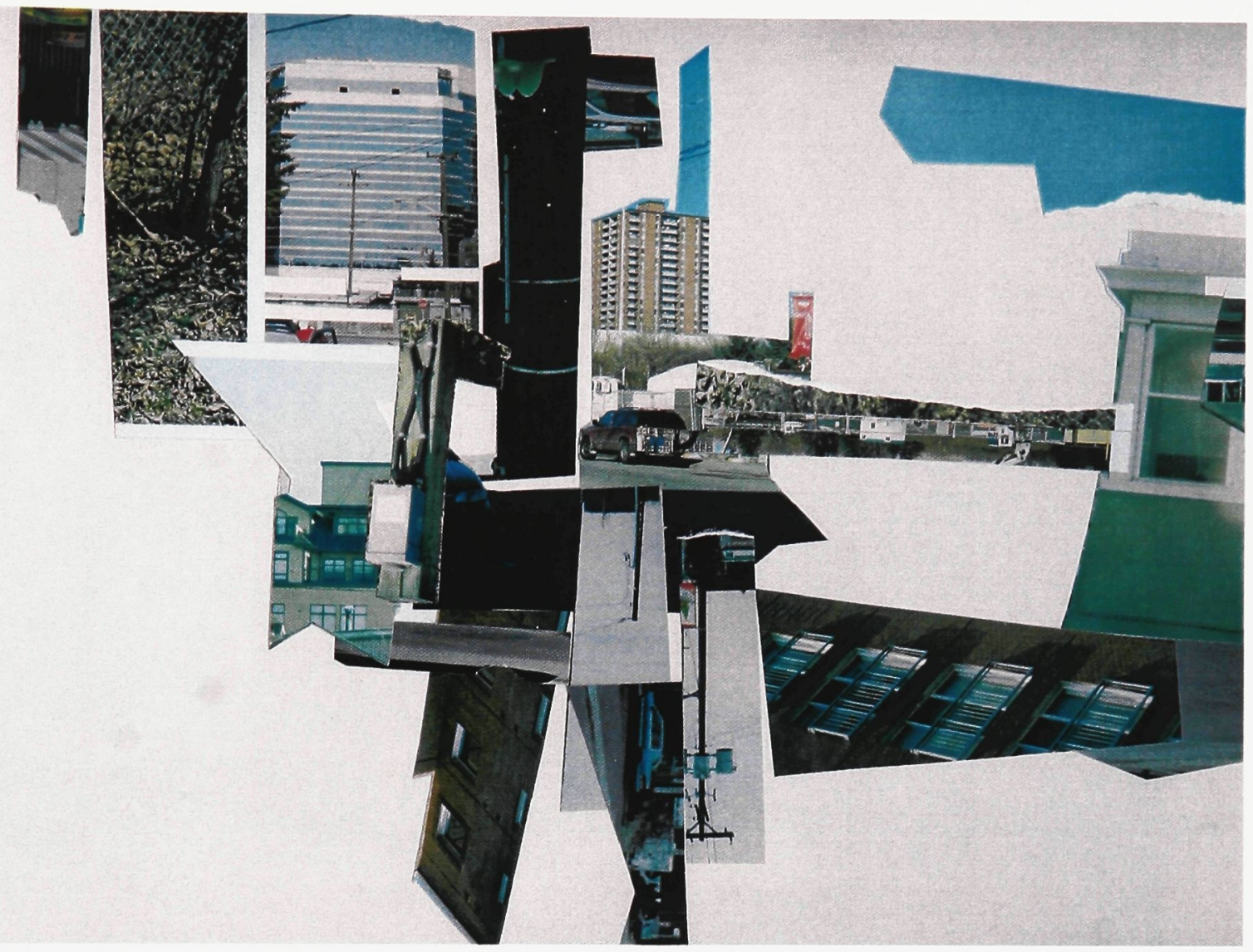

Figure 20. Site Collage Six 


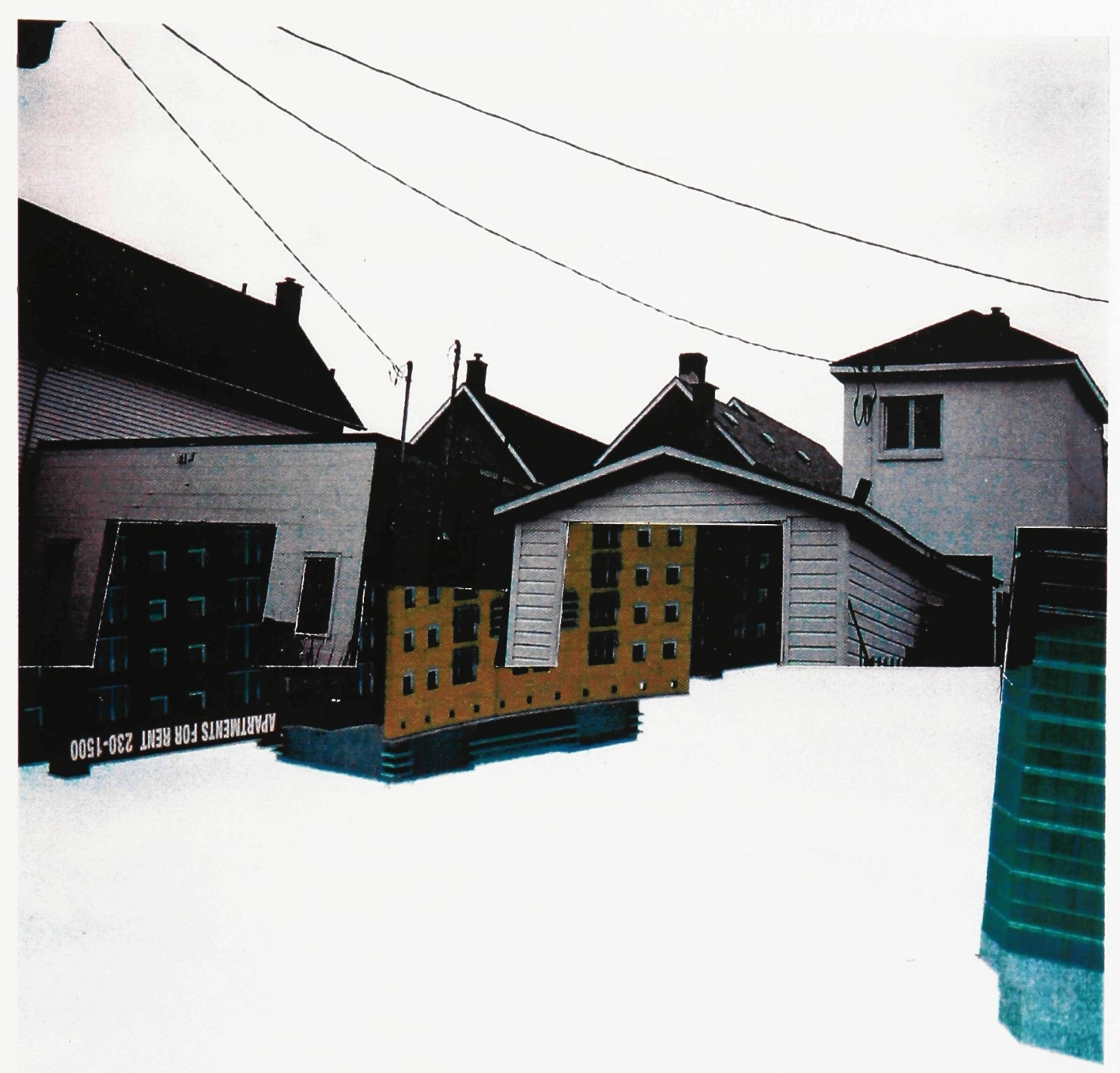

Figure 21. Site Collage Seven

\subsection{Rules of Operation}

The proceeding rules form parameters to guide the design of the thesis; they are derived from the collage experiments used during the exploration period of the thesis. By following the rules of operation, the following chapter demonstrates the design process beginning from gathering and collecting of materials, to the creation of collages and then lastly extruding architectural space from within the collages. 
1. All collages are created in two dimensions. In order to derive form and space, the foundation of a two-dimensional image acts as the catalyst to inform the design. Each collage is set at $35 \mathrm{~cm} \times 100 \mathrm{~cm}$ in size.

2. There is no restriction on materials used to create the collages. As long as the materials chosen to create the collages were able to remain two dimensional, they were used. The collage materials include site photographs and photocopies, acrylic paint, various types of adhesive tape, magazine and newspaper clippings and ink. Also, various objects and remnants found on site were used as materials for the collages.

3. Each collage informs a unique program. In order to avoid redundancy and repetition, 4 unique collages are created informing 4 different aspects of program. The bus terminal, the outdoor public plaza, commercial and retail spaces and office space are the 4 principal elements of program designated for the design project. Each collage is meant as a tool which informs the architecture of each specific program.

\subsection{Extruding Architecture}

Each collage created generates its own specific meaning and is representational of a programmatic and formal element of the design. Some allude to programmatic arrangement and spatial organization while other collages generate form and shape. For each collage created, the rules of operation were followed in order to produce a consistency throughout the work. 


\section{Collage One: The Bus Terminal}

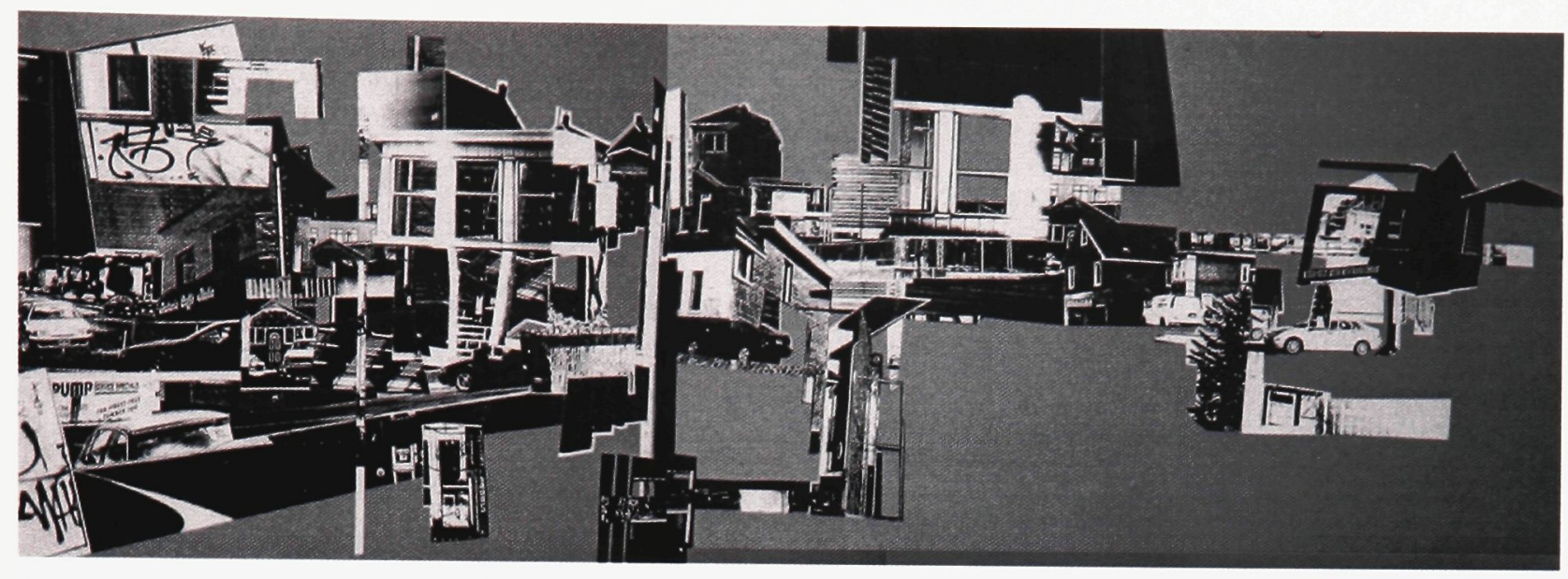

Figure 22. Bus Terminal Collage

This collage was generated from site photographs taken throughout the site analysis phase of the thesis. It evokes the mechanisms of spaces of transit and the dynamics of travel.

\section{Collage Two: Office}

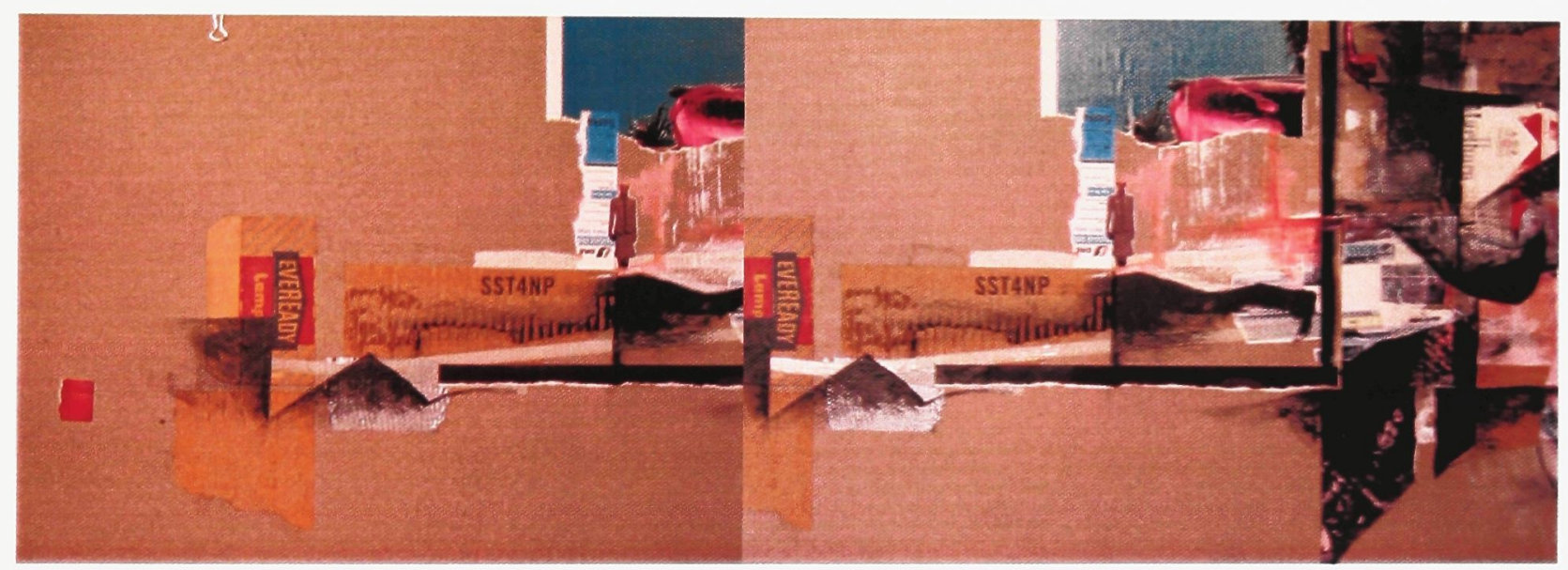

Figure 23. Office Collage

This collage was generated from site photos and materials gathered from the site. The collage evokes the repetition found in the typical office spaces found throughout. The office spaces for this terminal were extracted from the collage shown here. 


\section{Collage Three: Plaza}

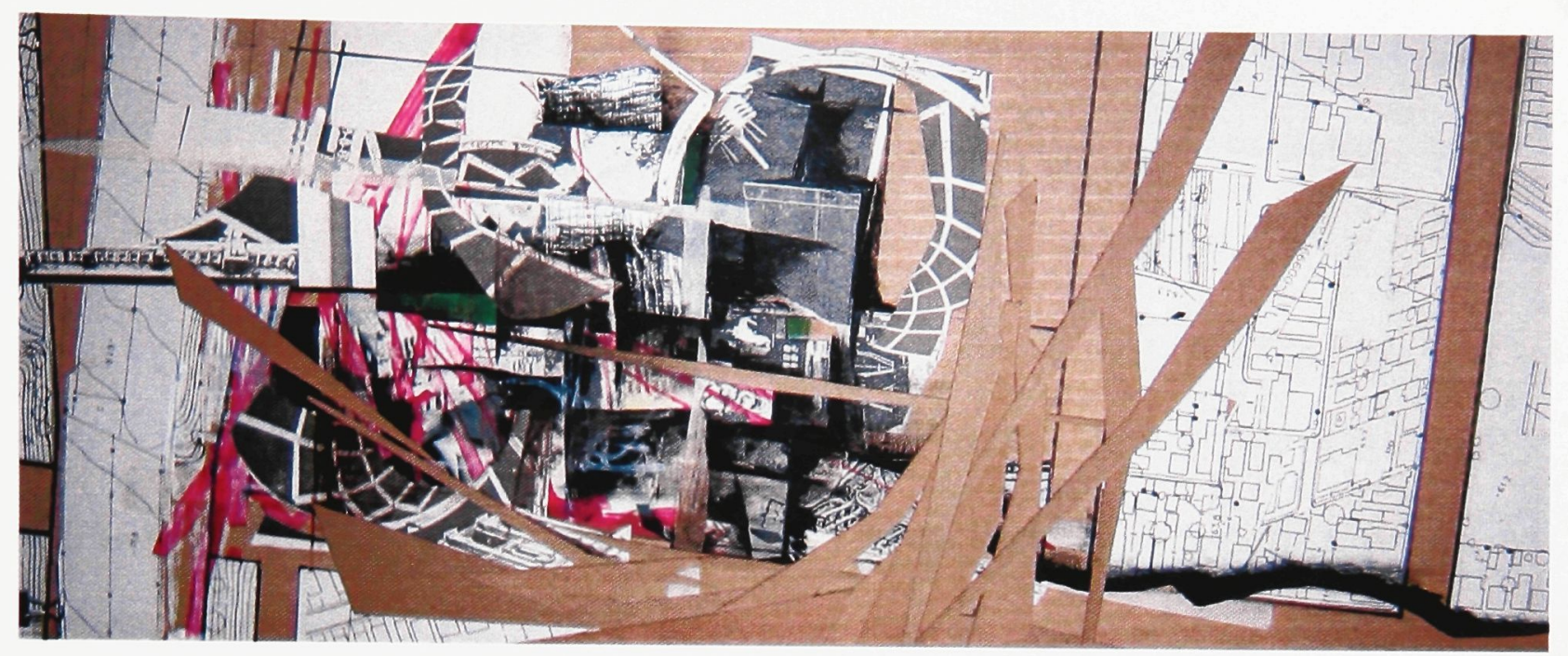

Figure 24. Plaza Collage

This collage began as a site plan of the site. Over time, images, materials and colours were added to create a two-dimensional imprint of the site. Once the collage was complete, a massing model that was carved from cardstock was created. The final design of the plaza echoes the moves made in this collage.

\section{Collage Four: Retail/Commercial Spaces}
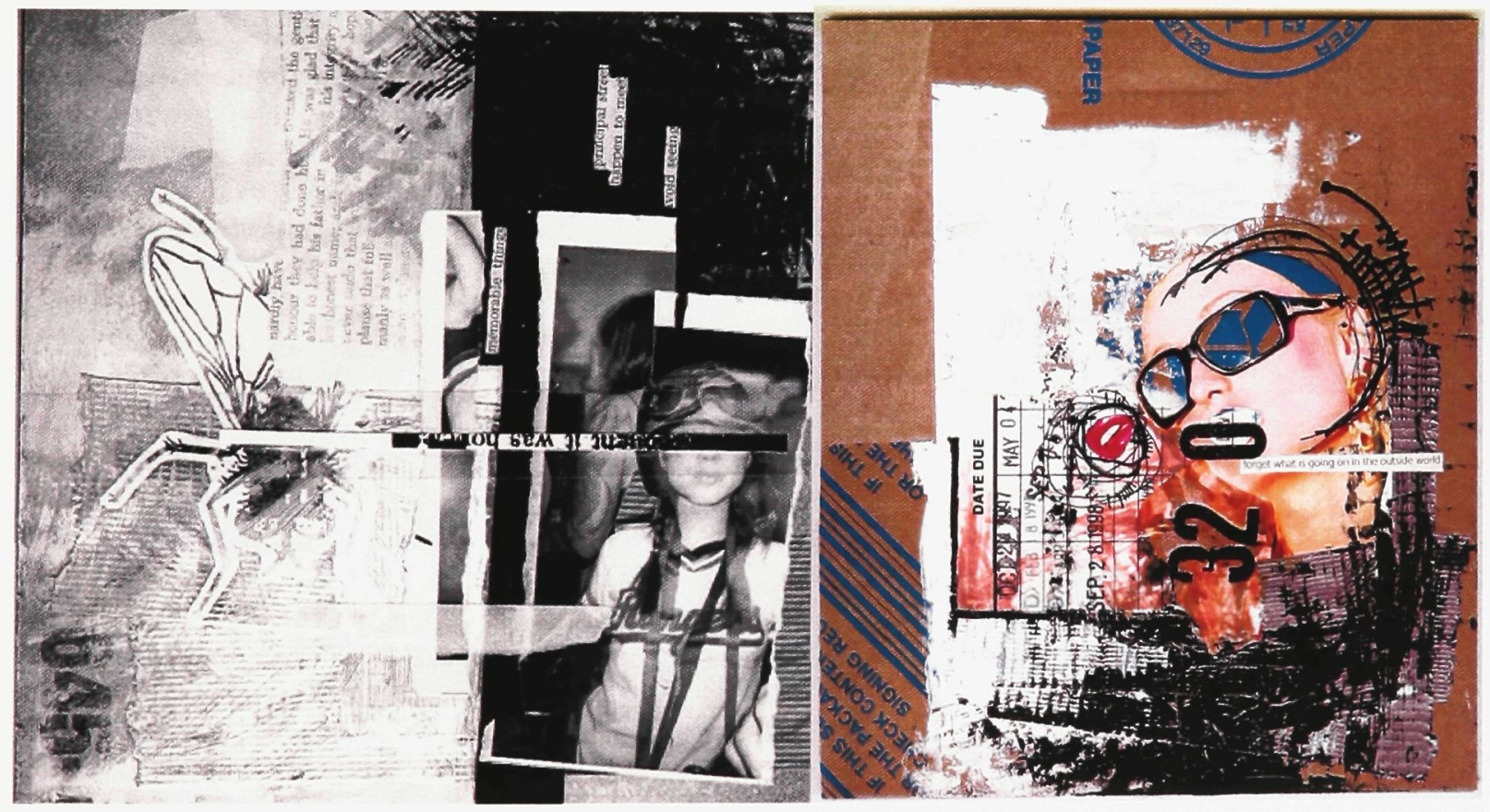

Figure 25. Consumerism

The collages executed to direct the design component of the thesis are meant to inform the architecture and reveal new unexplored possibilities within the design process. The technique was chosen as a means to extract and expel architecture which embodies chance as well as careful planning and consideration. 


\section{Part Three: The Design Proposal}

The design component of this thesis aspires to allow transit architecture to

infiltrate the city and create an intervention within its surroundings. The design aims to

evaluate, examine and re-interpret the spatial and societal implications of the bus terminal within a neighborhood of Ottawa. The program is the design of the new Ottawa

Greyhound bus terminal along with office space, retail space, commercial space as well as an outdoor public plaza. These four principle components complete the program for the development of the site.

\section{Chapter Five: Program and Site}

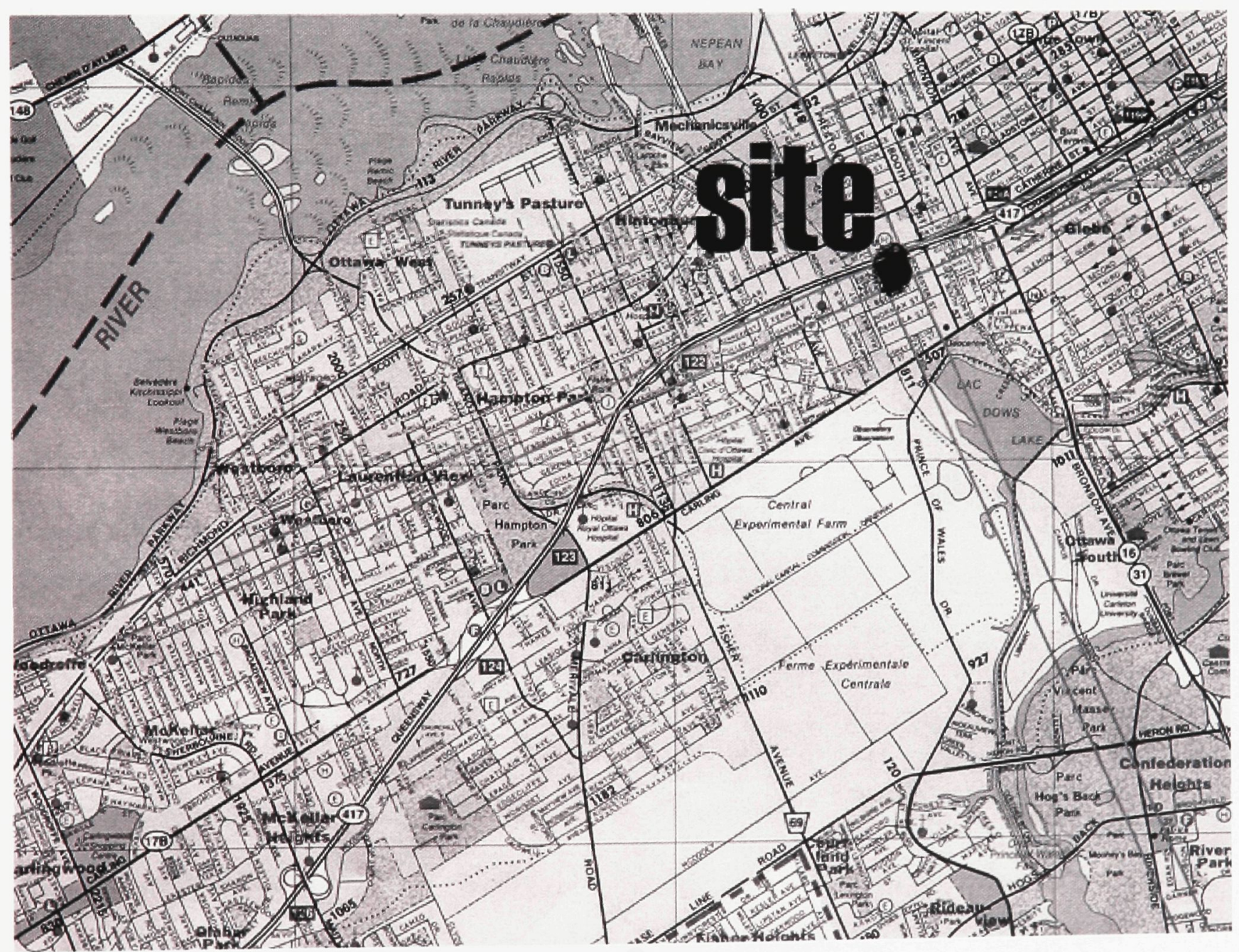

Figure 26. Location Plan

(http://www.ottawa.ca/city_services/maps/atlas/index_en.html) 


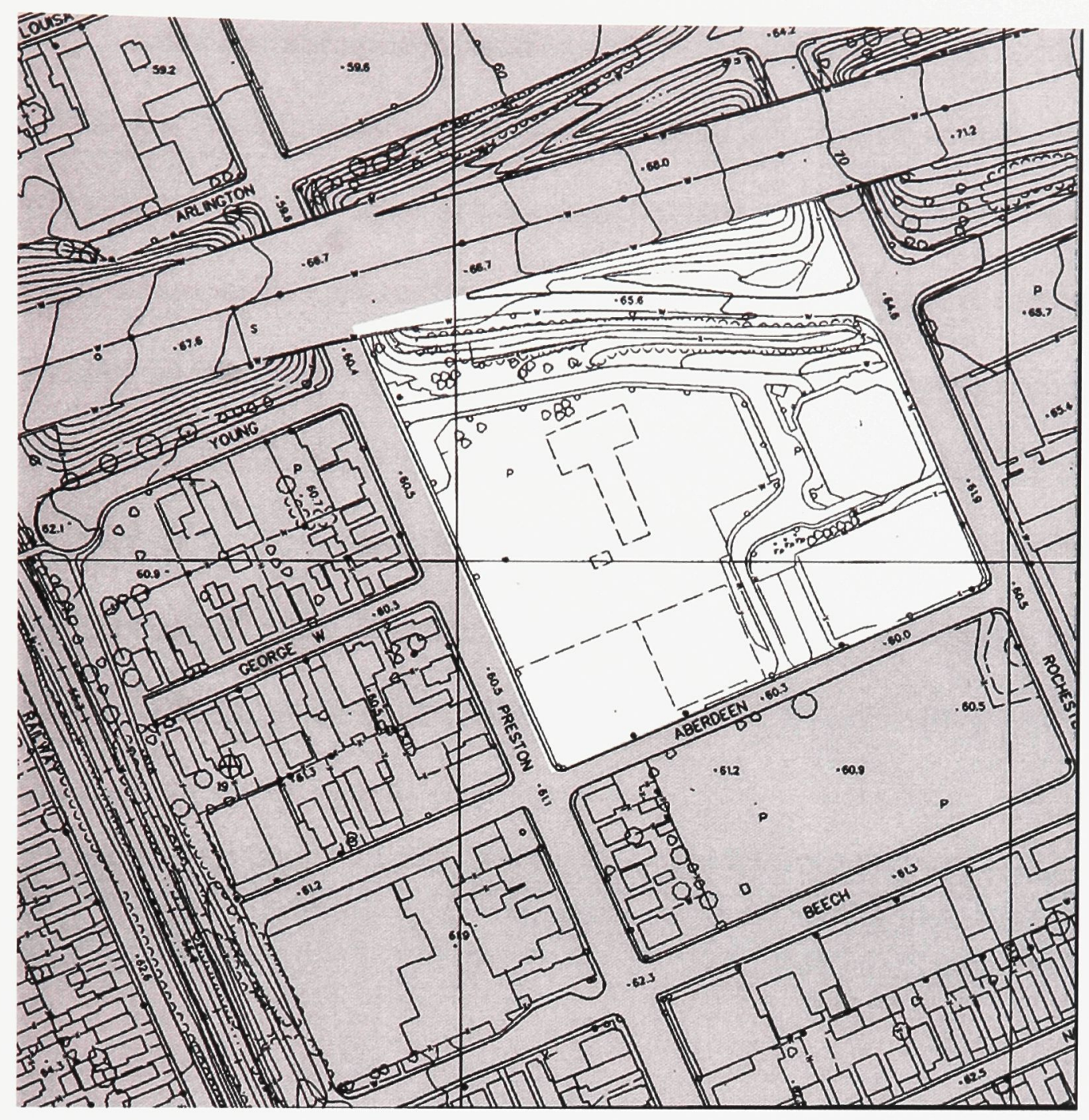

Figure 27. Site Plan

Carleton University Map Collection

The site chosen to house the new terminal is located in Ottawa, Ontario in the historic centre of Little Italy on Preston Street. It is bordered by Aberdeen Street, Rochester Street and Highway 417 (Queensway). At the commencement of the thesis two buildings sat upon the site and the remainder of the site was predominantly an asphalt parking facility. The Adelaide is an 8 storey luxury condominium tower which sits on the south eastern corner of the site. A 15 storey office tower also sits on the north eastern portion of the site. Also, the Rochester Street off-ramp from the Queensway diagonally cuts into the site. 
The surrounding area contains several diverse building types and programs and it can be described as a collage of programs imposed upon a small area. Firstly, small vernacular houses built post-war to accommodate the vast number of immigrants moving to the neighborhood are scattered throughout the area. Many have been converted and restored into stores or restaurants but many also still function as homes and a sense of community is still prevalent. To the east of the site there sits a few industrial government buildings still in use. These large scale buildings still function today as they have for many previous years. Tall office towers and high-end condominiums are also found in the surrounding area with the tallest office tower and largest apartment block placed on the same site as the new terminal.

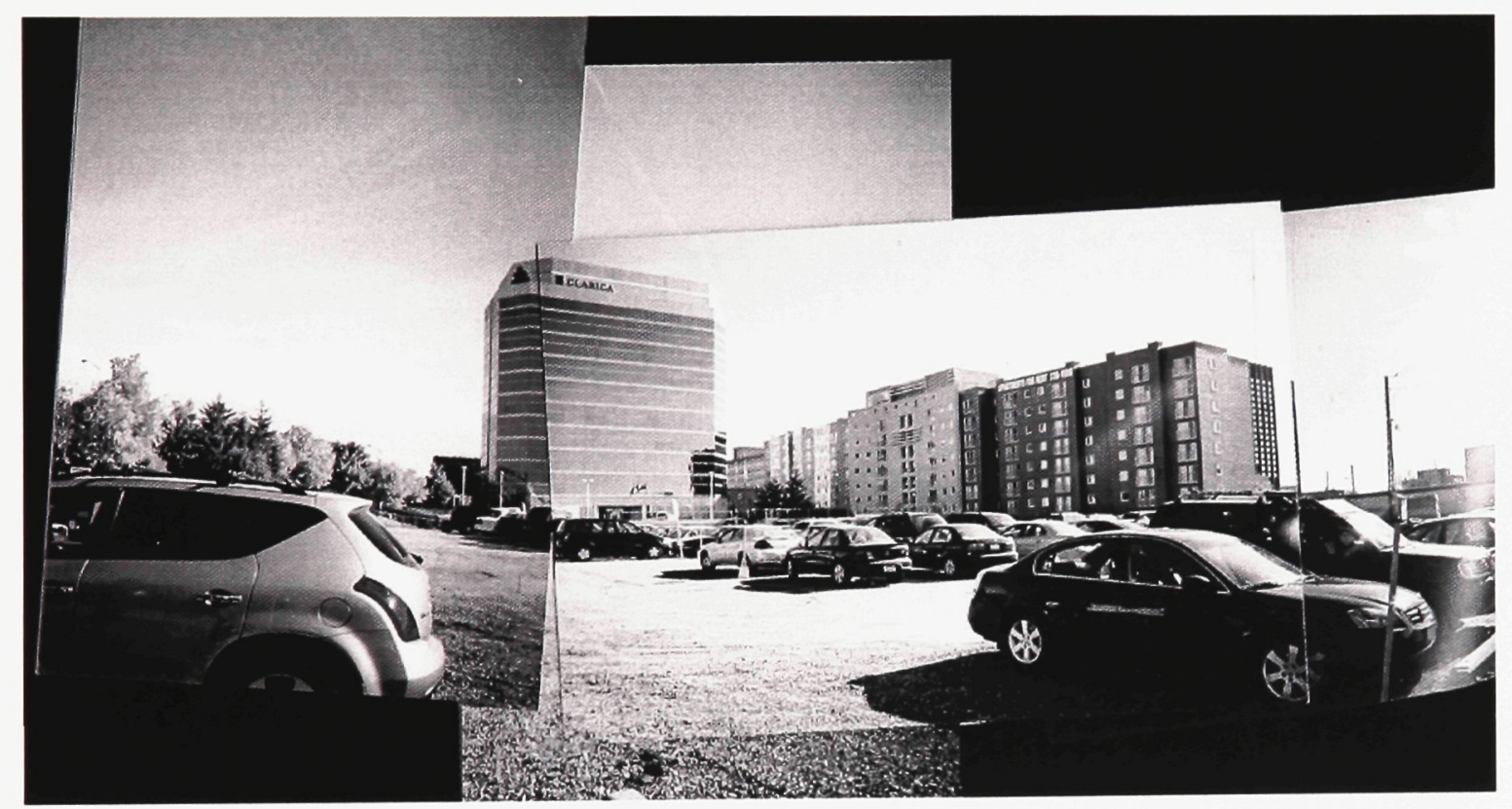

Figure 28. Site Montage

This montage depicts the site where the bus terminal will be located. The glass office tower and the lowrise residential apartment sits along the perimeter of the site whereas the parking lot sits in the interior. 


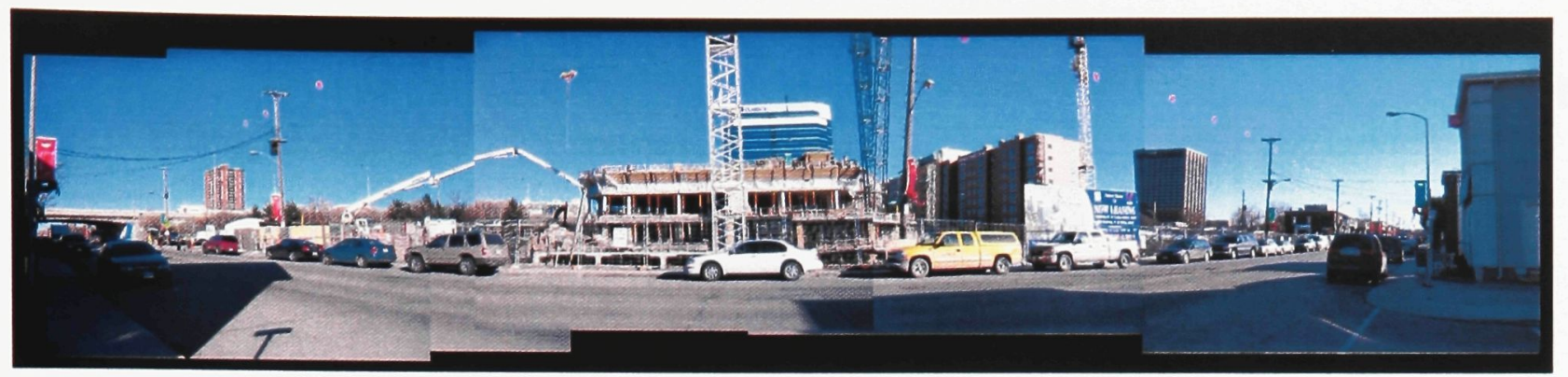

\section{Figure 29. Site Montage}

This montage depicts the current state of the site and the site's surrounding buildings. The new office tower and condominiums are transplanted within smaller pedestrian scale buildings found along Preston Street.

This particular site was chosen to house the new bus terminal because of the vicinity to the Queensway was a deciding factor in its selection. It was of the utmost importance for the building to be located as near to the highway as possible in order to obtain the important physical connection to it. The inspiration for creating a building in such close proximity to a highway developed after experiencing the highway stops found along the Italian Autostradas.

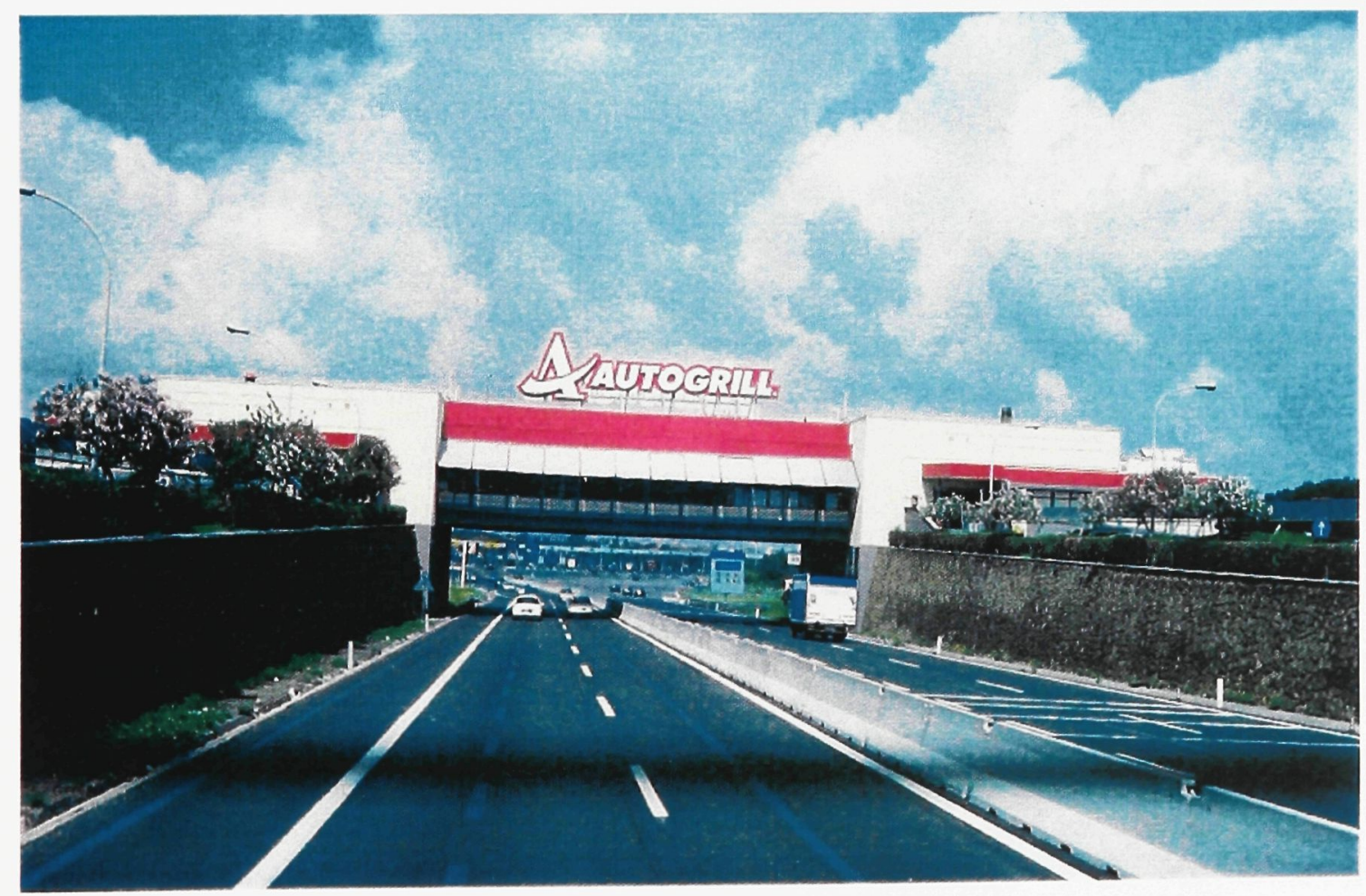

Figure 30. Autogrill

This photo depicts an Autogrill above the Autostrada in Italy. These vernacular highway buildings are found throughout the country and link the highway to the inhabitant by placing the building directly above the highway below. 
These "Autogrill's" are essentially pit stops for highway commuters in need of food or bathroom facilities and are found approximately every $100 \mathrm{~km}$ along the Autostradas. These buildings straddle the highway in order for both directions of commuters to gain access to the building. The result of this intervention causes the occupant to be constantly aware of its location above the fierce motorway. While the inhabitant eats, shops or relaxes they are in constant connection to the highway a few feet below. The rumblings and vibrations of the highway echo throughout the building and the sounds of speed are constantly heard. The building also offers dramatic views of the highway as automobiles race beneath the occupant's feet. All in all, this is a key component and reason as to the terminals vicinity to the highway.

The site was also chosen due to its historical context. Located within the center of Little Italy, the site sits adjacent to the bustling Preston Street (Corso Italia). The hub of the Italian immigrant community, the street now contains a multitude of restaurants, bars, commercial and retail stores as well as other places for consumerism. Its historical implications still remain as the street hosts festivals and gatherings and the main church of the Italian community is located in the area. Although the area has undergone a significant transformation, changing what the street means to its occupants now as it did in years passed, the historic importance of the street remains through the vestiges of its immigrant history. Collaging a building of this nature into a historic area of the city effects its connections to the site and place. By inserting a "non-place" into a place of history, identity and culture, these buildings become places. When building become destinations rather than just hubs or transfer points, then have the ability to become 
places. By collaging places with non-places, non-places have the ability to become places if the physical human and architectural connections to its surrounding environment are upheld.

The site is located adjacent to a street where consumerism plays a substantial role in shaping the fabric of the street. The terminal will attract travelers and commuters to the site and its surroundings resulting in businesses to prosper and activity to continue to develop upon the street in result of the elevated population.

\subsection{Program: Ottawa Greyhound Bus Terminal}

The anticipatory sense of travel is the underlying intention of the design, to create a terminal that not only generate an enduring effect but that is architecturally dramatic and stimulating to the inhabitants. The aim of the bus terminal itself is to upgrade the experience of the bus journey. An architecture which speaks of the anticipation sense of travel and departure was of importance in order to successfully create the new terminal. The bus terminal is divided into two major zones. The first is a zone for movement, motion and speed whereas the second is a zone of motionlessness, relaxation and tranquility. These two primary zones find connections with the conditions surrounding the site. On the north side of the terminal, the speed and ferocity of the highway infiltrates the interior space of high intensity where the inhabitants can experience the highway from within the building. Sound, motion, light and vibration of the exterior are joined to the building. The building acts as a vein detached from the highway artery. The off ramp nearly plunges right into the interior of the building creating the connections between interior and exterior similarly to the nearby highway. The outdoor 
public plaza located to the south demonstrates the opposite condition of the site. The outdoor public plaza sits in tranquility in opposition to the highway on the other side. The building acts as the buffer zone, a wall which divides but also joins together two different aspects of the site. The disparate conditions are conjoined by the building and it acts as mediator to the two conditions.

The building effectively acts in the same manner as the traditional transportation edifice and is a destination rather than a "pit-stop." This enables the terminal to act more like a place than a non-place. It is within the traditional archetype of the terminal where non-places can become places.

\subsection{Spatial Requirements}

This section defines each program and spatial requisites inserted with the building.

The Bus Terminal: 4000 square feet, accommodating a capacity of 200- 250 travelers and commuters. The space includes the bus terminal platform, a designated for line-ups. The uninhibited views of the plaza and the highway allow the commuter to link themselves to the exterior.

Waiting Area: 1500 square feet, accommodating a capacity of 150 . This area is allocated to those who wait. The space contains a waiting area located adjacent to the platform. The space is more intimate than the terminal platform and the heavy concrete wall which faces the highway is pierced with openings allowing controlled views of the building's exterior. 
Storage facilities: 800 square feet, capacity to store luggage, parcels and other necessities which require storage. The facilities may be accessed by all commuters.

Washrooms: 300 square feet, located throughout the building.

Ticket sales office: 400 square feet. The ticket sales counter greets the visitor as they enter off of the plaza or Rochester Street. It is a large open space where the office workers and the commuters are in constant visual contact since no barriers inhibit the space.

Other bus terminal offices: 1000 square feet. These offices are located above the terminal. They are allocated to the office workers of the terminal. The large glass curtain walls on both sides of the offices permit the connection to both the plaza and the opposing highway.

Circulation: 500 square feet. This includes stairways, ramps, elevators and passages allocated to the movement of automobiles and buses as well as the occupants within the bus terminal.

Repair Garage: large enough to house 2-3 buses. The garage is located below the platform and faces Rochester Street. Its façade allows interior views of the garage and is meant to reveal to the public and celebrate the beauty of the machine. The garage is no longer a dark, hidden away facet of transportation.

Commercial and Retail: 1000-1200 square feet interior space. These spaces are found adjacent to Preston Street in connection to the plaza. Large pivoting glass walls rotate in order to blur the boundary between interior and exterior. 
Outdoor Plaza: 10000-12000 square feet of exterior space. This large open plaza is allocated to the neighborhood and may perform a variety of function. A place to sit and relax, or host outdoor festivals are all possible programs the plaza can perform.

Parking: Parking for 40 cars is located beneath the terminal platform. It is allocated to the workers of the office as well as to short term pickups or drop-offs.

\subsection{Current Greyhound Bus Terminal Site: Analysis and Critique}

Currently, the Ottawa Bus Terminal is located on Kent Street and is an exemplary model of Functionalist architecture. The building has been created with the purpose of its function alone and few considerations were made to innovative design and aesthetics of space. Programmatically, the building functions fairly efficiently. Formally, the building is a long narrow slab allocated with 20 bus docks dispersed along the north side. The corridor remains open for circulation and the formation of line-ups. Ticket vendors, restaurants, gift shops, restrooms and storage facilities are located on opposite sides as the bus loading docks. The repair garage and shipping / receiving workings are located on the west side of the building. On the second storey of the bus terminal, office spaces for the terminals workers make up the entire floor. The terminal is surrounded by parking for approximately 30 cars on the north side and 15 are delegated to short term stays on the south side.

Because the building is surrounded on all four of its sides by busy streets, the appropriate connection on the scale of the pedestrian is substantially lacking. If on foot, the pedestrian is left to cross several busy intersections then proceed to cross a busy parking lot before entering the building. This lack of a strong connection on a human 
scale is a major design failure of the existing terminal. In order to ameliorate the experience, connections must be made on both the intimate human scale as well as the scale of the automobile.

The building lacks character, excitement, innovation, and the sense of good design and originality. The mood of the building is discouraging to the occupants and is insensitive to the inhabitants. The tempo of the building varies from overwhelmingly hectic to quiet and empty. However, as observed upon countless visits to the present site of the terminal, the occupants seldom spend more than a few minutes within the building and utilize it more for a processing machine for travel rather than experiencing it as a gateway into a new city. Although it functions in a decent manner, the impression it exudes is negative. The terminal is out of date and is unsuccessful in providing a positive memorable experience of the city. With such an important facet of the bus travel experience lacking creativity and effectiveness a new terminal is required to elevate the visitor's initial experience of the city.

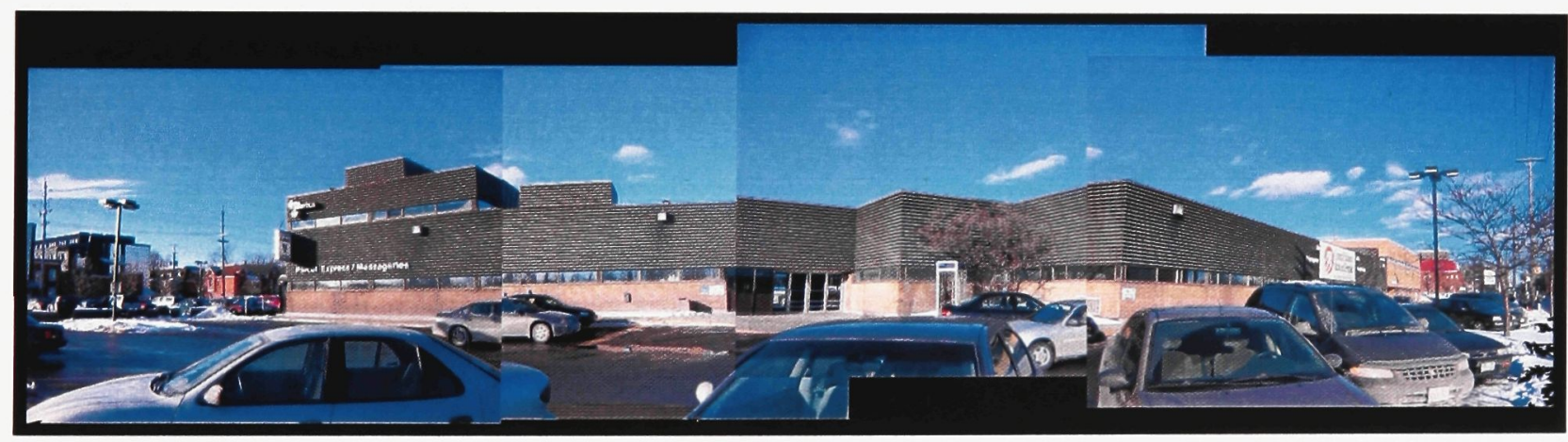

Figure 31. Existing Terminal Montage

This montage depicts the current Bus Terminal in Ottawa located on Kent Street. 


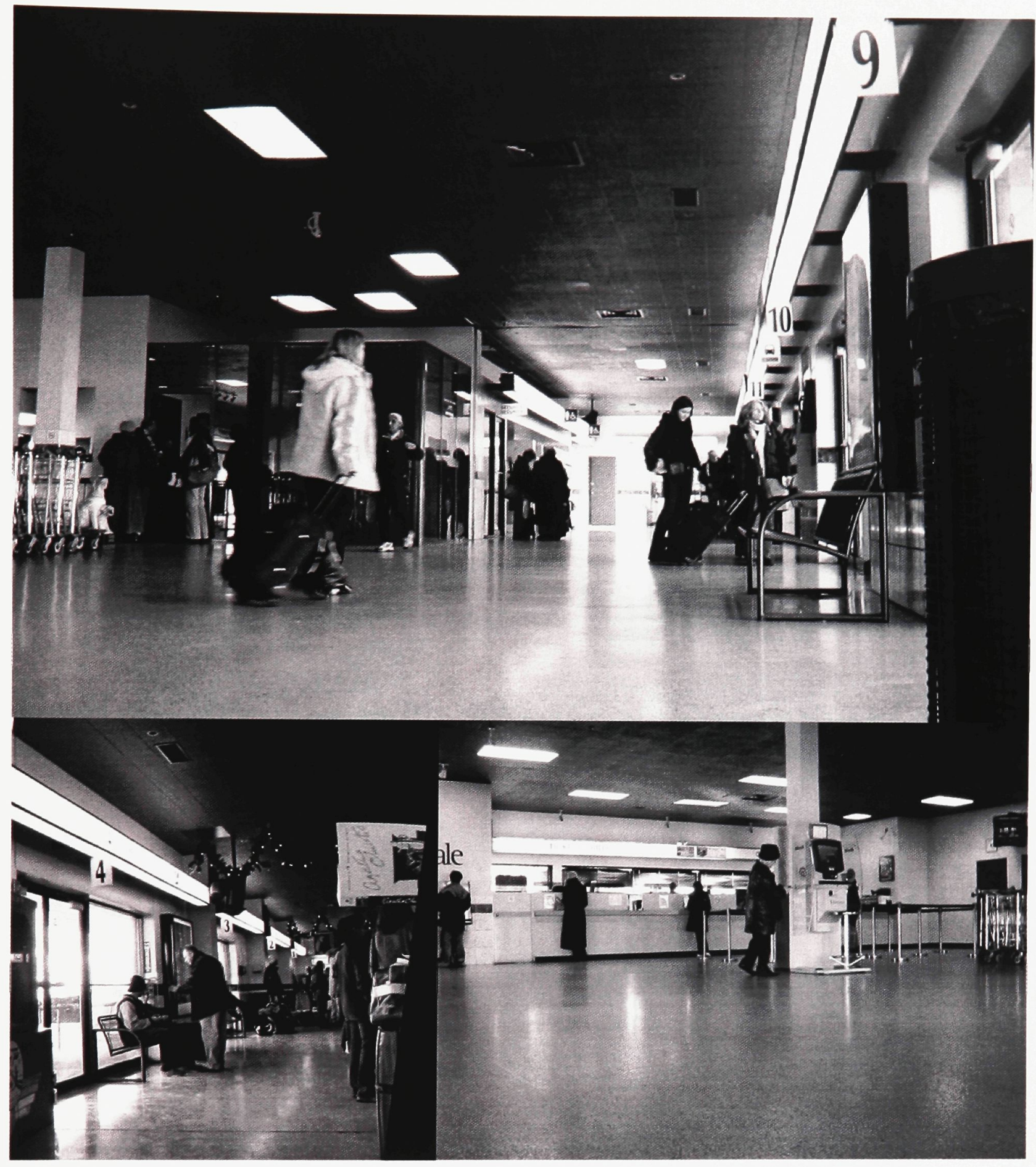

Figure 32. Interior shots of existing Voyageur terminal in Ottawa 


\section{Chapter Six: Building Design}

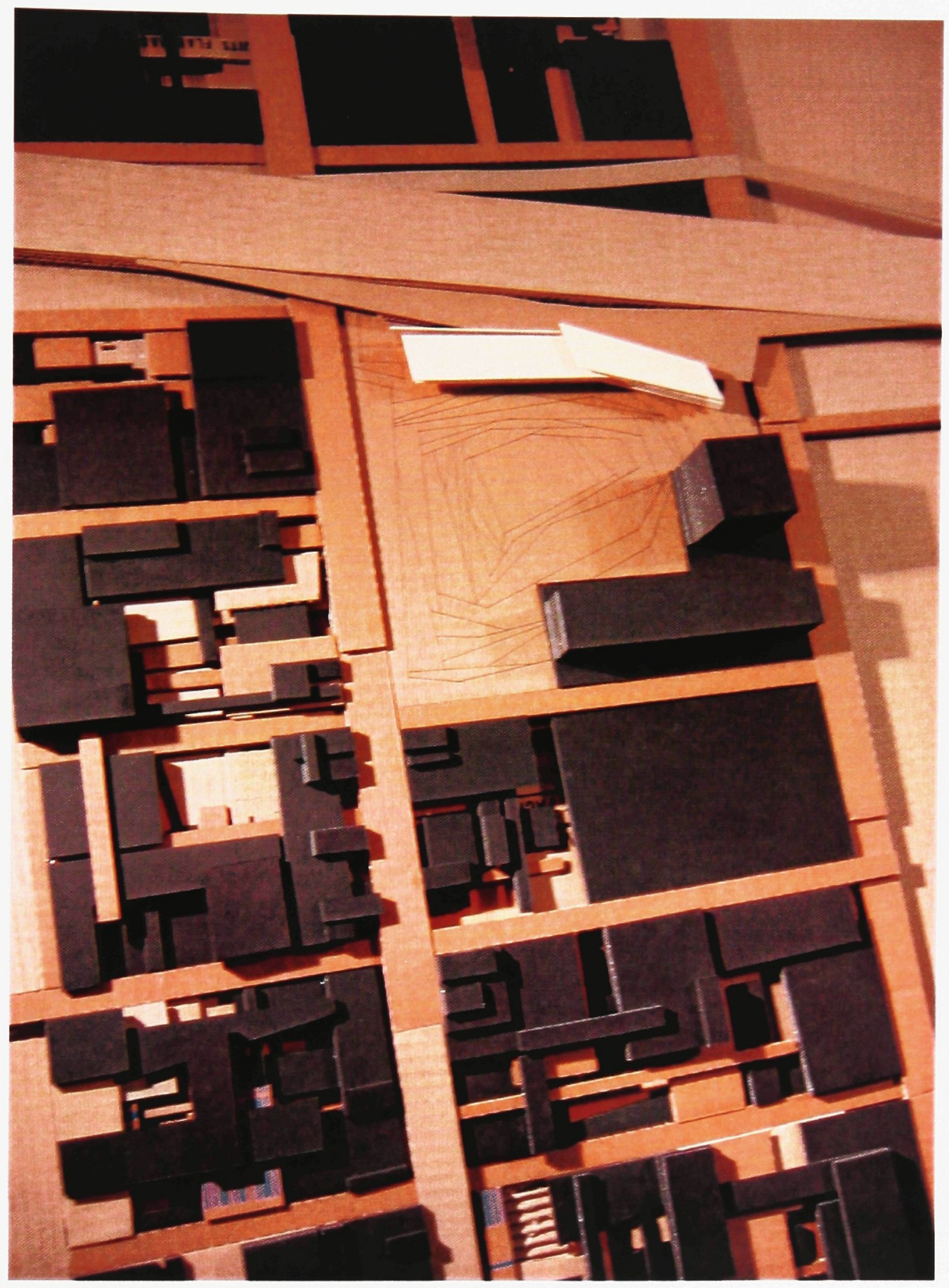

\section{Figure 33. Site model showing surrounding conditions}

The site model shown above depicts the buildings location upon the site. The terminal sits adjacent to the highway in order to interact with it visually, aurally and physically. The building acts as a barrier and buffer zone between the two disparate conditions of the site, the highway and the outdoor public plaza. It also is a barrier and a focal point to the smaller existing dwellings which surround the site. The model also demonstrates how the terminal sits within the existing urban fabric and its relationship to the scale of the neighborhood. The small scale dense neighborhood blocks are contrasted with the three larger scale buildings upon the site. 


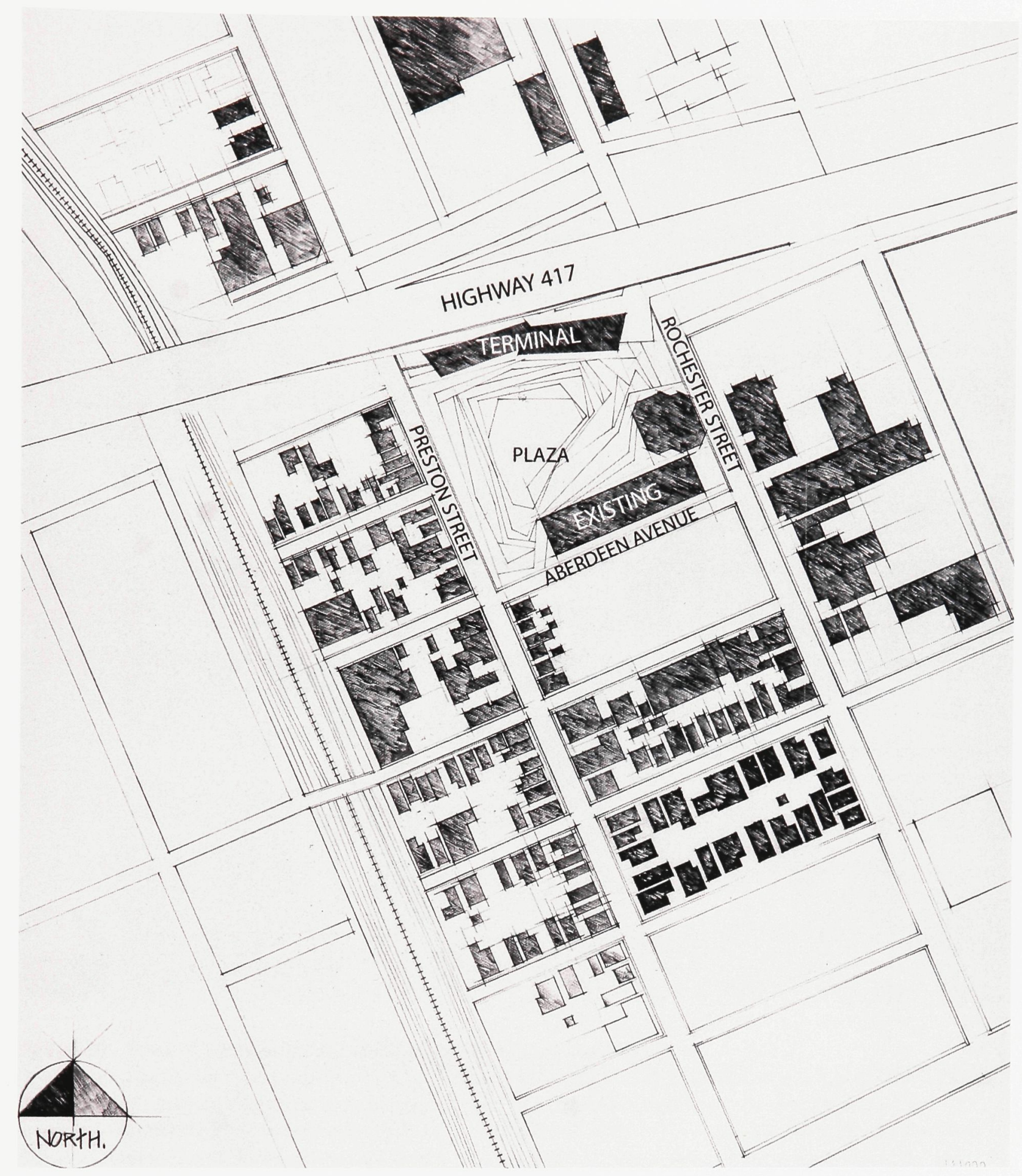

Figure 34. Site plan showing surrounding conditions

The site plan shown above demonstrates the situation of the site and its surrounding scales. It is evident here that there exists a variety of scales, programs and functions within the small area. To the east, large offices and factories take up large city blocks whereas to the south and west smaller domestic scale buildings are scattered upon smaller city blocks. The north of the site is dominated by the highway which bisects the city streets and creates a barricade between the two sides of the neighborhood. 


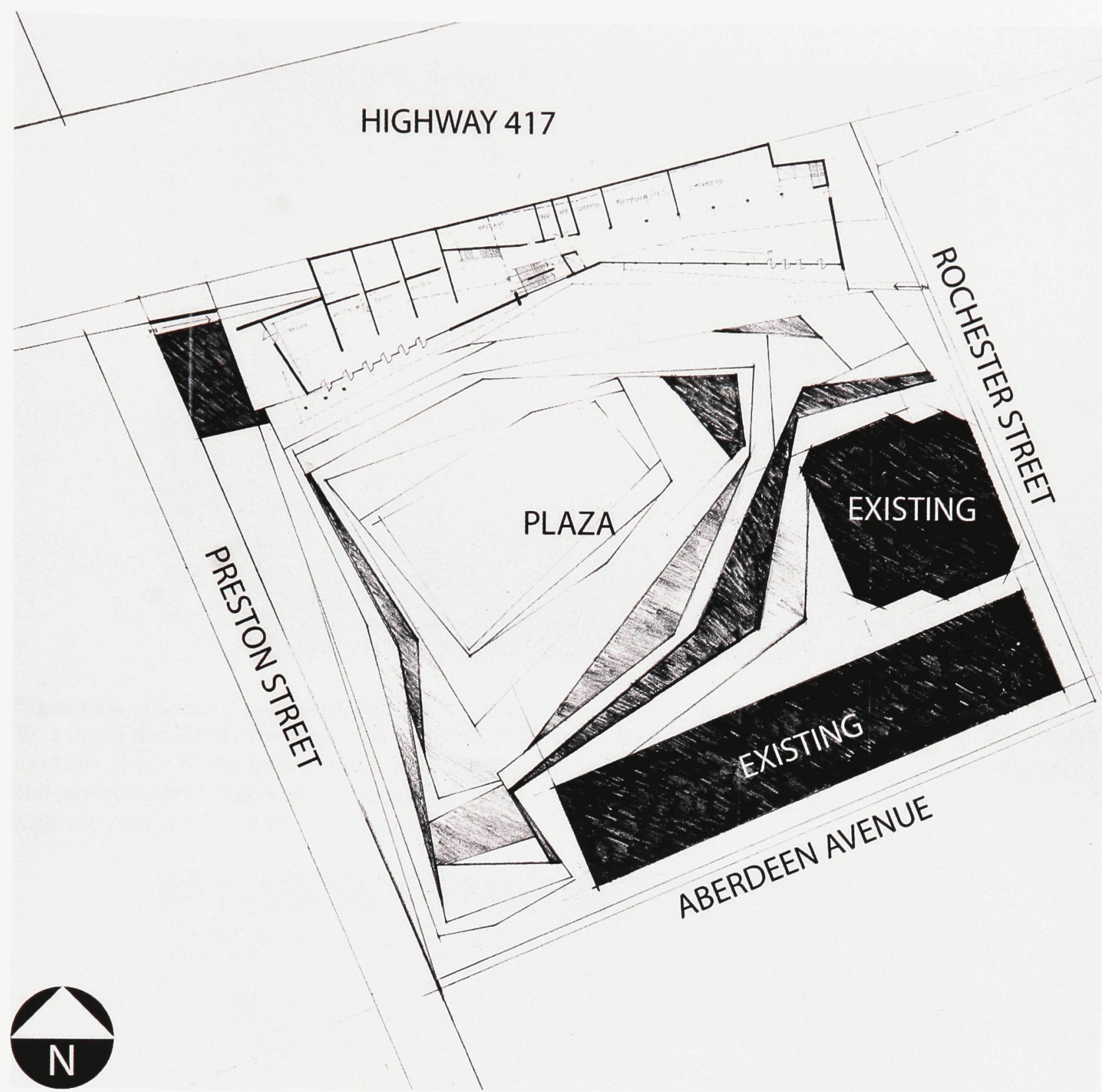

Figure 35. Plan of exterior plaza and surrounding existing conditions

This figure depicts the characteristics of the outdoor plaza and how the exterior space meets the building. The large dark masses shown on the site indicate the existing buildings which border the site. The numerous fragmented levels and steps of the plaza are constructed with a variety of materials including concrete, treated wood, brick, grass and water. The purpose of which is to create a more dynamic and diverse outdoor space. The tiers may be used as places to sit, lie down or gather. During certain celebrations such as the Italian festival, the plaza may also be used to house outdoor concerts since it is carved from the earth much like an amphitheatre. The figure also demonstrates the plan of the first level of the terminal. Retail spaces with large pivoting doorways which open up onto the plaza blur the boundary between interior and exterior space. These openings also link the spaces to Preston Street while being sheltered from the highway. Storage spaces, washrooms and ticket sales offices are also found upon this level. 


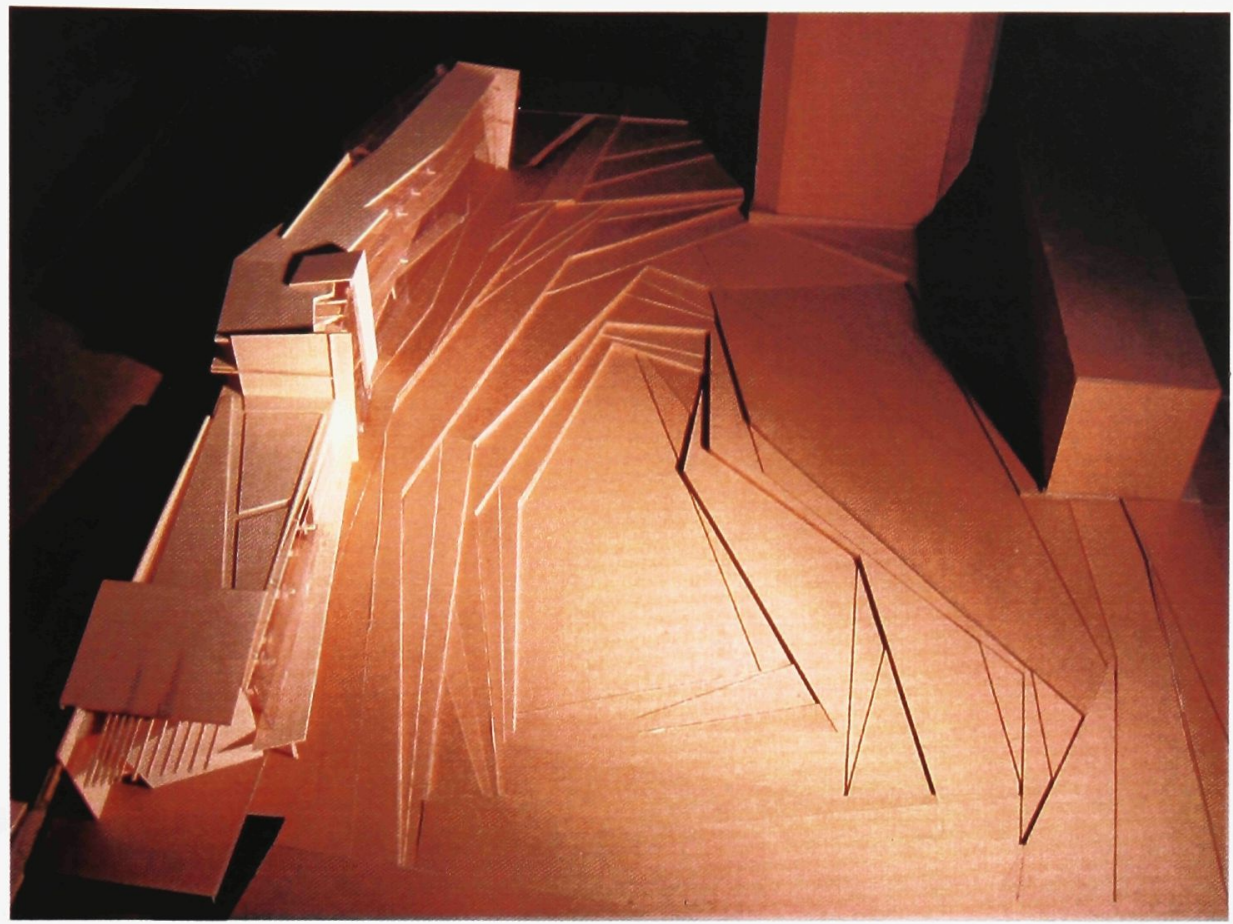

Figure 36. Terminal surroundings

This figure depicts an overhead view of the terminal and its surroundings. It illustrates the fragmented and dynamic nature of the outdoor plaza and its connection to the building. The element of the building in the foreground houses retail and commercial program whereas the terminal sits in the background. The highway runs parallel to the building to the left.

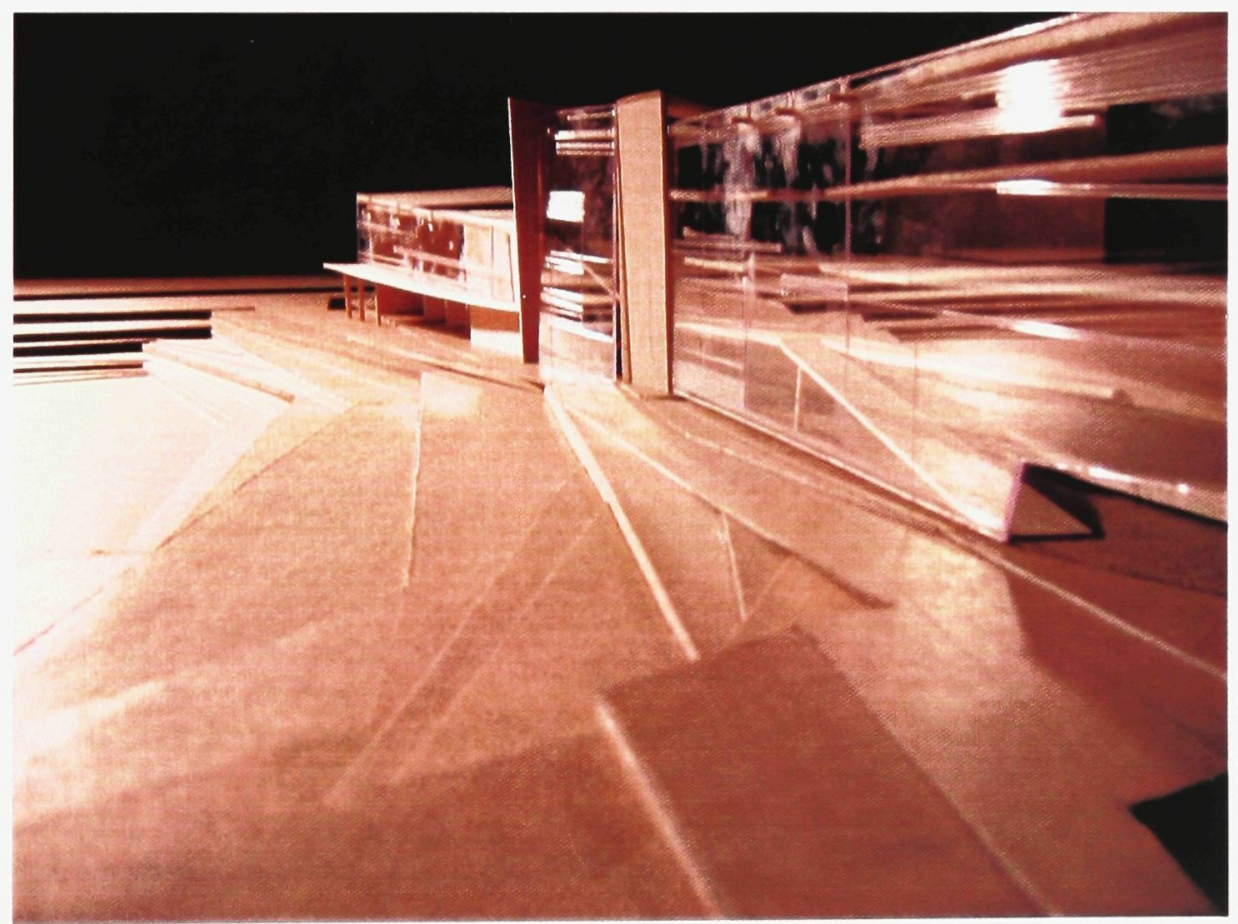

Figure 37. Rochester Street entrance

This figure depicts the building as seen from Rochester Street. The building and plaza meet and interact and the line between interior and exterior space is blurred. The terminal entrance is located off of Rochester Street on the right of the photo. 


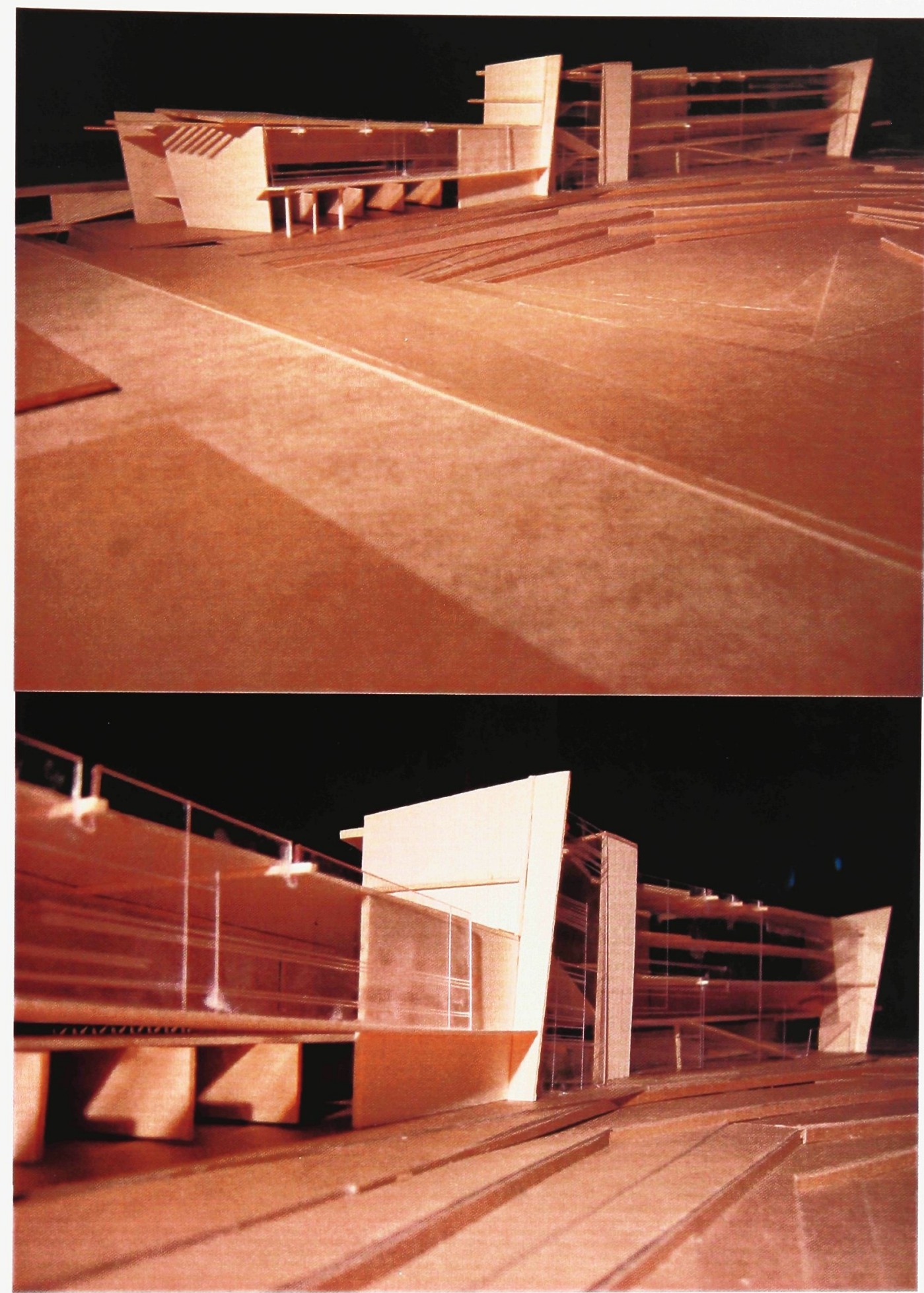

\section{Figure 38. Preston Street entrance}

These figures are views from Preston Street. They demonstrate the relationship between the building, the plaza and the street. The spaces adjacent to Preston Street house retail and commercial functions which pick up on the existing conditions of the street. The figures also depict the manner in which the stepped, fragmented plaza meets and then enters into the building, blurring the line between interior and exterior space. 


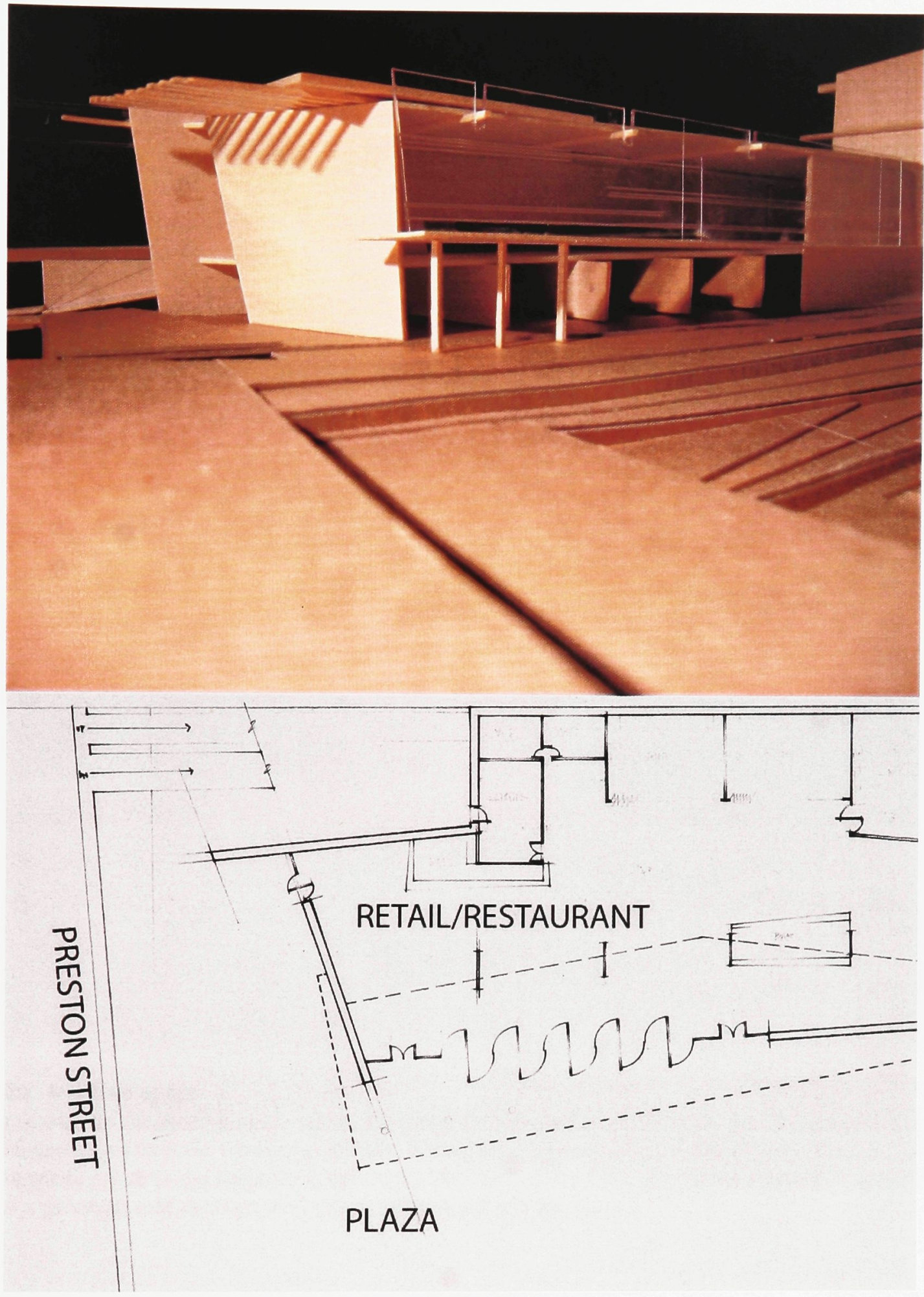

\section{Figure 39. Preston Street interaction}

These figures depict the retail and restaurant programs and their interaction with Preston Street and the plaza. The large pivoting glass doors allow the interior and exterior spaces to flow into each other. During the summer months, the cafés and eatery's spill into the plaza creating dynamic and energetic spaces much like the patios and terraces found along the adjacent Preston Street. 


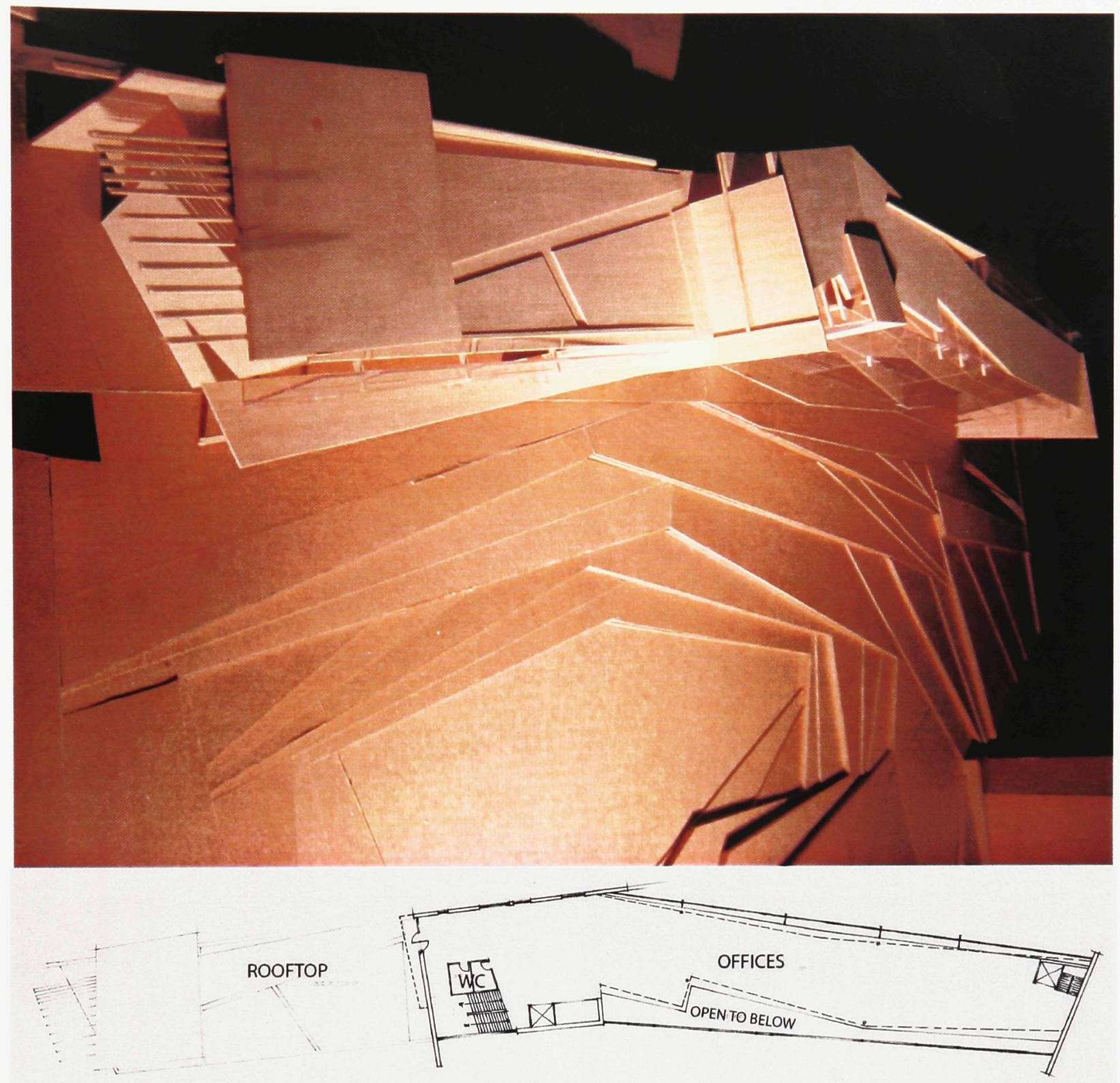

Figure 40. Rooftop space

This figure depicts the rooftop space which sits upon the terminal on the Preston Street side of the building. The space acts as an exterior viewing platform. It contains vegetation and a green roof system to add an important green space to the large scale building. Workers within the complex may retreat to this space and view a panoramic of the highway, the neighborhood and the plaza. 

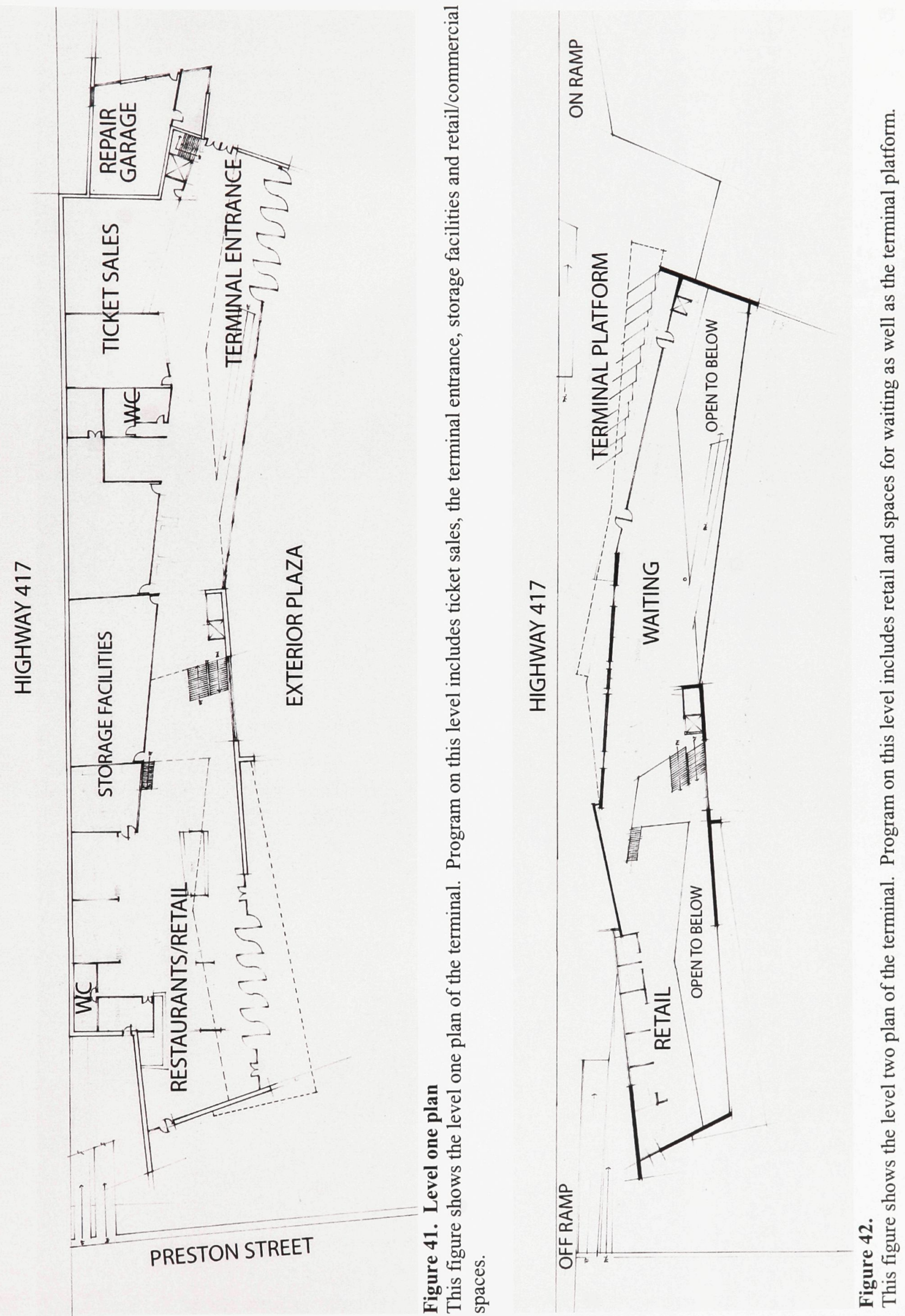


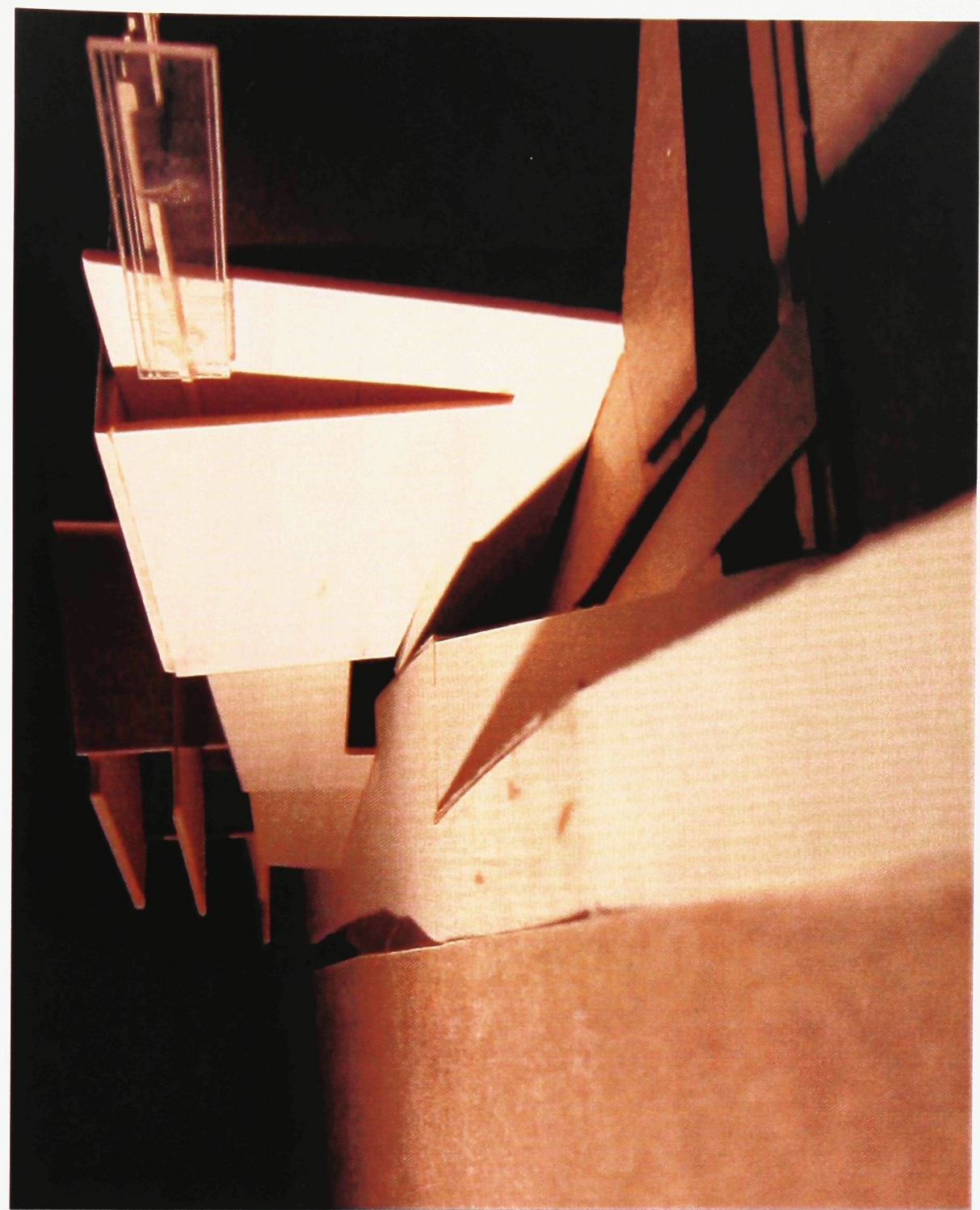

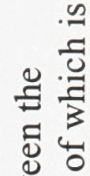

这

올

ญ

范

䒕

希㐘

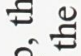

응

존.

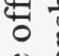

폼

䒝

훙

స్త్ర

ฮี

के

हี่

遇

을

콩

ह

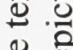

웜

영 힝

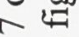

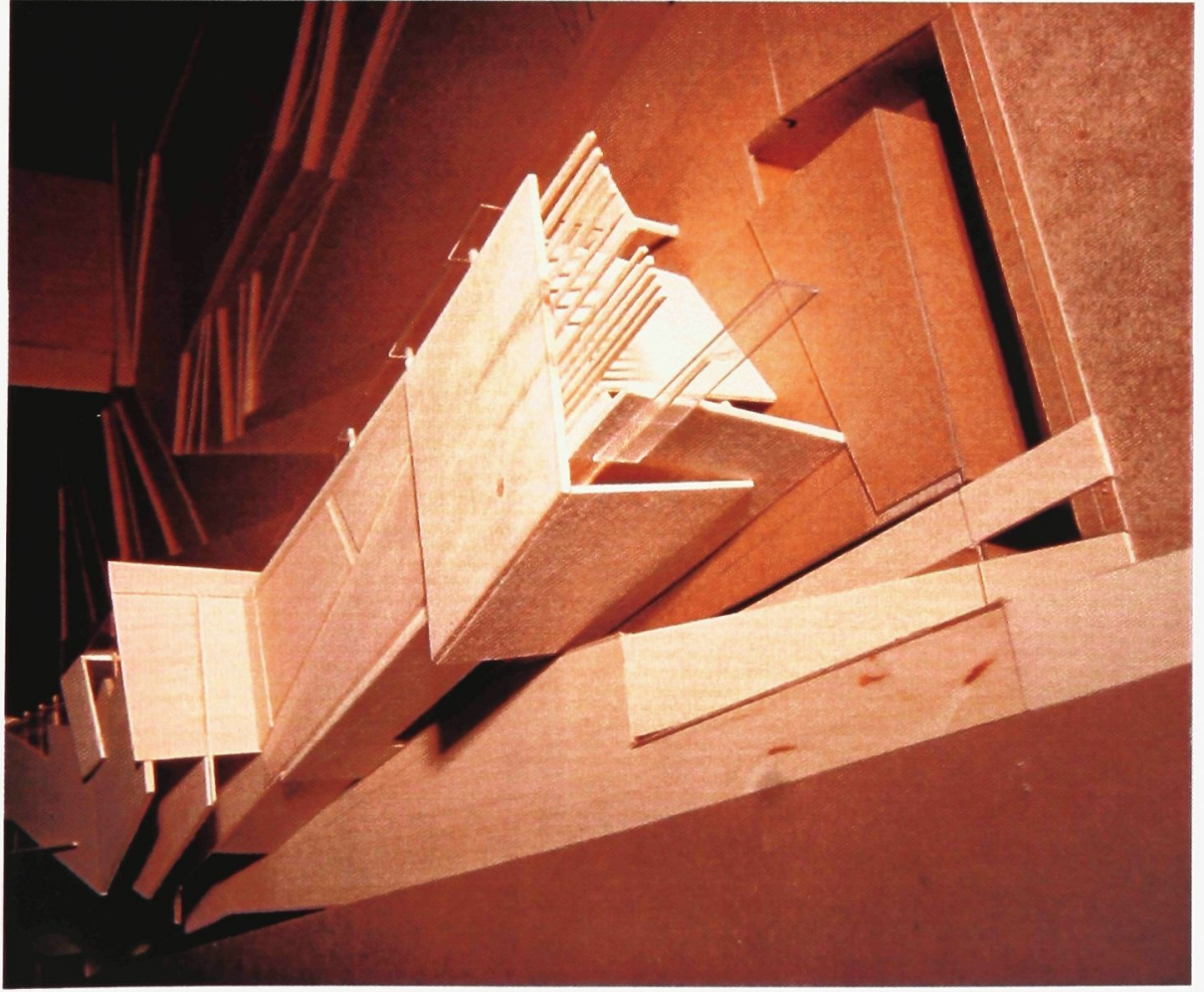

于

輁 焉

Ð

폴

은

열

氙 0

出.

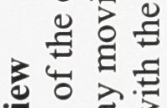

क त

릉

.0.

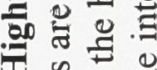

표

ஓं ق

广

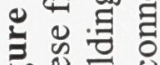

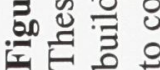



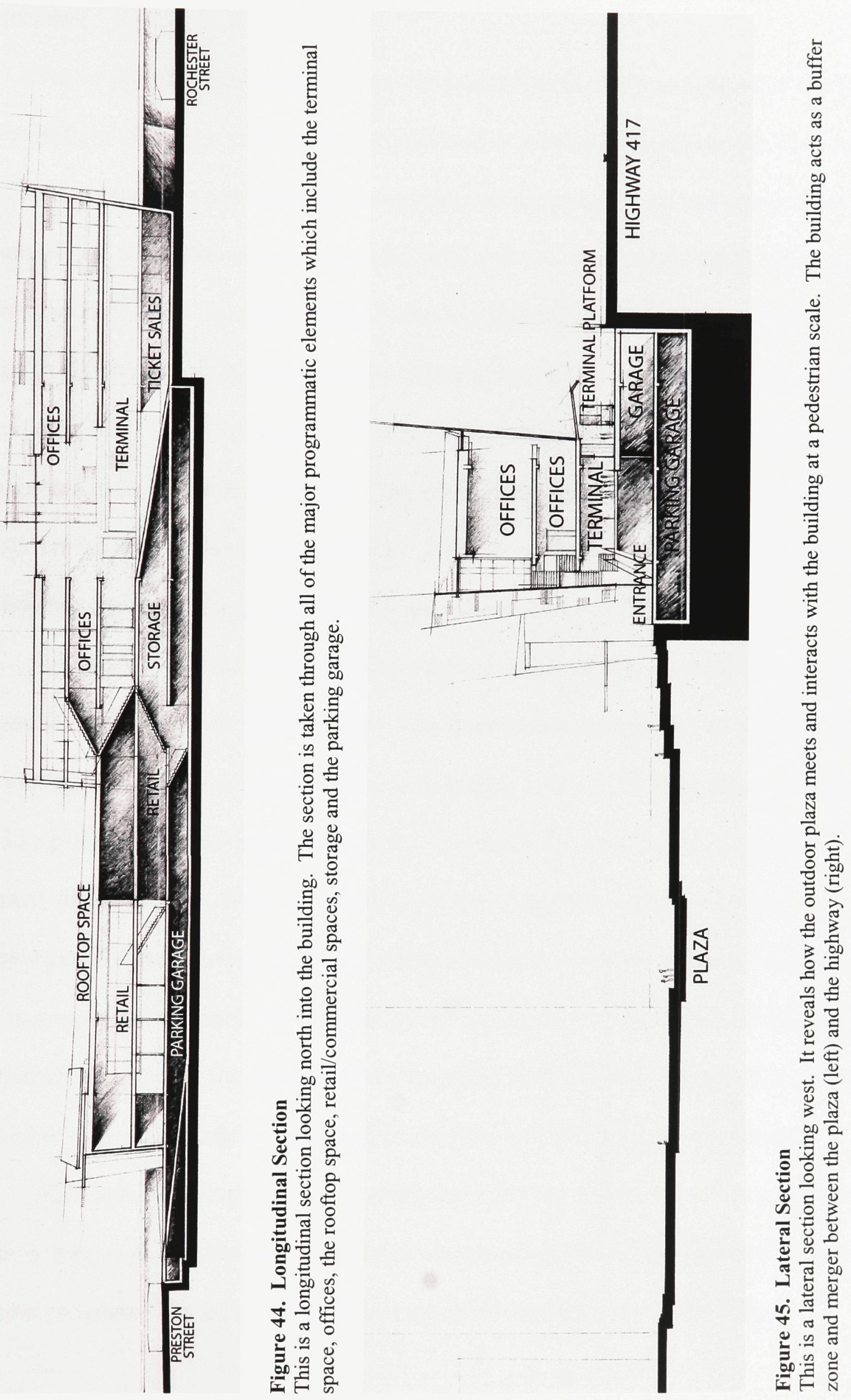


\section{Conclusion}

As an alternative to functionalist architecture seen in many non-places of transit, a new paradigm for design process has been devised. It is based on intuition, the discovery of spatial relationships and form, yet always considering program and the impact upon community. Unique connections are consciously and sub- consciously made during the collage process which translates into an individual architecture. Architecture has the ability to simultaneously be an expression of innovative, unique design as well as a well functioning building. The process of collage imposed upon terminal architecture allows architecture to be both simultaneously. The criterion for successful, meaningful design of transit terminals depends on several factors. Location within the city, its connection to its surrounding and its role upon society all impact the architecture of transit terminals.

It is evident that although non-places are the spaces of everyday life this must not lessen their importance on the collective. Transit terminals are complex building types that embody a hybrid of programs that simultaneously interact. By collaging a non-place within a place, this juxtaposition enables new paradigms for successful transportation terminal design to exist. With the use of the collage process as a means to create architecture and the insertion of it into a suitable location which holds culture, identity and history, transit terminals have the ability to become places that are rich in memorable experience. In essence, the architecture of the transit terminal holds the potential for the traveler to have a meaningful connectedness to the city if all proper criteria are met.

Although the collage process in architecture has the ability to produce a specific building type, such as a bus terminal seen in the preceding thesis, collage is not limited to singular program. The act of collage is not specific to produce an explicit kind of 
architecture. Any building program may be applied to collage. In this thesis, a specific program with a specific methodology was carried out in order to extract architectural space and experiences. Fundamentally, this thesis attempted to illustrate that transportation terminals such as the bus terminal has the potential to become memorable places of experience which help define the city. 


\section{Bibliography}

Augé, Marc. Non-Places: Introduction to an Anthropology of Supermodernity. New York: Verso Publishers, 1995.

"Ben Nicholson's Faith Based Initiative." Archinet. 12 September 2005 $<$ http://archinect.com/features/article.php?id=14916_0_23_0_C $>$

"Brief History of Collage and Assemblage." Zimmerlimuseum. 23 May 2005 $<$ http://www.zimmerlimuseum.rutgers.edu/collections/summ/brief\%20history. html>

Brassai, Pierre Daix. Conversations with Picasso. Chicago: University of Chicago Press, 1999.

Blau, Eve and Nancy J. Troy, eds. Architecture and Cubism. Cambridge: MIT Press, 1997.

Clark, David. Urban World/ Global City. London: Routledge, 1996.

Collins, Samuel. "Head Out On the Highway": Anthropological Encounters with the Supermodern, Postmodern Culture: v.7 n.1, September, 1996.

Debord, Guy. The Society of Spectacle. New York: Zone Books Publishing, 1995.

De Certeau, Michel. The Practice of Everyday Life. Berkely: University of California Press, 1984.

De Sola-Morales Rubio, Ignasi. "From Contrast to Analogy: Developments in the Concept of Architectural Intervention." Theorizing a New Agenda for Architecture: An Anthology of Architectural Theory 1965-1995. Ed. Kate Nesbitt. New York, 1996.

Dickerman, Leah. Dada: Zurich, Berlin, Hanover, Cologne, New York, Paris. Victoria: National Gallery of Victoria, 2004.

Dietrich, Dorothea. The Collages of Kurt Schwitters. Cambridge: Cambridge University Press, 1993.

Fischer, Volker. Richard Meier: The Architect as Designer and Artist. New York: Edition Axel Menges, 2003.

Gabrielsson, Catharina. "Out of Nowhere.” 26 January 2006 $<$ http://www.mikaellevin.com/catharina_gabrielsson.html> 
Harbison, Robert. The Built, the Unbuilt, and the Unbuildable: in Pursuit of Architectural Meaning. Cambridge: MIT Press, 1991.

Harries, Karsten. The Ethical Function of Architecture. Cambridge: MIT Press, 1998.

Hodermarsky, Elizabeth. The Synthetic Century: Collage from Cubism to

Postmodernism. New Haven: Yale University Press, 2002.

Hoffmann, Katherine. "Collage: Critical Views." Collage in the Twentieth Century: An Overview. Ed. Katherine Hoffman. Ann Arbor, Michigan: UMI Research Press, 1989.

Kracauer, Siegfried. Rethinking Architecture: A Reader in Cultural Theory "The Hotel Lobby". London \& New York, 1997. Pg. 53-59.

Krell, David Farrell. “Thinking Ben Nicholson's Collage Thinking: From the Laurentian Library to the Appliance House, Loaf House, and B-52 Pickup."

Bennicholson.com. 13 September 2005

$<$ http://bennicholson.com/home/krell.pdf $>$.

Lefebvre, Henri. The Production of Space. Malden: Blackwell Publishing Ltd., 1991.

Meilach, Dona. Collage and Found Art. New York: Reinhold Book Corporation, 1964.

Middleton, Robin, ed. The Idea of the City. MIT Press, 1996.

Nesbitt, Kate, ed. Theorizing a New Agenda for Architecture: An Anthology of Architectural Theory 1965-1995. Princeton Architectural Press: New York, 1996.

Nicholson, Ben. The Appliance House. Cambridge: MIT Press, 1990.

Norberg-Schulz, Christian. "The Phenomenon of Place." Architectural Association Quarterly 8 no. 4 (1976): 3-10.

Poggi, Christine. In Defiance of Painting: Cubism, Futurism and the Invention of Collage. New Haven: Yale University Press, 1992.

"Richard Meier Collages." Arcspace. 12 September 2005.

$<$ http://www.arcspace.com/studio/meier/>

Rowe, Colin and Fred Koetter. Collage City. Cambridge: MIT Press, 1978.

Smith, Catherine. "Looking for Liminality in Architectural Space." Limen: Journal for Theory and Practice of Liminal Phenomenon no. 1 (2001): 06 June 2006 $<\mathrm{http}$ ///www.cartage.org.lb/en/themes/Arts/Architec/ArchitecturalStructure/ 
LookingforLiminality/LookingforLiminality.htm>

Somel, R.E. "No Place Like Home: Domesticating Assemblages." Assemblage Vol.13 (1990): 89-92.

Sorkin, Michael, ed. Variations on a Theme Park: The New American City and the End of Public Space. New York: The Noonday Press, 1992.

Sullivan, Louis, The Autobiography of an Idea. Press of the American institute of Architects, Inc.: New York City, 1924.

Tschumi, Bernard. Questions of Space. London: AA Publications, 1990.

Turner, Victor. The Forest of Symbols: Aspects of Ndembu Ritual. New York: Cornell University Press, 1967.

Van Gennep, Arnold. The Rites of Passage. Chicago: University of Chicago Press, 1961.

Venturi, Robert. Complexity and Contradiction in Architecure. New York: The Museum Of Modern Art, 1966.

Waldman, Diane. Collage, Assemblage, and the Found Object. New York: Harry N. Abrams Publishers, Inc., 1992.

Walker, Hamza. "Many a House Hath Yet to be Built." Bennicholson.com. 9 February $2005<\mathrm{http}$ ://bennicholson.com/home/about/hamzam.htm>.

Wolfram, Eddie. History of Collage: An Anthology of Collage, Assemblage and Event Structures. Studio Vista Publishers Ltd: New York, 1975. 